NAVIGATION AND SOCIAL LEARNING AMONG FIRST SEMESTER RETAINED UNIVERSITY STUDENTS: EXPLORATION OF PROGRAMS AND EXPERIENCES AT A COMPREHENSIVE, PUBLIC, OPEN-ENROLLMENT INSTITUTION

A Dissertation
presented to
the Faculty of the Graduate School
at the University of Missouri-Columbia
In Partial Fulfillment of
the Requirements for the Degree
Doctor of Education
Alizabeth B. Ballard
Dr. Nissa Ingraham, Dissertation Supervisor

May 2020 
(C) Copyright by Alizabeth B. Ballard All Rights Reserved 
The undersigned, appointed by the dean of the Graduate School, have examined

the dissertation entitled

NAVIGATION AND SOCIAL LEARNING AMONG FIRST SEMESTER RETAINED UNIVERSITY STUDENTS: EXPLORATION OF PROGRAMS AND EXPERIENCES AT A COMPREHENSIVE, PUBLIC, OPEN-ENROLLMENT INSTITUTION

Presented by Alizabeth B. Ballard

a candidate for the degree of Doctor of Education and hereby certify that, in their opinion, it is worthy of acceptance.

Dr. Nissa Ingraham

Dr. Timothy Wall

Dr. Carole Edmonds

Dr. David Oehler 


\section{DEDICATION}

To the ones who know that nothing happens without students, you inspire me to show up daily as my most authentic self and to give my heart fully to the work we do. Thank you for continuing to make the field of education more accessible and equitable for all people. You make the American education system better. I hope you always remember that our students will change the entire world for the better because of you. 


\section{ACKNOWLEDGMENTS}

First, I would like to acknowledge my wonderful and supportive family; thank you for always supporting me. You taught me to work hard and instilled life lessons in me that served me well while I completed my dissertation. Thank you for never letting me quit. I am glad you did not have to edit this one, Katherine.

To the Northwest Cohort and 1B, thank you for your friendship. I am a better person for knowing all of you. I have waited my whole life to make the kind of friendships that transverse the years that pass us by. You are truly my tribe. Life would not be the same without any of you, especially Chris, Chris, Trish, and Brooke.

To my writing partner, Kirk; thank you for going through this journey with me. Your friendship has been a gift. I know I could not have done this without you and our regular writing hangouts. I am looking forward to getting coffee and just catching up on what is happening in your life without the writing.

To my work family, thank you for giving me the grace to complete my educational journey. No matter where I go from here, I will always have fond memories of you and will take the lessons I have learned from you on to the next chapter.

To Britt and Emily, you are my people. Thank you for reminding me that I am worthy and deserving.

To my committee, thank you for the feedback and endless support. You are truly an exceptional group of humans. I am forever in awe of your generosity.

Finally, I need to thank Dr. Nissa. No words will ever describe my gratitude and appreciation for you. You made me a stronger writer, a superior scholar, and a better human being. Thank you. 


\section{Table of Contents}

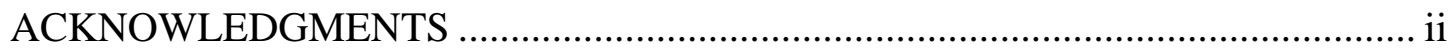

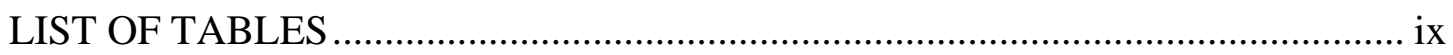

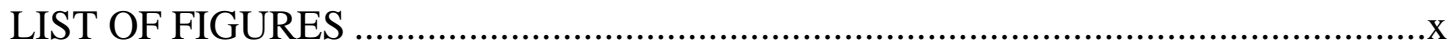

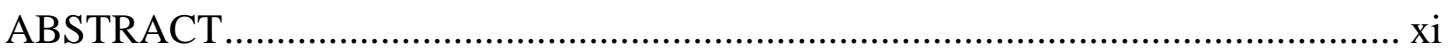

CHAPTER ONE INTRODUCTION TO DISSERTATION IN PRACTICE ................1

Navigation and Social Learning Among First Semester Retained University

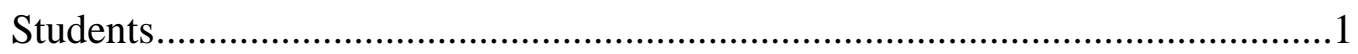

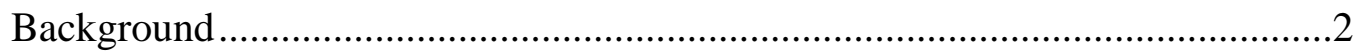

Academic Achievement of College Students ......................................................

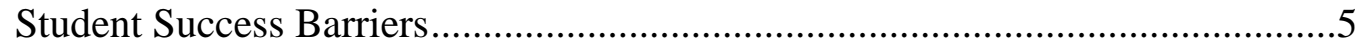

Student Navigation of College..........................................................................

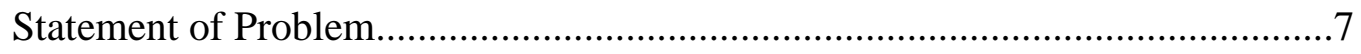

Existing gap in literature ................................................................

Problem of practice. ………………………....................................

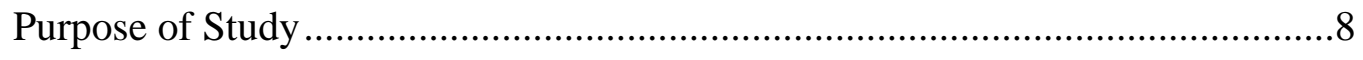

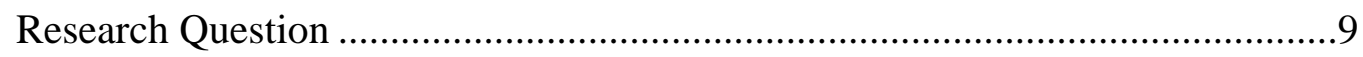

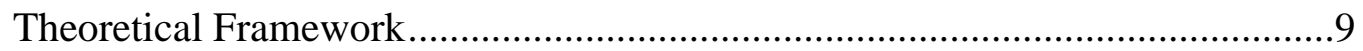

Social Learning Theory ............................................................................10

Social Learning and Education ......................................................................10

Social Learning and Modeling.....................................................................11

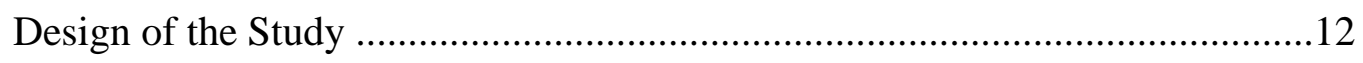

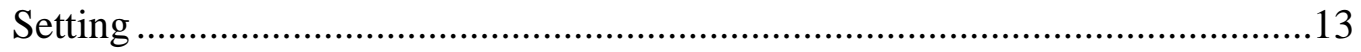




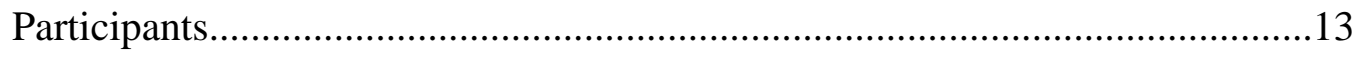

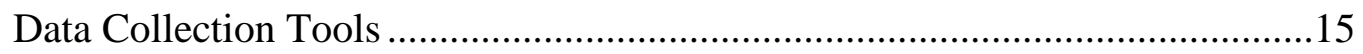

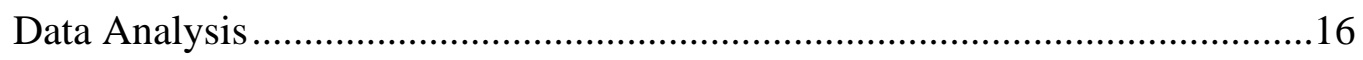

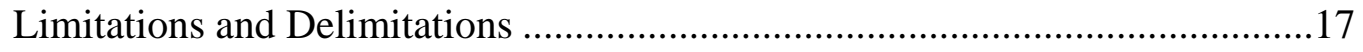

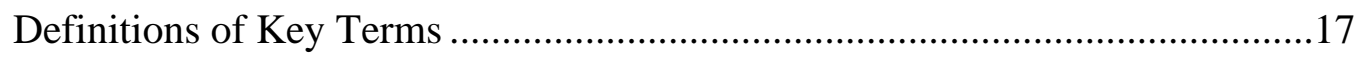

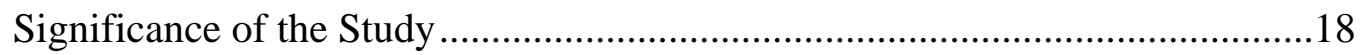

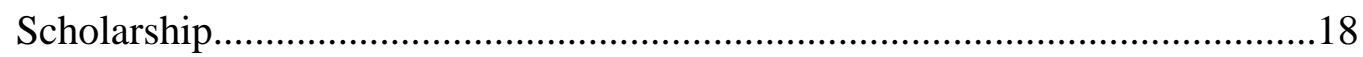

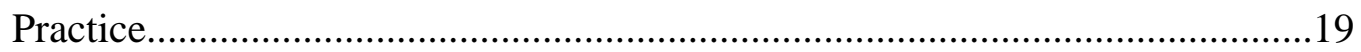

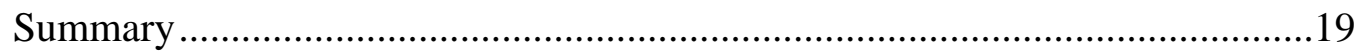

CHAPTER TWO PRACTITIONER SETTING FOR THE STUDY ........................20

History of Organization and Introduction..................................................20

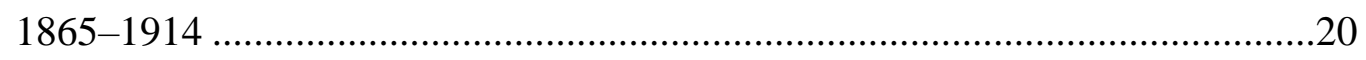

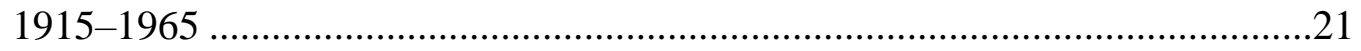

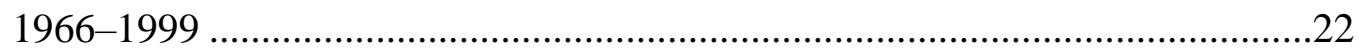

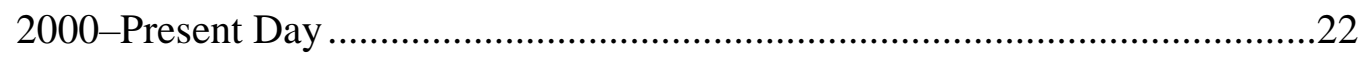

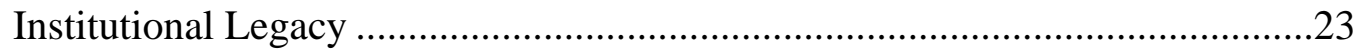

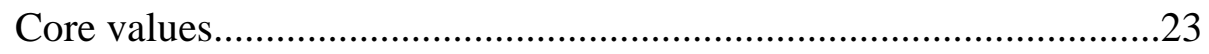

Organizational student-centered culture. ......................................24

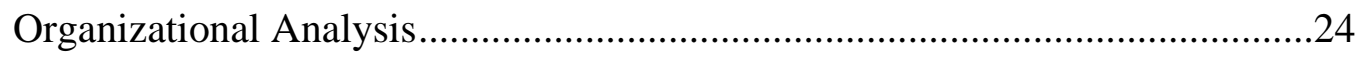

Structural frame and the university...........................................24

Human Resource Framework and Municipal Library ..................................28

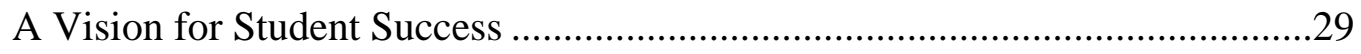

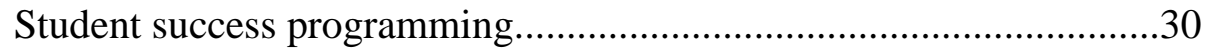


Student Success Collaborative.

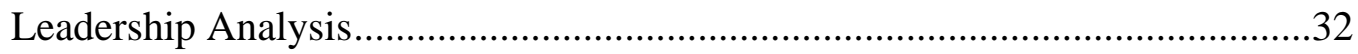

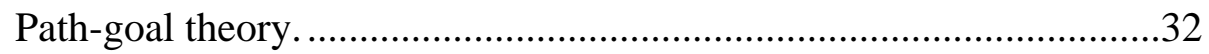

Goal Definition: Desirable Student Outcomes ..................................................34

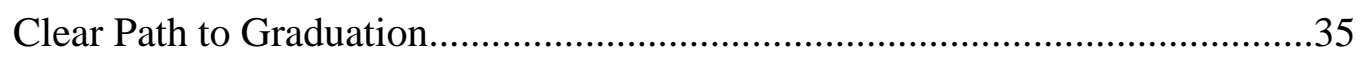

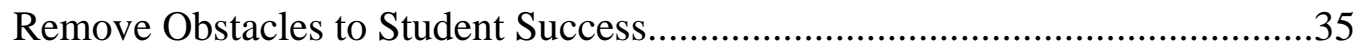

Provides Support to Earning Baccalaureate Degree .........................................36

Implications for Research in the Practitioner Setting .....................................37

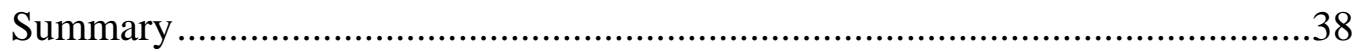

CHAPTER THREE SCHOLARLY REVIEW FOR THE STUDY ..........................39

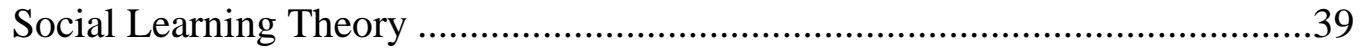

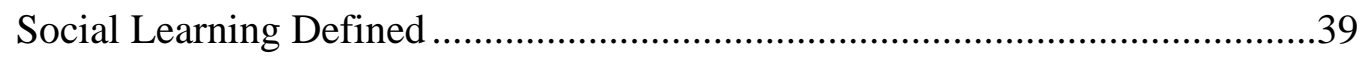

Cognitive Components of Social Learning Theory …......................................40

Attention. ........................................................................... 41

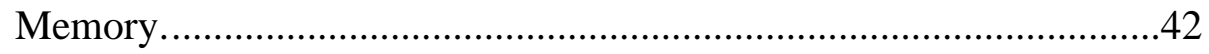

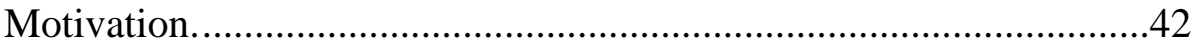

Behavioral Components of Social Learning Theory ….................................44

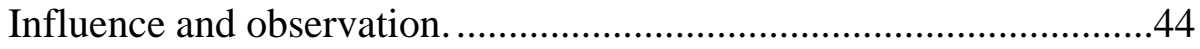

Imitation and modeling .......................................................45

Additional Concepts for Consideration .................................................46

Retention of College Students ..........................................................4 47

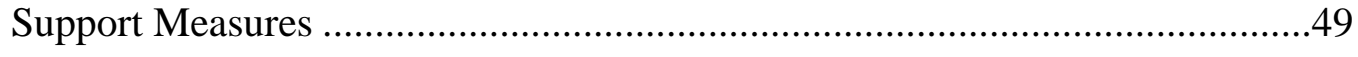

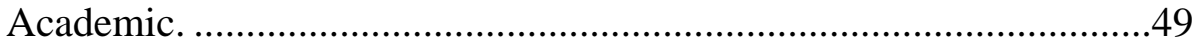




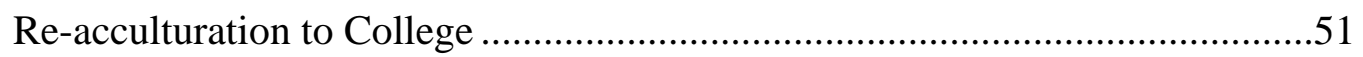

Social Learning in the Collegiate Setting ..........................................................52

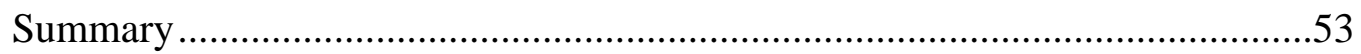

SECTION FOUR CONTRIBUTION TO PRACTICE ………………………….......

Plan for Dissemination of Practitioner Contribution ............................................55

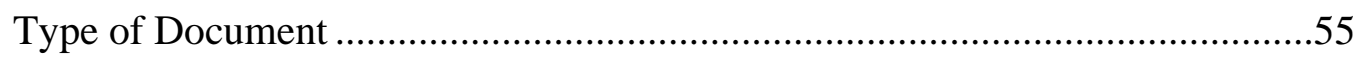

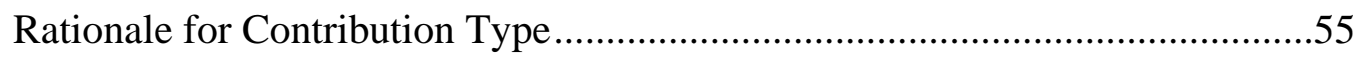

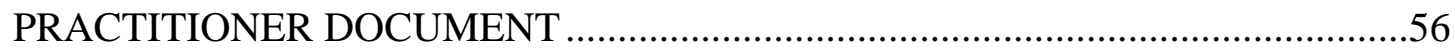

CHAPTER FIVE CONTRIBUTION TO SCHOLARSHIP.........................................

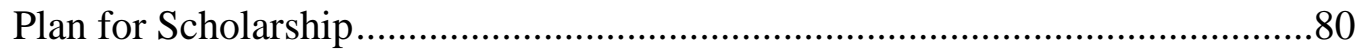

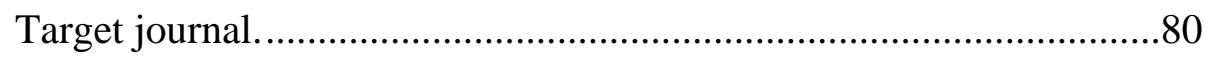

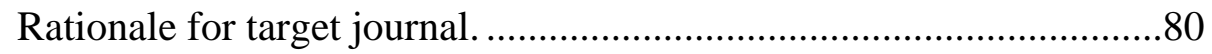

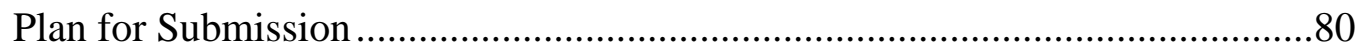

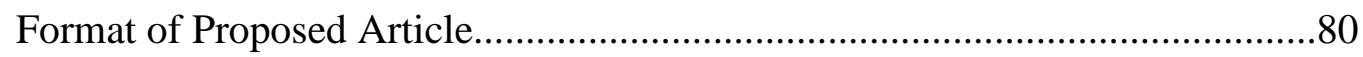

Navigation and Social Learning Among First Semester Retained University

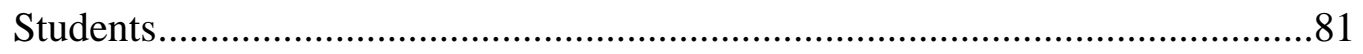

Navigation and Social Learning Among First Semester Retained University

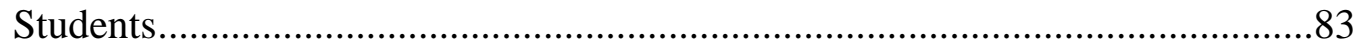

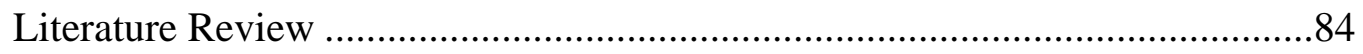

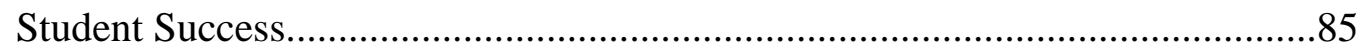

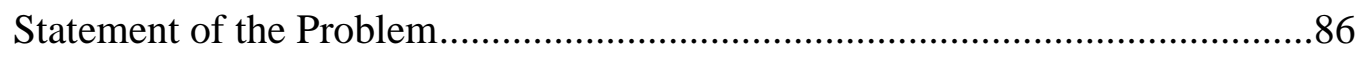

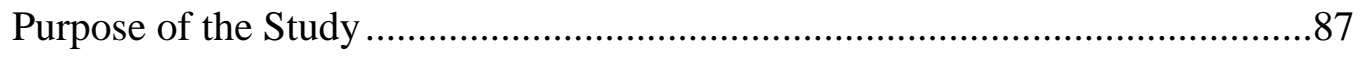




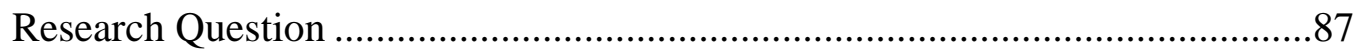

Theoretical Framework: Social Learning Theory ...............................................8

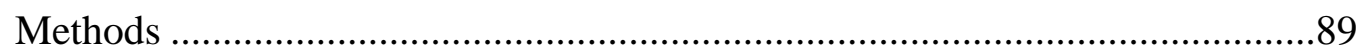

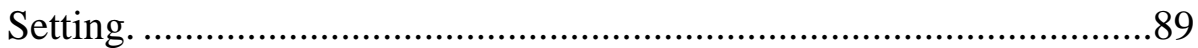

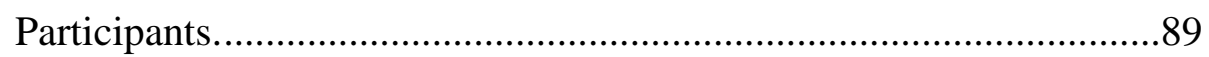

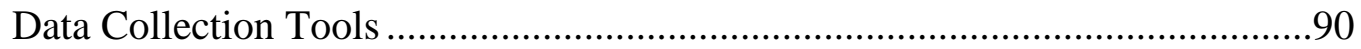

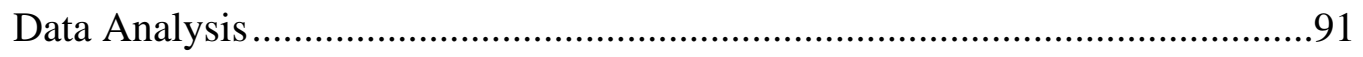

Limitations, Assumptions, and Design Controls ……………...........................91

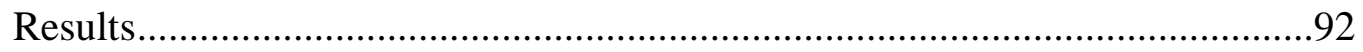

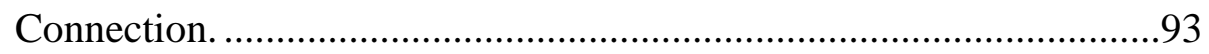

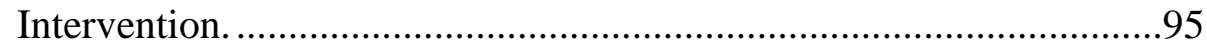

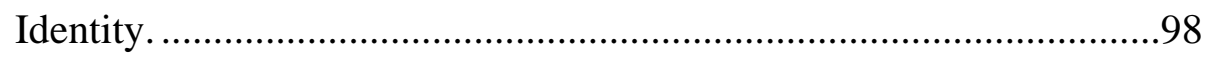

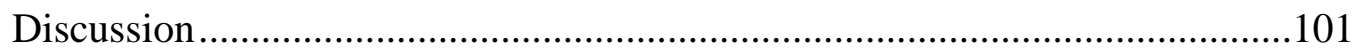

College Navigation and Student Success.....................................................102

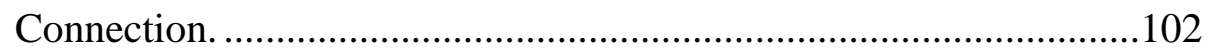

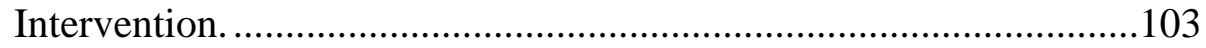

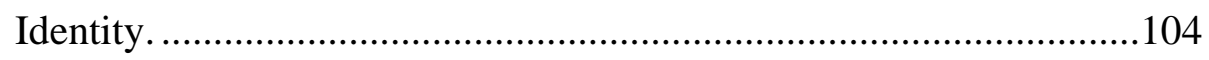

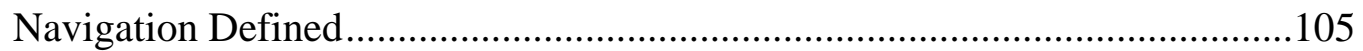

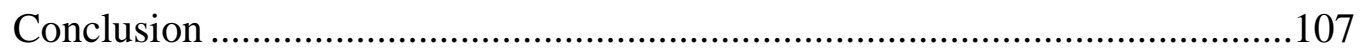

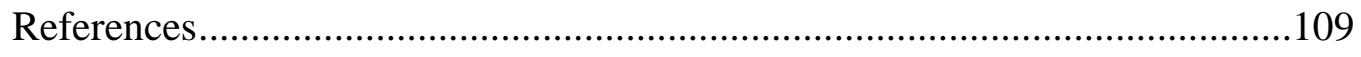

CHAPTER SIX SCHOLARLY PRACTITIONER REFLECTION...........................115

Leadership Development Reflection .........................................................115

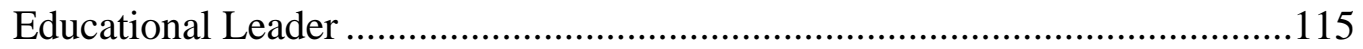


Constructivist Learning Paradigm .........................................................116

Authentic Leadership........................................................................117

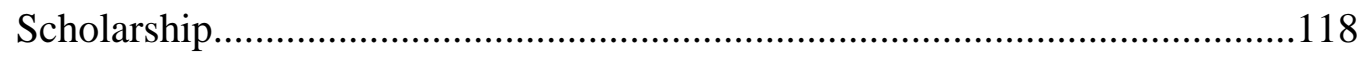

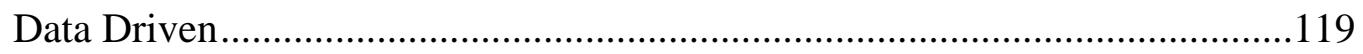

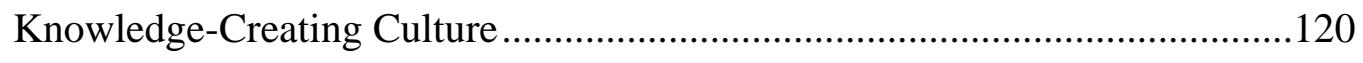

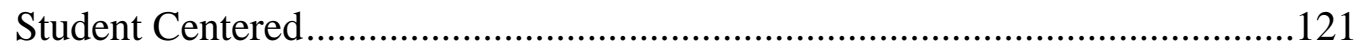

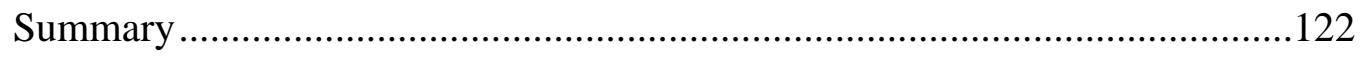

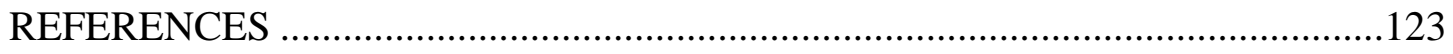

APPENDIX A: PROBING RESEARCH QUESTIONS FOR STUDENT FOCUS

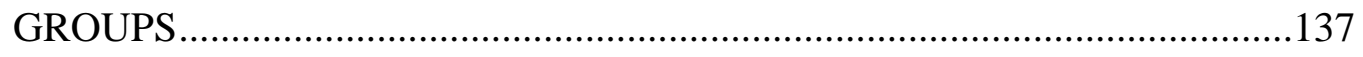

APPENDIX B: PROBING RESEARCH QUESTIONS FOR FACULTY/STAFF

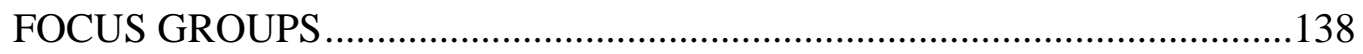

APPENDIX C: INTERVIEW QUESTIONS FOR FACULTY/STAFF ..................139

APPENDIX D: INFORMED CONSENT LETTER .......................................... 140

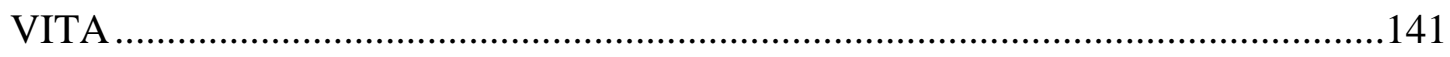




\section{List of Tables}

Table 1. Themes and Subthemes from Data Analysis.............................94

Table 2. Resources Students Use to Navigate College ...........................................99

Table 3. Understanding of Identity as a tool of Navigate College...................100 


\section{List of Figures}

Figure 1. Student Characteristic Funnel...............................................................

Figure 2. Worthington University Organizational Chart ......................................26

Figure 3. Worthington University Academic Affairs Unit Organizational ................27

Figure 4. Organizational Chart of Municipal Library ..........................................29

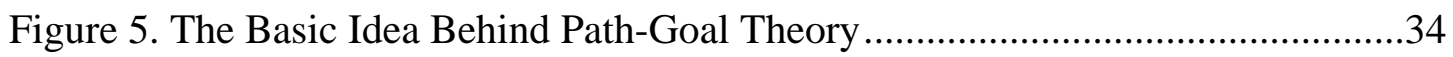

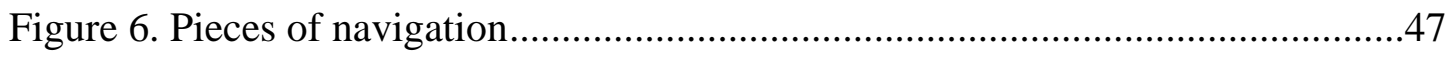

Figure 7. Triadic Reciprocality Model of Causality ................................................54

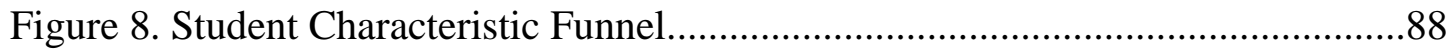

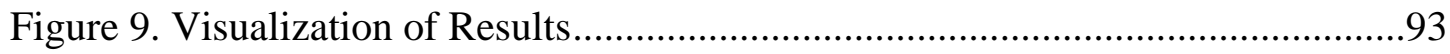




\begin{abstract}
Retention is an important measure of success (Tinto, 1999); therefore, student success is an area of interest among professionals in the field of higher education (Hunter, 2006; Rendon, 1995). This qualitative study sought to understand how first-year students navigate the university and aimed to increase student success and support students to commencement exercises and beyond. Specifically, the study examined student experiences through social learning and considered the various programs, interventions, and resources that work together to support student success. Focus groups, one-on-one interviews, document analysis, and observations were conducted to collect ample data. Three themes emerged from the collected data: connection, intervention, and identity. Each of these themes revealed insights about the associations between college navigation and student success. Prior literature supported the idea that connection, intervention, and identity are tools of college navigation (Bruffee, 1999; Caldwell \& Siwatu, 2003; Garrison \& Kanuka, 2004; Harper, 2012; Smith, 2007; Umbach \& Wawrzynski, 2005). Moreover, the literature acknowledged that students who use intervention support services to increase social learning reported higher levels of academic achievement (Caldwell \& Siwatu, 2003; Grant-Vallone, Reif, Umali, \& Pohlert, 2003; Wibrowski, Matthews, \& Kitsantas, 2017). The findings of this study reaffirmed that higher education professionals, faculty, programs, and interventions occur simultaneously to increase student potential for successful college navigation; these resources are deeply connected and cannot support student success alone.
\end{abstract}




\section{Chapter One}

\section{Introduction to Dissertation in Practice}

\section{Navigation and Social Learning Among First Semester Retained University}

\section{Students}

Student success is an area of interest among professionals in the field of higher education (Hunter, 2006; Rendon, 1995). Furthermore, literature in the field identified underlying issues or barriers that decrease the likelihood for students to be retained and succeed at the post-secondary level (Rendon, 1995; Tinto, 1975). Traditionally underrepresented student populations — such as those who identify as a racial minority or come from a low socioeconomic background — are at a higher risk of experiencing barriers to academic success (Lucas, 2001). Underrepresented students often experience lack of academic preparation, lack of direction, lack of understanding on which questions to ask about college-going, and lack comfort in the academic environment (Rendon, 1995). Prior literature supported the study's focus on underrepresented student populations; however, retention is an important measure of success in all student populations (Tinto, 1999). This study sought to approach student experiences through multiple lenses by exploring student experiences that are representative of the whole student population. This approach is supported by Tinto's (1999) critical understanding that all students must be supported to graduation day through various retention efforts. Furthermore, this study sought to explore the experiences of students as they navigate the university setting. This study illuminated how students navigate their academic career and campus resources for student success using qualitative data collection and analysis, including focus groups, observations, and interviews. In order to qualify this information, 
the study provides a background, a statement of the problem, a theoretical framework based in literature, the study's research question, and the study methodology.

\section{Background}

In 1800, only 25 degree-granting colleges existed in the United States (Thelin, 2011). By 1900, the higher education field had grown; enrollment reports cited more than 33 times the number of institutions reported 100 years earlier (Labaree, 2017; Thelin, 2011). During the 1800 s and the early 1900s, higher education was primarily inhabited by students from affluent backgrounds (Labaree, 2017); however, a shift in institutional structure occurred in the beginning of the 1900s (Thelin, 2011). The educational system, once a religious-affiliated entity, shifted to public, private, rural, urban, liberal arts, state, normal, and land grant institutions (Labaree, 2017; Thelin, 2011). This change allowed for a more middle-class student population (Labaree, 2017).

Enrollment of students in higher education from 1900 to 1940 increased from 250,000 to 1.5 million (Labaree, 2017). The growth of student enrollment at the university meant that both middle-class populations and veterans could access formal education (Labaree, 2017). With the award of the GI Bill, the veteran population accessed and further diversified the university setting; institution enrollments rose to 2.4 million by 1944 (Labaree, 2017). An era of policy change came after the GI Bill. Policy changes in the 1960's made higher education more accessible to middle-class families (Loss \& McGuinn, 2016). Policies like the Economic Opportunity Act and the Higher Education Act introduced equitable initiatives in the field of education. The Higher Education Act, established in 1965, created the federal Pell Grant program and supported equitable access to post-secondary institutions for low-income and socioeconomically 
disadvantaged students (Loss \& McGuinn, 2016; Thelin, 2011). By 1980, college enrollment grew eight times larger in only 40 years (Labaree, 2017). Higher education became a tool for status attainment (Lucas, 2001); higher education was no longer only for the elite (Labaree, 2017; Thelin, 2019). New student populations and larger enrollments prompted new needs in the field of higher education.

\section{Academic Achievement of College Students}

The changes in state and federal higher education policy between 1940 and 1990 provoked further research regarding academic achievement and persistence in higher education. Astin and Oseguera (2002) revealed that degree attainment had changed significantly over the past decade; fewer first-time students completed their degree and

even fewer completed "on time." An on-time graduation at the university level is defined as completing a bachelor's degree in 4 years' time (Complete College America, 2014). Furthermore, racially diverse students were graduating at a lower rate compared to their White peers (Astin \& Oseguera, 2002). The degree completion and persistence of college students has concerned many vested stakeholders (Complete College America, 2017). Students and their families invest time, money, and other valuable resources in earning a degree in hopes of a large return on investment (Complete College America, 2017).

Faculty, staff, and university constituents are vested in the success of their hard work with students (Williamson, Goosen, \& Gonzales, 2014). Additionally, governmental organizations and agencies have a vested interest due in part to the economic balance of the system (Complete College America, 2017). Degree persistence has long term outcomes that could potentially impact the economy. Historically, college 
graduates earned more money and therefore had more money to spend (Astin \& Oseguera, 2002).

Institutions have established collaborative efforts to support student success and persistence to graduation; these measures have been designed to assist students in learning about the institution and its processes (Bruffee, 2012). First-year seminars assist students in making connections and understanding resources that are available at the university level (Goodman \& Pascarella, 2006). Interventions such as first-year seminar programs and social support programs are designed to support first-year students (GrantVallone et al., 2003; Hunter, 2006). A focus has been placed on first-year student success within the higher education community in recent years, and proactive interventions such as the first-year experience (FYE) program have played a role in student success (Hunter, 2006). FYE programs are a transitional tool to support student acclimation to the university setting (Hunter, 2006). Prior studies explored the experiences of students in first-year programming; however, a gap still exists regarding the navigation of these students throughout the university setting at large. Rendon (1995) supported the idea that the experience of navigating the university setting is larger than the confines of a single classroom or program; Rendon highlighted that "academic integration... [and] social integration [are] equally important to student retention" (p. 6). Rendon also noted that higher education institutions should "create conditions for optimal learning" (p 1). I reviewed additional literature from the field of education to understand the existing relationship between academic and social integration and the role they play in student success. 


\section{Student Success Barriers}

A large amount of literature examines persistence and retention of university students; therefore, it is natural that the literature also examines student success. Rendon (1995) studied student success among historically underserved students at the community college level. Rendon discovered that community college students find it difficult to remain at the institution as they attempt to negotiate their new identity, adapt to evolving environments, and identify areas for potential academic support. Many scholars have identified barriers that relate to student retention and graduation from college. Tinto $(1975,2003)$ examined barriers that exist for all students, such as prior education preparation, institutional connection, and external factors. Tinto's examinations supported Rendon's notion that underlying issues impact successful student retention. These barriers include lack of academic preparation, lack of direction, lack of understanding which questions to ask whom, and discomfort in the academic environment. It is critical that higher education professionals better understand these experiences.

A portion of existing literature explained various types of student experiences in the university setting. Terenzini, Springer, Yaeger, Pascarella, and Nora (1996) studied first-generation student experience as it relates to cognitive development. $\mathrm{Hu}$ and Kuh (2003) studied student experiences in relation to diversity and inclusion. Umbach and Wawrzynski (2005) studied student experiences in relation to faculty members in the university setting. The literature that examined the specific experiences of university students is thick and rich; however, none of the literature examined the navigation of the university from a more inclusive approach to student success. This navigation and social 
learning study will explore experiences of first-year students who have been retained to the spring semester and participated in a first-year seminar course along with other various programs in the prior semester.

\section{Student Navigation of College}

Institutions have grappled with the best practices of connecting students to resources to increase student success (Aljohani, 2016). Helping students navigate social, cultural, and environmental variables in the education system can boost academic persistence in underrepresented student populations (Caldwell \& Siwatu, 2003). It is important to note that navigation is referenced in points of academic literature but is not commonly defined. Caldwell and Siwatu (2003) used the term navigation to identify a process of orientation as it relates to student success and academic efficacy among culturally diverse students. Navigation skills are "developing cognitive factors, which has legitimately been found to impact academic achievement" (Caldwell \& Siwatu, 2003, p. 33). Griffin and Toldson (2012) used the term navigation to highlight the personal and intimate process of completing a journey in the workplace as supported by mentorship.

Specifically, Griffin and Toldson cited "providing support" (p. 103) and "sharing a piece of themselves" (p. 103) as tools for navigation. Furthermore, Livingston, Havice, Cawthon, and Fleming (2011) used the term navigation as a process of transition and gathering information to overcome barriers and clarify the experiences of underrepresented students, in this case, veteran students. Navigation proved to be challenging for veteran students due to "the vulnerable nature of transitions" (Livingston et al., 2011, p. 325). For the purpose of this study, navigation is defined as a process in 
which an individual develops efficacy and cognition to use existing, supporting resources for the transition and supersession of barriers and accomplishment of goals.

\section{Statement of Problem}

Existing gap in literature. Prior studies in higher education examined persistence, non-cognitive factors impacting the student lifecycle, and the reacculturation process students experience through the lens of student retention and success (Aljohani, 2016). Rendon (1995) provided a basis for further questioning about student experiences as they relate to students' lack of understanding the world of higher education. Rendon laid the foundation for future studies to investigate student experiences related to navigation. Furthermore, Rendon asserted that the university setting is often difficult for students to navigate, positing that "students lack the cultural and social capital needed to make full use of the academic and social learning community" (p. 7). A gap exists in the literature regarding how students use their university's academic and social resources. Minimal data exists on how successful university students learn to navigate the university in the first semester of college.

Problem of practice. Scholars have studied student success since state and federal policy changes such as the authorization of the Higher Education Act in 1965 (Loss \& McGuinn, 2016). Success is loosely defined in the literature through various lenses. Tinto (1975) studied persistence to learn more about patterns and contributing factors of student departure from the university from a quantitative perspective. Caldwell and Siwatu (2003) investigated how non-cognitive factors play a role in student persistence. Additionally, Murphy and Fleming (2000) studied the process of students learning new cultures and customs that exist at the collegiate level. The data collected by 
these scholars has impacted higher education professionals' understanding of how students navigate their college experience until graduation. This dissertation-in-practice sought to understand the barriers to first-year student success. Higher education professionals can better support student success through greater understanding which experiences and programs support and contribute to students' successful navigation of the university. Figure 1 demonstrates how these characteristics work together to support student navigation.

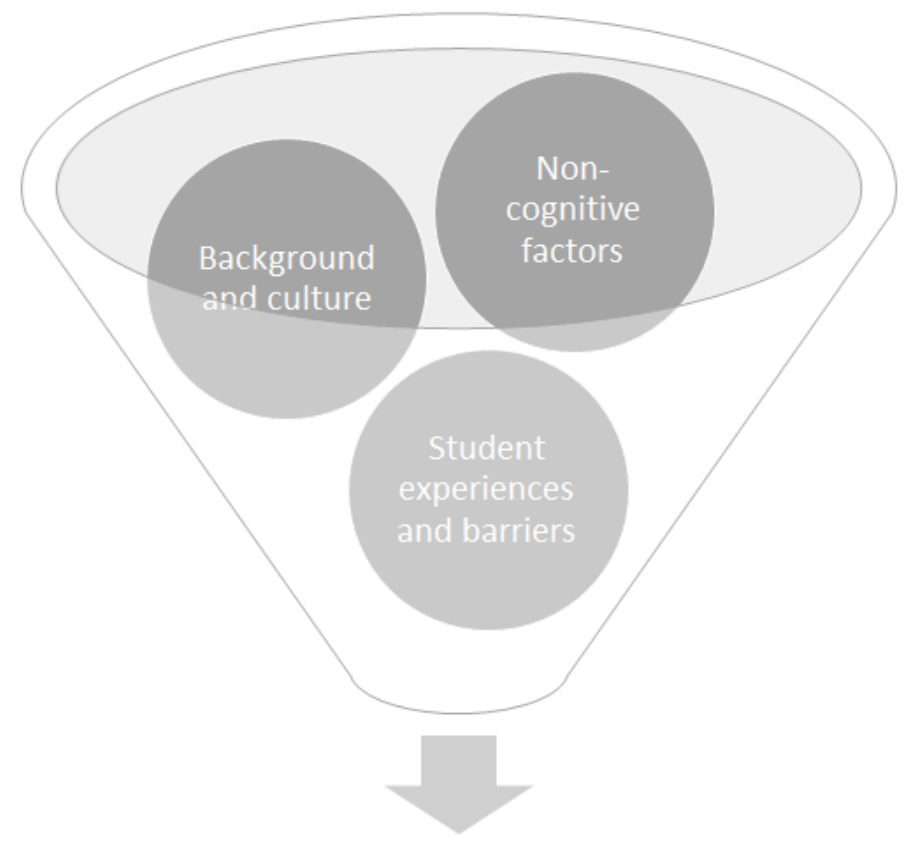

Figure 1. Student Characteristic Funnel.

\section{Navigation}

Student Characteristic Funnel. The student characteristic funnel was developed by Alizabeth Ballard (2020) to explain how existing characteristics come together to yield student navigation of the university.

\section{Purpose of Study}

This study sought to explore the experiences of first-year, first-time students navigating a comprehensive, public, 4-year university in an urban midwestern city that enrolls approximately 6,500 students annually. The study will fill a gap in the literature 
that was highlighted by Rendon (1995). Rendon focused on the experiences of community college students who were learning to re-acculturate at the postsecondary level and suggested methods of supporting higher education professionals' understanding of best student services practices. The study will inform practitioners in higher education working with first-year students in the university setting.

\section{Research Question}

This qualitative study sought to understand how first-year students navigate university systems. The overarching research question guiding this study was: "How do first-year university students navigate the university?" Rendon (1995) asserted that future studies must explore students' experience of navigating the university setting without the confines of a single classroom or program.

\section{Theoretical Framework}

To better understand and inform practice regarding the student experience, this dissertation will explore social learning theory and other aligning concepts as they relate to students in the university setting. The social learning theory encompasses attention, memory, and motivation and can be linked to both behavioral and cognitive learning theories (Bandura, 1971, 2017). This dissertation-in-practice is guided by Berlyne's (1951) definition of attention, Craik and Lockhart's (1972) definition of memory, and Maslow's (1943) understanding of motivation. This dissertation-in-practice viewed the concepts of attention, memory, and individual motivation through the lens of the social learning framework. 


\section{Social Learning Theory}

Bandura established social learning theory $(1971,2017)$, initially postulating that social learning occurs when people learn from one another through various techniques. Bandura theorized that individuals learn in social situations from influence, observation, imitation, and modeling. Bandura also proposed that individuals learn by noting patterns in behavior of others and through various social interactions. This learning occurs with the use of attention, memory, and individual motivation; an individual cannot learn without proper attention (Schunk, 1996). Prior literature has also connected memory to learning (Craik \& Lockhart, 1972). Additionally, Maslow's (1943) work on the theory of motivation noted that learning cannot occur without basic needs first being met. These tenets of social learning theory identify the optimum environment in which individuals learn.

\section{Social Learning and Education}

Similar to Bandura's (1971) research, Vygotsky (1978) noted the relationship of social environments and development of cognition. Though this work was not published for viewing in the United States until much later, Vygotsky studied similar behavior patterns, specifically in adolescents. The social learning theory lens can be applied to higher education to investigate informal types of learning. Additionally, supervised peer educators on university campuses can act as a resource; these student facilitated programs are one-way institutions can share information, counsel, and drive outreach efforts (Badura, Millard, \& Shah, 2008). By nature, peer-education programs are a less formal way to share institutional knowledge (Badura et al., 2008). Social learning also occurs within student residential communities. Informal learning environments such as 
residential learning communities are designed with shared knowledge in mind (Tinto, 2003); shared knowledge can support students' institutional knowledge. Furthermore, residential living learning communities on the university campus are a resource for students transitioning to college; these communities are a way of connecting traditionally underrepresented student populations to the campus at large (Inkelas, Daver, Vogt, and Leonard, 2007). All of the afore mentioned research supported the notion that learning can occur in and out of the traditional classroom.

\section{Social Learning and Modeling}

Bandura $(1971,2017)$ postulated that individuals learn in social situations from influence, observation, imitation, and modeling. The current study investigated a wide range of informal and formal environments designed for social learning when considering a social learning theory approach to higher education. Informal methods of social learning were discussed frequently in prior literature and scholars shared that students often relied on friends to understand college-going processes (Bell, Rowan-Kenyon, \& Perna, 2009; Badura et al., 2008; Inkelas et al., 2007). Peer educators on university campuses often act as a resource for the development of appropriate social norms at the university level (Badura et al., 2008) and living learning communities support student transition and acculturation to the university (Inkelas et al., 2007). Another avenue for social learning on university campuses includes first-year seminars (Allen, 2006; Schmidt \& Graziano, 2016). First-year seminars are critical to the academic success of first-year, first-time students (Tinto, 1999). First-year seminars are designed for first-year students to explore the university setting and support appropriate academic and social transitions (Allen, 2006; Schmidt \& Graziano, 2016). Instructors of these seminar programs are 
considered to be social supports for new students as well (Allen, 2006; Schmidt \& Graziano, 2016).

Additionally, students with greater peer support reported better academic and social adjustments (Grant-Vallone et al., 2003). Likewise, students who made more friends or institutional connections also demonstrated more success at achieving academic goals (Skahill, 2002). Furthermore, universities retained students at a higher rate when students reported being supported academically, socially, and personally (Tinto, 1999).

\section{Design of the Study}

This qualitative study explored student experiences in an emergent nature. Creswell (2009) identified emergent design as a tool to reduce bias through minimizing preconceived notions while starting the research process. Emergent research designs allow the initial research plan to be altered or shifted as data is collected and themes emerge to best learn about the phenomenon (Creswell, 2009). This non-experimental study focused on collecting rich and thick descriptions of student experiences; qualitative research methods are a valid way to collect such a description (Merriam, 2009). The study was conducted in an ethical and transparent manner compliant with the code of ethics set forth by the American Education Research Association (2011). The Institutional review board (IRB) approved this research study prior to data collection; completing the application and receiving approval met the institutional guidelines and expectations for ethical research according to Creswell (2009). Creswell (2009) suggested that the collected data be kept locked in a secure location for 10 years. 
Data collection was purposive. Purposeful sampling is a technique where intention and thought are employed to ensure participants are reflective of the typical Worthington University student (Seidman, 2013). Additionally, data collection upon transcription of interviews and focus groups were vetted with participants through a process known as member-checking. Member-checking is a process where data are shared with study participants to ensure that the data reflect the participant's thoughts and intentions appropriately (Seidman, 2013). The process of member-checking bolsters the reliability and integrity of a research study (Seidman, 2013). The data underwent member-checking, and then axial coding was used to analyze the collected data and highlight emerging themes that were relevant to the setting. Merriam (2009) noted that axial coding comes from "interpretation or reflection" (p. 180) of the data.

\section{Setting}

The study was conducted at a midwestern, mid-sized, public, 4-year university with a reporting enrollment of approximately 6,500 students across all programs and levels. The well-established university has been granting degrees for more than 150 years. Additionally, the institution offers multiple degrees types, including certificates, associates, baccalaureate, masters, post-graduate, and doctoral. The institution is known for accessibility for all student types and is considered to be an open-enrollment institution, meaning the institution does not have minimum admission requirements (Worthington University, 2019a).

\section{Participants}

Participants included a) first-time, first-year freshmen who were retained from the fall to spring semester, b) FYE course instructors, c) peer educators, d) faculty, and e) 
university administrators. Participants were selected through a purposeful sampling technique. Purposeful sampling is a research method where participants are selected to intentionally meet specific criteria; this sampling technique is well supported as a qualitative research best practice (Creswell, 2009; Merriam, 2009). The participants for this purposeful sampling were recruited through e-mail inquiry and included first-year students enrolled for the full-time at the institution. Potential participants were sent an initial interest email regarding the opportunity to participate in the study. Upon potential participant response, students were screened to ensure that they met the basic characteristics of the desired participant and were assigned a focus group time that worked within the participant's schedule. The focus group size was limited to eight participants. Focus groups should be no larger than 10 participants to ensure efficiency of the focus group (Merriam, 2009).

It is also important to note that students at the university are predominantly white, middle-class students enrolling in various majors. The university reported that $66 \%$ of students enrolled at the university identify as White, while $25 \%$ of enrolled students identify as a racial minority. Four percent of students identify as international and 5\% of students did not report race (Worthington, 2019b). Additionally, more female-identifying students enroll at the university compared to male-identifying students. Sixty-one percent of students identify as female (Worthington, 2019b).

All staff and faculty participants were employed full-time at the university. Staff and faculty at the university are predominantly White, upper-middle class individuals. Faculty members who act as the lead faculty member for orientation courses also teach across various majors and programs on campus. The participating staff members work 
directly with first-year students at the university in various roles. Worthington University (2019) reported that $84 \%$ of faculty and staff identify as White, while the remaining $16 \%$ of faculty and staff identify as racially diverse.

Faculty, staff, and administrator potential participants were recruited in a similar manner. Participants were selected through a purposeful sampling technique using e-mail inquiry. Potential participants were sent an initial interest email regarding the opportunity to participate in the study. Upon potential participant response, students were screened to ensure that they met the basic characteristics of the desired participant and assigned a focus group time that worked within their schedule. Again, focus groups were limited to eight participants.

\section{Data Collection Tools}

Data collection methods included focus groups, one-on-one interviews, observations, and document analysis of campus-wide resources. Multiple resources were used for data collection; this practice is known as triangulation (Merriam, 2009). Triangulation is a best practice in qualitative studies and strengthens the validity of the study (Creswell, 2009; Merriam, 2009; Picardi \& Masick, 2013). Focus groups were conducted with student participants, instructors, and other faculty. One-on-one interviews were conducted in a semi-structured manner with administrators of university programming, including orientation, first-year experience, residential living, and student services. A semi-structured interview format gives the interviewer the ability to respond situationally and allows the interviewer to explore the emerging response to the phenomenon (Merriam, 2009). 
I reviewed the materials available to students regarding campus-based resources. These materials included documents such as the orientation manual, the student handbook, and additional admission materials. The use of mining data from documents such as surveys or public records is a practical data collection method that allows one to gather further insight into a phenomenon (Merriam, 2009).

\section{Data Analysis}

Axial coding was used to construct categories and analyze the data before themes were compared. Axial coding is a practical way to identify emerging themes in the data of qualitative studies (Merriam, 2009). The use of an open-coding approach to review the data allowed the categorical construction to occur more organically. The use of open coding allowed me to take specific words or phrases used by the participants to support the categorical construction (Merriam, 2009; Picardi \& Masick, 2013).

A constant comparison method was also implemented; the use of constant comparison in qualitative research segments the data (Merriam, 2009). The segments can be examined once the initial data is segmented, placing more attention on the focus group questions and the data being collected. The study included data from one-on-one interviews and clarifying focus group questions. This process was repeated after each focus group. Observations and document analysis were conducted to triangulate the findings after the interviews and focus groups were completed.

The findings were reviewed through the lens of social learning theory after data collection and initial analysis were completed. The practice of connecting findings to theory allows one to make sense of the study's practical aspects (Merriam, 2009). It is critical to note that member-checking were used to validate the collected data. Member- 
checking — or respondent validation — is a practice in qualitative research that gathers feedback from participants on the collected data and emerging themes to ensure the data was not misinterpreted during the analysis (Creswell, 2009; Merriam, 2009).

\section{Limitations and Delimitations}

Several limitations exist within qualitative research. These limitations include, but are not limited to, the lack of generalizability, validity of self-reported data, reliability of data collection methods, and ability to replicate the study (Merriam, 2009). Limitations for this qualitative study included intentional small samples and purposeful sampling. The use of qualitative techniques meant that not all students at the institution were represented in the findings. The generalizability of the study was limited due to the qualitative nature of the data collected. Additionally, I worked at the institution where the study was conducted during the time of the study and had a pre-existing professional relationship with the majority of interview and focus group participants. Finally, the data collected was primarily self-reported data. The self-reported data is the experience of the individual participants and may not reflect the experience of every student. 100

\section{Definitions of Key Terms}

College-going: behaviors and knowledge that support the access to, enrollment in, and participation of post-secondary education.

Diverse student: students who identify as a member of an underrepresented student group, including but not limited to, race, ethnicity, gender, sexual orientation, sexual identity, housing status, parental status, marital status, veteran status, background, first-generation, or English as a second language learner. 
Navigate: the process in which students learn and understand the existing, supporting resources at the university for the transition and supersession of barriers and accomplishment of goals (Caldwell \& Siwatu, 2003; Strayhorn, 2015).

Re-acculturation: the process of gaining new cultural experiences to form a new identity in place of old culture, experiences, or identity (Bruffee, 1999).

Student success: positive and desired student outcomes, including, but not limited to, student satisfaction, retention rate, graduation rate, learning accumulated, experience gained, or engagement.

\section{Significance of the Study}

This qualitative study added information to the field using a more inclusive lens of gathering and using college-going knowledge. Higher education professionals will be able to determine gaps that exist in student needs through understanding students' experiences of navigating the university setting. Additionally, administrators will be able to implement best practices that support student success. The results of this study could lead to policy change at the institutional level to support students as they navigate the university.

\section{Scholarship}

At this point in time, scholarship has largely been segmented in regard to how students use campus resources for their success. Scholars invest more time and resources in learning about individual programs and theories than understanding how those programs, initiatives, and theories are used together to support student success. This study adds to the existing literature on student success in a new and meaningful way. 


\section{Practice}

Higher education practitioners will gain insight regarding student needs that may be unmet at this time. Practitioners will also gain an understanding of how students gain college-going information to create more intentional experiences and how students gain the skills or knowledge needed to be successful. It is beneficial for practitioners to analyze the resources or initiatives that may no longer be serving the institution and its mission.

\section{Summary}

Rendon (1995) developed a foundation for the experiential study of students navigating a post-secondary setting. This study sought to explore the experiences of students in traditionally underrepresented populations. This section provided background on navigation in higher education, introduced the social learning theoretical framework and detailed the planned methodology of the study. The study results were drawn from interviews, focus groups, and document analysis. Furthermore, the study results provided insight on how students navigate their academic career and use campus resources to increase success. The next section details the setting in which the study took place. More information regarding the history, organization, and leadership of this specific institution will be detailed to provide a solid context for understanding the student and administrator experiences. 


\section{Chapter Two}

\section{PRACTITIONER SETTING FOR THE STUDY}

\section{History of Organization and Introduction}

This dissertation-in-practice was set at Worthington University. According to the Carnegie Classification, Worthington University is a public, 4-year, medium-sized institution considered to be primarily nonresidential (Carnegie Foundation for the Advancement of Teaching, 2011). This public institution boasts an enrollment profile high in undergraduate students with a record of several small graduate and professional programs (Worthington University, 2019). Furthermore, the university enrolls approximately 6,500 students with an open-enrollment approach to higher education access (Worthington University, 2019). The history of the institution is outlined to provide context for the study. Furthermore, an analysis of the organization and its leadership is detailed to further provide context for the current dissertation-in-practice.

\section{5-1914}

Worthington University, established as Leery College in 1865, was a private, protestant congressional school with a commitment to educating all students-including women and minority students - in a two-story building (Dodd, 2015). Classes officially began in January of 1866 with a curriculum designed to help students complete a high school education and support their transition into higher learning (Imparato, 2006). The inaugural class of 1866 enrolled 38 high school students and two college students (Imparato, 2006). Less than 2 years later, the institution was struggling financially and sought a financial backer to support the new institution (Imparato, 2006; Worthington University, 2019). In the fall of 1868, Leery College secured a benefactor who donated 
$\$ 25,000$ to the institution to continue providing education to underrepresented student populations (Dodd, 2015; Worthington University, 2019). Out of immense gratitude, the institution changed its name to Worthington College after the generous donor. In 1869, the first college president $-\mathrm{a}$ former reverend of the affiliated protestant church—was appointed by the Board of Trustees (Dodd, 2015).

By 1874, the institution had outgrown the original two-story building and moved the campus across the city (Dodd, 2015). With the move, the institution expanded and included dormitories for students to live on campus (Imparato, 2006). The now thriving institution expanded the physical campus and its educational offerings through the turn of the century. Educational offerings continued to expand until the institution decided to cease high school education and separated the secondary curriculum from the institution (Dodd, 2015).

\section{$1915-1965$}

Beginning in 1915, the support provided by the protestant church began to diminish (Dodd, 2015). The Great Depression further impacted the financial state of the institution. Faced with financial hardship, the institution became a municipal institution supported primarily by a property taxation (Dodd, 2015; Worthington University, 2019). In 1941, Worthington College became Worthington Municipal University and was governed by a Board of Regents (Imparato, 2006; Worthington University, 2019). In the 1950s, the institution opted to shorten the cumbersome name to Worthington University (Imparato, 2006; Worthington University, 2019). In 1961, the institution began receiving state-funded appropriations (Imparato, 2006). Though the state funding supported 
institution growth, the institution's primary funding source—revenue from a county sales tax — continued to be the primary source of funding for the institution (Imparato, 2006).

During this time, new funding sources were created, and tuition was lowered to make post-secondary education more accessible. Enrollment grew and the institution expanded once more to provide additional educational facilities and more student housing (Imparato, 2006). This enrollment increase was well supported by the change in tuition costs and the passing of legislation that provided veterans educational benefits to attend college (Imparato, 2006).

\section{6-1999}

In 1966, Worthington University experienced extreme devastation in the form of an F-5 tornado (Dodd, 2015; Worthington University, 2019). The tornado destroyed five of the campus buildings; however, the destruction did not slow classes. The institution borrowed space at a local high school and provided mobile classrooms until the damage could be repaired (Dodd, 2015). The following years were full of progress and rebuilding. All of the damage from the tornado was repaired within 5 years; classrooms had been restored and five additional buildings had been added to the campus community (Imparato, 2006; Worthington University, 2019). The progress did not stop after the tornado. From 1976 until 1999, the university continued to grow and build additional facilities on the campus (Dodd, 2015; Worthington University, 2019).

\section{0-Present Day}

Much has changed about the institution since its inception more than 150 years ago; however, several characteristics have remained. The institution is still funded by state appropriations and is still supported by the local community (Dodd, 2015). The 
institution no longer identifies as a municipal university; yet the organization is still supported through taxation. A percentage of the county's sales tax comprises $22 \%$ of Worthington's annual operating budget (Dodd, 2015; Worthington University, 2019). The remainder of the institution's annual operating budget is comprised of tuition revenue (59\%), state appropriations (13\%), and donations (6\%); the county sales tax provides Worthington significant monetary support compared to other revenue sources (Worthington University, 2019).

The institution has continued to grow and expand. Several new facilities and programs have been designed to attract and recruit students to the institution in a climate of competitive enrollment (Dodd, 2015). The institution continues to hold the values upon which Worthington University was founded many decades ago, and has noted specific commitment to the organization's core values of integrity, excellence, inclusion, accountability, respect, collaboration, and innovation (Dodd, 2015; Imparato, 2006; Worthington University, 2019). These core values are a critical component to the organization's dynamics and decision-making. The remainder of this section will highlight the connections between the institution's core values and the organizational and existing leadership structures.

\section{Institutional Legacy}

Core values. The institution at large has set core values embraced by the community of faculty, staff, and students. Those core values include integrity, excellence, accountability, respect, inclusion, collaboration, and innovation. These core values guide the mission, strategic plan, and work of the institution. Additionally, the University Libraries have set forth additional values that support the culture and mission established 
by the institution. The organization values people, access, social responsibility, stewardship, and transparency. The University Libraries and the Center for Student Success and Retention strive to "acknowledge and share in the successes and failures in the pursuit of supporting and improving our Community of Learning" (Worthington, 2019b).

Organizational student-centered culture. Worthington University's culture could be described as a learning culture. The learning culture is an "environment that supports and encourages the collective discovery, sharing, and application of knowledge" (Gill, 2010, p. 5). Organizational culture is the shared visioning and core values of an organization (Levi, 2015). Worthington University's culture can be demonstrated by the Office of Undergraduate Initiatives' commitment to improve retention rates and graduate rates at the institution. The university's culture is also demonstrated through the various studies conducted, research grants awards, and national presentations completed by various programs and staff members. Furthermore, the culture is evident by the vision of the institution to build a "Commitment to transparency... which fosters teamwork and unleashes innovation and ensures the responsibility of each individual to both the unit and institution" (Worthington, 2019b). The university has a clear and shared vision, which is a key component in creating an organizational culture of learning (Gill, 2010). Effective teams encourage contribution and innovation from all members; this is a strategy enacted by the office staff at Worthington University (Levi, 2015).

\section{Organizational Analysis}

Structural frame and the university. Organizations can be difficult to understand and manage (Bolman \& Deal, 2013); Worthington University is no different. 
The organization, designed similarly to Mintzburg's (1979) divisionalized form, is organized in a basic hierarchy with the quasi-autonomous divisions described by Mintzburg. Each division within this organizational structure serves a distinct purpose and supports the functioning of the unit (Bolman \& Deal, 2013). It was further noted that this structural type, as described by Mintzberg, controls economic risk while providing resources and responsiveness to issues or problems in the individual unit (Mintzberg, 1979). Mintzburg's structural framework asserts that organizations exist to achieve goals (Bolman \& Deal, 2013). At Worthington University, the units of academic affairs, administration and treasury, student life, enrollment management, and athletics work alongside each other to achieve the same goal while, yet each of these units work independent of one another. Figure 2 demonstrates the structure at Worthington University.

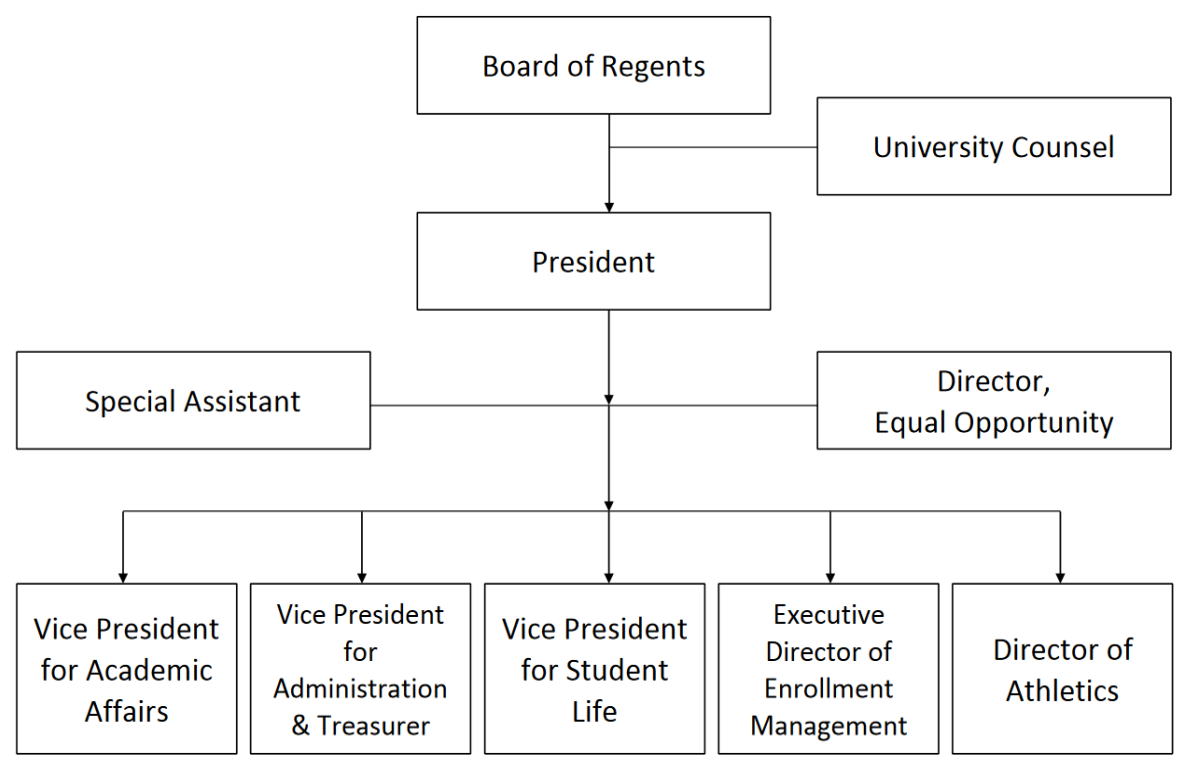

Figure 2. Worthington University organizational chart. Worthington University, 2014, p. 1. 
This dissertation-in-practice further examined the individual unit of academic affairs. The academic affairs unit was of particular interest because it houses the University Library and Center for Student Success and Retention. See Figure 3 for a further detailing of the organizational structure of this particular academic unit.

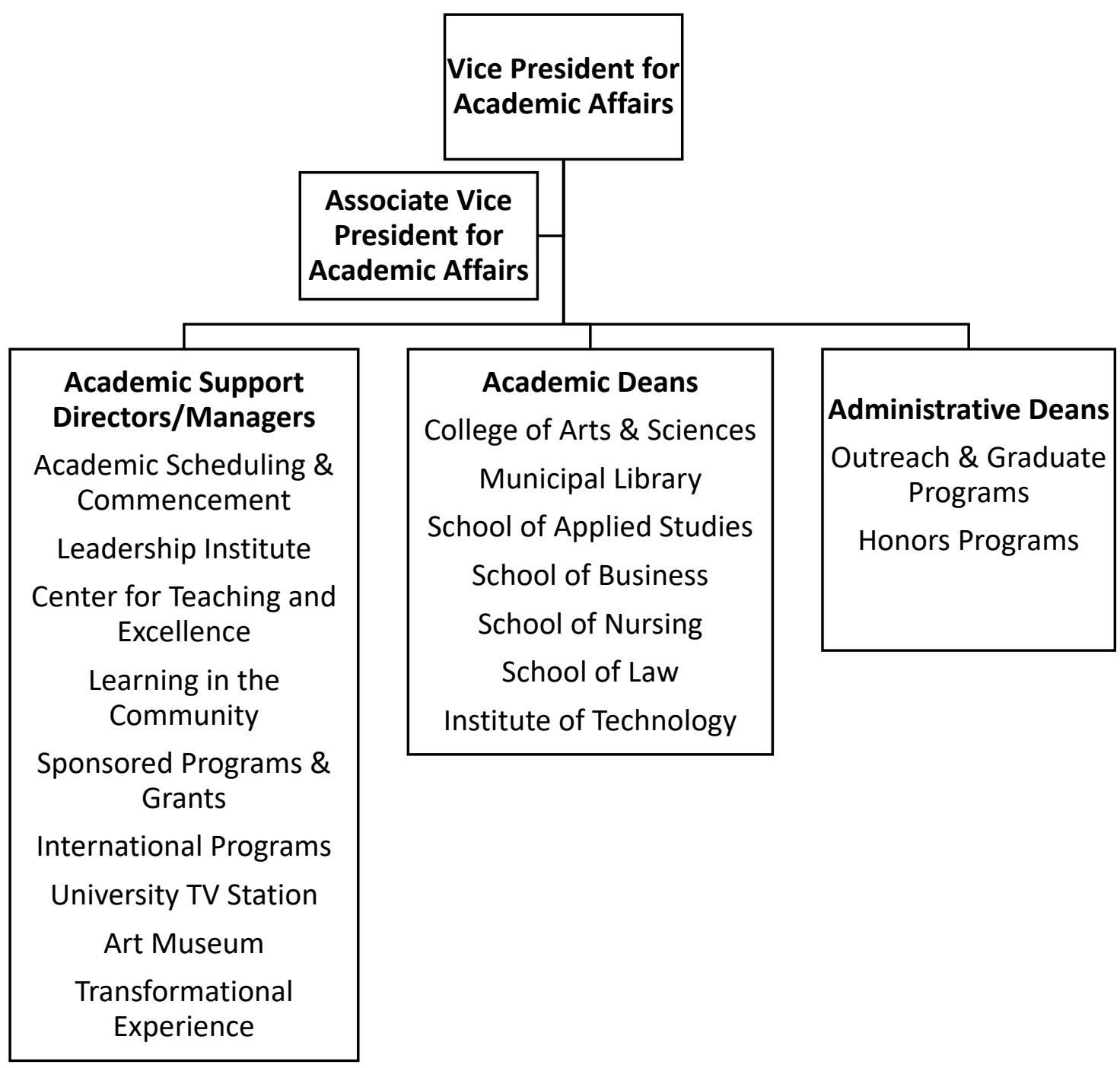

Figure 3. Worthington University academic affairs unit organizational. Worthington, University, 2014, p. 3. 
It is important to note that student programming stems from the municipal library within academic affairs. The Municipal Library (see Figure 4) houses the Center for Student Success and Retention, a multi-department organization designed to improve the student experience at Worthington University. Ten primary departments make up the organization; these departments include Academic Advising, Access Services, the Education Library, Information Literacy, Library Operations, Non-Traditional Student Success and Retention Office, Open Access Initiatives, Student Employment Initiatives, Undergraduate Initiatives, and the University Tutoring and Writing Center. Each of these departments serves a different role, which bolsters the vision, mission, and strategic plan of the University Libraries and Center for Student Success (See Figure 4). The departments of Undergraduate Initiatives and Non-Traditional Student Success and the Office of Retention are of particular interest for this dissertation-in-practice, as these departments house first-year student experience programming and are actively involved with first-year seminar courses as well as orientation programming. 


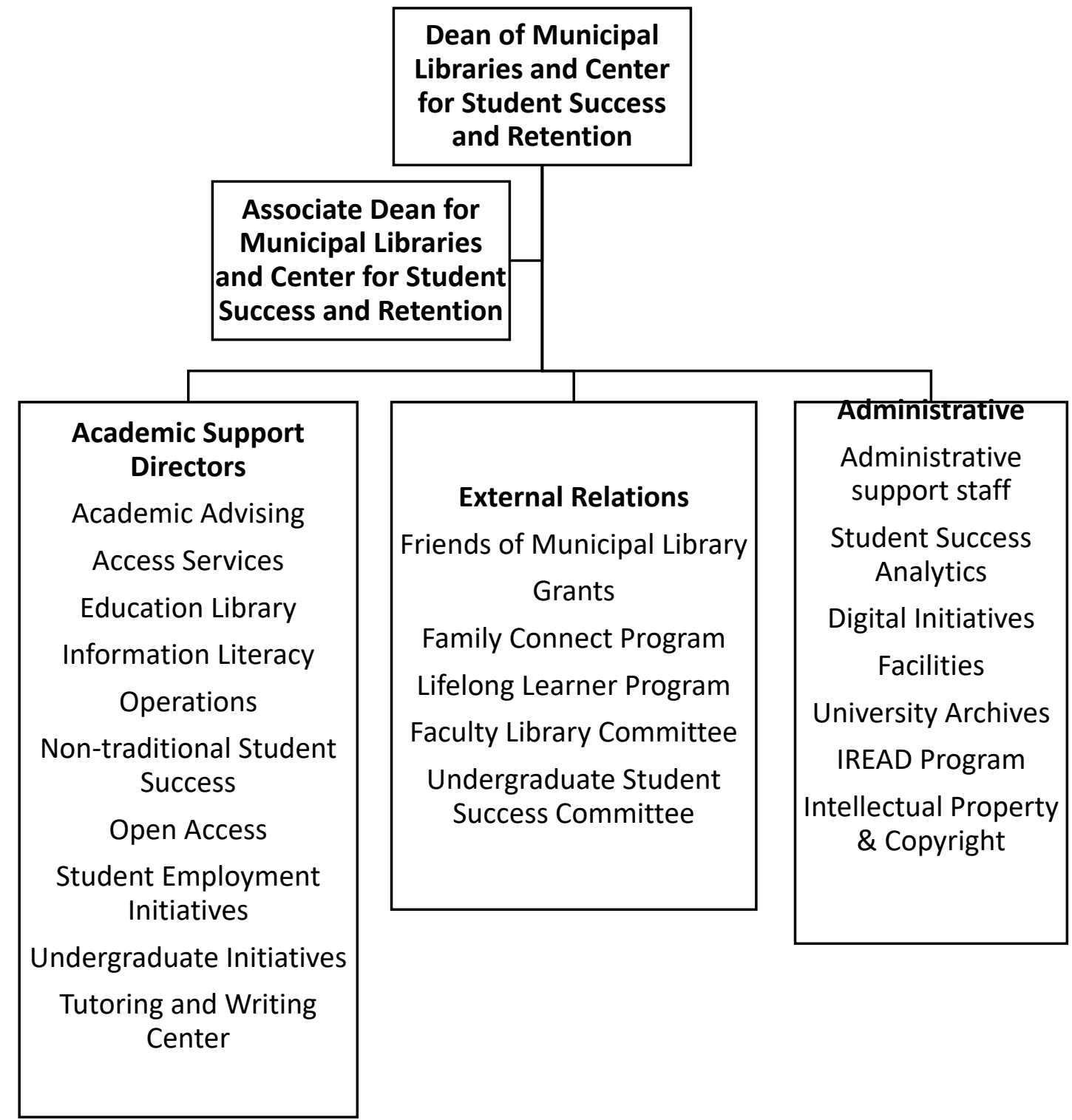

Figure 4. Organizational Chart of Municipal Library.

Relates to Figure 2 and Figure 3 as a smaller branch of the VPAA unit. From Worthington University, 2014, p. 7.

\section{Human Resource Framework and Municipal Library}

The human resource framework approaches organizations with a people-oriented lens; organizations need people to function and exist to serve the needs of others (Bolman \& Deal, 2013). Bolman and Deal (2013) illuminated that the human resource framework is people-centered in nature, acknowledging that "Organizations exist to serve human 
needs" (p. 117) and "People and organizations need each other" (p. 117). The human resource framework is based upon core assumptions that support the style and approach to organizational culture and structure (Bolman \& Deal, 2013). The human resource framework's core assumptions include the understanding that a) organizations cater to individuals, b) organizations and individuals need one another; and c) individuals need jobs and opportunity to make life meaningful (Bolman \& Deal, 2013). The human resource framework mirrors the institution's approach to decision-making and strategic planning and practices a student-centered mindset (Worthington, 2019b). This peoplecentered lens ensures that every decision made at the institution is made with the success of the student in mind. The organization exists to serve student needs. The primary example of this concept is the number of initiatives, grants, and programs designated to meet the needs of Worthington students. Programs are available for a multitude of student sub-populations. From veteran students to first-generation students, you will find numerous initiatives on Worthington's campus to support students' needs. The intense number of programs and projects on Worthington's campus are all part of the visioning for the Center for Student Success and Retention.

\section{A Vision for Student Success}

The understanding that "The University Libraries and the Center for Student Success and Retention are integral to the student-centered, teaching-focused Community of Learning that is Worthington University" (Worthington, 2019b) guides the practices of the university. This vision drives all happenings within the university, but also within the University Libraries and the Center for Student Success and Retention. This vision guides the work of the organization and the mission statement supports the work of the 
University Libraries and the Center for Student Success and Retention; the vision and mission statement are separated for focused purposes. The mission of the University Libraries is to act as "teaching libraries, dedicated to student success and the development of a Community of Learning that effectively, efficiently and ethically uses information in the knowledge society" (Worthington, 2019b). The mission of the Center for Student Success and Retention is more relevant to the current dissertation-in-practice. The Center for Student Success and Retention's mission states that the center "leads institutional efforts to transition students successfully into our Community of Learning and empower them to achieve academic success" (Worthington, 2019b). It is the mission of the Center for Student Success and Retention that drives initiatives and programming that support students in the navigation of college-going.

Student success programming. In recent years, the University Libraries and Center for Student Success and Retention have implemented multiple new campus initiatives to support student retention. In particular, the Office of Undergraduate Initiatives houses more than 10 initiatives implemented to bolster student success; these initiatives include FYE programs, first-generation retention initiatives, academic integrity program, peer educator program, 2nd through 4th year experiences programs, the Ignite Program, the STAR program, the Mentoring program, and the Local Student Support program. Another office housed within the Center for Student Success and Retention includes the Office of Non-Traditional Student Initiatives. This office offers the campus community nine additional programs designed to support student success. This office includes programs such as adult initiatives, pre-college programming, competency-based education programs, military student services, the prior learning and testing center, test 
preparatory services, the Success Institute, the Senior Academy, and community outreach. These programs and initiatives all work together to support students and their understanding of college-going knowledge. Furthermore, these programs and initiatives connect in a useful way that encourages the free exchange of information and student support. All-channel networks create multiple connections and communication pathways; the Center for Student Success and Retention were an exemplar of this network (Bolman \& Deal, 2013).

This study focused on services and programs that serve first-time, first-year students at the institution. These types of programs and initiatives are managed by the Office of Undergraduate Initiatives. The Office of Undergraduate Initiatives is operated by university staff members, including a director, multiple student success coaches, lecturers, retention specialists, and peer educator student staff. This office has formed informal networks, meaning that the office staff create relationships built on similar interests and shared goals to provide a stronger connection among members of the group (Bolman \& Deal, 2013). This action sets the tone for the office and organizational culture.

Student Success Collaborative. One of the newest initiatives at the institution is the Student Success Collaborative (SSC). The SSC is a partnership focused on improving the retention and graduation rates of students at Worthington University. The SSC is overseen by university administrators in partnership with a consulting firm known as EAB, formerly the Education Advisory Board. The EAB firm has a contract with the institution that supports the work of the Center for Student Success and Retention. The center noted that the goal of the SSC is to connect offices across campus to improve 
student support services. The data and best practices presented by the EAB firm are used on campus to drive decision making regarding initiatives, programs, and support. Datadriven leadership is a best practice in the field of education; when used appropriately, educational data can guide leaders to make informed decisions about curriculum, instruction, and support (Datnow \& Park, 2014).

\section{Leadership Analysis}

Path-goal theory. Path-goal theory also aligns with the current dissertation-inpractice. The theory, introduced by Evans (1970) and further developed by House (1971), described this approach to leadership as a linear path to successful outcomes. The leadership theory was initially based on Vroom's (1964) expectancy theory. The expectancy theory states that individuals' willingness to act in a particular manner will increase based on the expectation that a desired outcome is likely to occur (Vroom, 1964). Furthermore, House's literature was built on motivation studies completed by Georgopoulos, who examined the path-goal hypothesis. In the most basic understanding, the theory is used when leaders give clear and detailed instructions, followers execute those directions, and a successful or desirable outcome is yielded (Northouse, 2009). Through a more complex lens, the path-goal theory is used in leadership by adapting leadership styles and characteristics to help followers enhance performance, improve motivation, and achieve desired goals (Northouse, 2009). At any level, the path-goal theory follows three basic steps: determine the employee and environmental characteristics, select a leadership style, and focus on motivational factors that will help the employee succeed (House, 1971). 
In path-goal theory, relationships are a critical component of successful leadership (Northouse, 2009). Path-goal theory supports the leader's ability to develop followers; leaders guide followers through environmental and external barriers that occur on the path to achieve individual or shared goals (House, 1971). Path-goal theory is an adaptive approach to leadership, allowing leaders to select and enact behaviors that are more likely to support a follower's needs, situation, and goals (Northouse, 2009). This practice is reflected in higher education practice. Figure 5 demonstrates how leaders guide their followers in order to accomplish goals.

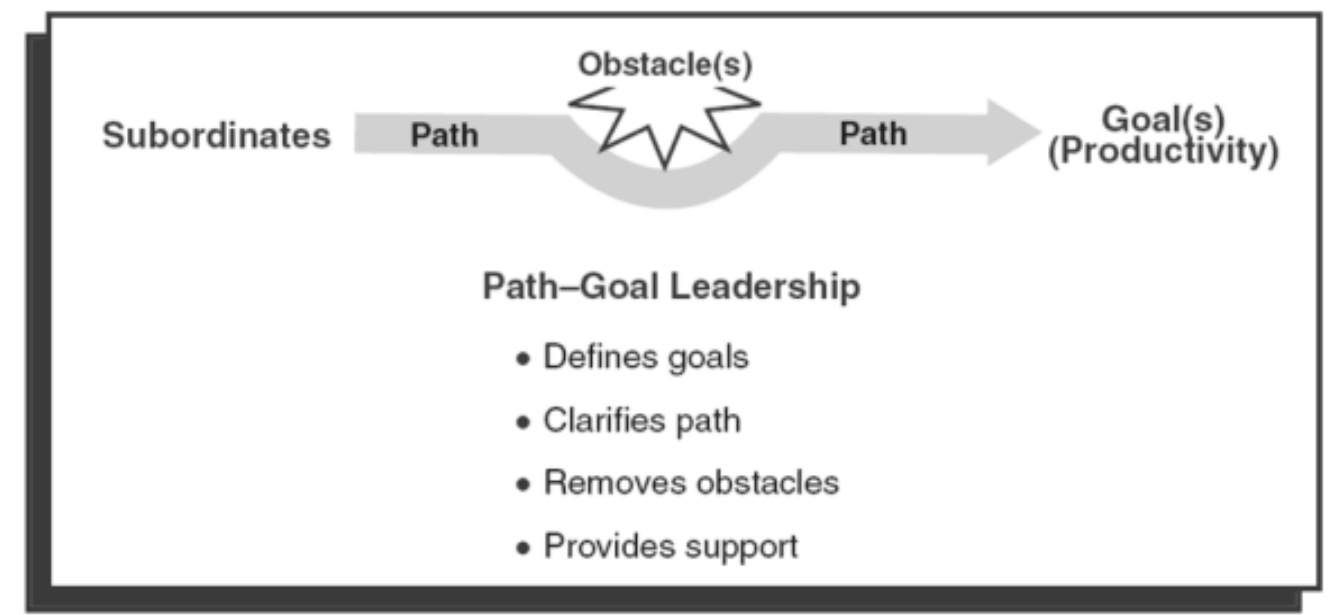

Figure 5. The Basic Idea Behind Path-Goal Theory Northouse, 2009, p. 126.

Path-goal theory is applicable to the current study because the theory supports the clarification of goals, clears a path to achieve those goals by removing obstacles, and provides individual support. Worthington University takes these same steps to support students upon admission to the institution. The remainder of this section will detail how these theories align with the vision and mission of the institution as they relate to the current dissertation-in-practice. 


\section{Goal Definition: Desirable Student Outcomes}

The university clearly defines the desirable student outcomes. At this particular institution, multiple measures are used to account for successful student outcomes. These measures include university student learning outcomes (USLO), major and program outcomes, and the institution core values. The USLO assessment measures a student's critical and creative thinking, communication abilities, global citizenship, commitment to ethics and diversity, information literacy, and quantitative and scientific reasoning skills (Worthington, 2018). The institution at large reports the measures collected through the USLO assessment and reviews the information annually. Furthermore, various programs and majors at the institution measure how students meet program outcomes. All majors have designated program or major outcomes. Some programs align these outcomes to professional agencies or organizations in their respective field; nursing, allied health, and criminal justice are good examples of that practice at the institution. Additionally, the university's core values are threaded through the university's curriculum. These values include integrity, excellence, accountability, respect, inclusion, collaboration, and innovation.

This dissertation-in-practice examined the student learning outcomes associated with the FYE program. The program was designed to support students in the following manner.

Practice academic honesty and exhibit ethical conduct. Demonstrate membership in and engagement with the WU community. Develop an academic success plan and demonstrate an understanding of the purpose of a university education. Establish connections to faculty, staff, and students in the WU community. 
Demonstrate effective collegiate learning and study skills. (Worthington, 2018, p. $1-2)$

These outcomes were developed to support student learning and are clearly presented to students through course syllabi and program introductions.

\section{Clear Path to Graduation}

Path-goal theory's next step in leadership is the leader's ability to clear a path for

followers. The university addresses this step through intentional advising experiences and the use of professional advisors for exploratory and declared majors. Additionally, an assignment within the FYE program requires students to complete a 4-year academic plan to guide their time and direction at the institution. Additionally, the institution requires regular advisor meetings. These experiences are designed to clear the path to graduation for the university students.

\section{Remove Obstacles to Student Success}

The next step a leader takes in path-goal theory includes removing obstacles in the followers' way to help the follower achieve their desired outcomes or goals. Worthington University implements multiple initiatives to remove common barriers and obstacles that students face in college. Institution programs include the lowering of all majors to degree confirmation status at 120 credits or less. Another program, known as the Think30 program, is designed to encourage students to enroll in 15 or more credit hours a semester to graduate "on-time." The final obstacle the institution addresses is that of academic preparation and access. The university operates as an open-enrollment institution, which ensures that all persons can access a post-secondary degree or certificate. 


\section{Provides Support to Earning Baccalaureate Degree}

The final step a leader must take to help followers achieve desired outcomes or goals is to support followers. The institution implements multiple levels of support for students to achieve their goals. The Center for Student Success and Retention has spearheaded many of these initiatives. Some of these programs include an early alert system, the tutoring, writing, and math center, student retention and support software, and retention coaches. Early alert systems allow instructors, advisors, and other campus staff to communicate about concerning academic or personal behaviors that involve students and their success at the institution. The tutoring, writing, and math center helps students with homework, test preparation, and papers free of cost. Additionally, the student retention and support software that student transition support and services was a customer relationship management tool implemented to streamline student enrollment, communication, and use of support services. The final initiative to detail is the retention coaches program. The institution's retention coaches work with students from specialized populations to address questions and help bolster retention efforts through targeted and specific communications. Specialized populations include first-generation students, diverse students, veteran students, students on academic probation, students in remedial courses, and students from the local school district. Retention coaches vary in their level of intervention. Multiple retention coaches are assigned to support students at time of enrollment and throughout their first year, second through fourth years, and upon withdrawal of classes. Retention coaches are trained to address the student's specific needs at certain times in the student's academic career. 
One final support developed by the institution and the Center for Student Success and Retention is the FYE program. The primary function of the FYE program is to enroll students in an orientation course that provides students with tools to navigate the first semester of college and beyond. The FYE program is a critical component and vehicle for the current dissertation-in-practice. The FYE program course has been developed to include multiple resources and an introduction to the outcomes desired for the students.

\section{Implications for Research in the Practitioner Setting}

The study of student success in the field of higher education is critical to the future of the university (Hunter, 2006; Rendon, 1995). Existing literature has highlighted individual areas of concern for student success and retention efforts at the post-secondary level (Rendon, 1995; Tinto, 1975). While existing literature addressed critical components of the student lifecycle as related to social learning, it did so in a segmented fashion. This dissertation-in-practice sought to provide a multifaceted approach to social learning and navigation of a particular university.

College is experience-focused and process-oriented (Strayhorn, 2015).

Universities can better support students on an individual basis through better understanding student experiences and the processes used to navigate the university. Because existing research in higher education often focused on specific interventions or programs, the understanding of student experiences is narrowed to that exact program or intervention. By widening the lens, higher education professionals have the opportunity to better support students navigating new processes and experiences at the university level. Intentional opportunities for learning, retention, support, and re-acculturation for all student populations are created when leadership understands how students navigate the 
university. Existing literature considered how first-year programming, academic curricula, and peer relationships impact, benefit, and support students; however, it would be of value for higher education professionals to better understand how students navigate the university setting through a multitude of lenses connected through social learning and shared experiences.

\section{Summary}

Worthington University has a rich and time-tested history. From the institution's inception, the university has demonstrated both a commitment to providing access to higher education for all persons and a commitment to student success. The institution's legacy of integrity, excellence, accountability, respect, inclusion, collaboration, and innovation have remained steadfast over decades of changes in higher education. The organization's structure and leadership are designed to support student-centered and datadriven decision-making. Furthermore, the leadership of the vice president for academic affairs - in partnership with the dean of the Worthington libraries and Center for Student Success and Retention — provided oversight and direction for key administrators working with first-year students. The leadership of these key administrators has been instrumental in the development of a comprehensive system designed to help students achieve their goals. The institution's leadership clearly identifies student goals and desired outcomes and uses the path-goal theory approach to leadership. The multitude of leaders in and out of the classroom help the administration be nimble in their delivery of leadership skills. An understanding of the organization's history, culture, structure, and leadership provides context and guidance to this dissertation-in-practice. The next section will further clarify the literature related to the current study. 


\section{Chapter Three}

\section{Scholarly Review for the Study}

\section{Social Learning Theory}

This section synthesizes the key concepts from relevant literature that guided this dissertation-in-practice. This dissertation-in-practice investigated the following research question: "How do students navigate the university?" The tenets of social learning theory and related threads of pertinent educational literature were examined for their intersection with the navigation of college-going. The first half of this section details tenets and assumptions of social learning theory. The latter half of this section will explore related areas, such as retention, support measures, and re-acculturation. The concepts reflected in this scholarly review of literature served to further guide this dissertation-in-practice. The definition of social learning must be further explored before learning more about the intersectionality of social learning and college-going.

\section{Social Learning Defined}

Bandura (1971, 2017) established the notion of social learning theory, initially postulating that social learning occurs when people learn from one another through various techniques. Bandura (1979) understood social learning to be goal oriented in nature and hypothesized that most human behaviors are goal related. Vygotsky (1978) reinforced the understanding of social learning in adolescents by studying cognition development and behavior patterns. Vygotsky thought social learning could be applied to tutoring and learning situations; tutors or teachers modeled behavior in a social environment and students mimicked said behaviors. Social learning theory encompasses modeling behaviors and intersects with the areas of attention, memory, and motivation as 
tools for intellectual expansion (Vygotsky, 1978). These mechanisms for learning can be linked to both cognitive and behavioral learning (Bandura, 1971, 2017). Social learning theory is a primary vehicle for human learning, as social settings create endless opportunities for development (Schunk, 2008). Vygotsky referenced social learning as a tool for intellection and adaptation. Additionally, Schunk (2008) stated that "Knowledge, rules, skills, strategies, beliefs, and attitudes" become solidified through social interactions and observations (p. 78).

For this study, social learning theory will be defined as the cognitive and behavioral developments that are derived from learning in group settings and used for navigation; this definition is well supported by Bandura's (1971) initial findings. Social learning theory is connected to education through Vygotsky's (1978) work with adolescents and social learning; therefore, this theory directly relates to the current dissertation-in-practice. Like adolescents, university students also learn in social settings; students learn college-going knowledge, rules, and strategies from peers and teachers (Bruffee, 1999; Harper, 2012). Social learning is critical to understanding how students learn to navigate college and gain an understanding of college-going. In turn, behaviors demonstrated by students further illustrate the cognitive and behavioral aspects of social learning theory.

\section{Cognitive Components of Social Learning Theory}

Bandura $(1971,2017)$ based a portion of his understanding regarding social learning theory on the work of Piaget (1936), who studied cognitive learning among children. Piaget focused on how learning could be developed in a phasic method through maturation in adolescents. Piaget studied sensorimotor, pre-operational, concrete- 
operational, and formal-operational phases and correlated these phases to age ranges. Piaget asserted that development progresses through a series of stages, meaning that cognition is developed in periods rather than by individual experiences and learned concepts. Bandura further expanded on these concepts, noting that social learning theory encompassed components of attention, memory, and motivation. These cognitive tools were further investigated by Bandura to garner a better understanding of how people learn rather than develop.

Attention. Attention was first studied in relation to behavior (Berlyne, 1951). Berlyne (1951) noted that attention involves habit, drive, stimuli, and inhibition. Attention has been described and studied in various manifestations since its inception. Relevant literature has defined attention as a limited resource (Schunk, 1996; Zins, 2004) and a developmental process (Durlak, Weissberg, Dymnicki, Taylor, \& Schellinger, 2011; Rhoades, Warren, Domitrovich, \& Greenberg, 2011; Zimmerman, 1990). Attention skills as a specific process can be improved through self-instruction (Zimmerman, 1990). In addition to descriptions, other ideas or concepts can be connected to attention; for example, Schunk (1996) and Zins (2004) both found that learning and cognition are strongly connected to attention. Blair (2002) and Rhoades et al. (2011) noted that emotion is also related to attention. It is even theorized that attention skills are necessary for social and emotional success in children (Rhoades et al., 2011). Blair supported this idea, noting that school readiness and attention skills are interconnected as well.

It is evident that a positive relationship exists between attention and education (Blair, 2002; Rhoades et al., 2011; Schunk, 1996; Zins, 2004); learning simply cannot occur without attention (Schunk, 1996). Durlak et al. (2011) highlighted that "Sufficient 
time and attention must also be devoted to any task for learning to occur" (p. 408). Social environment is also tied to learning and attention, as attention is ultimately impacted by the social environment in which students learn (Zins, 2004). School-aged children with better attention skills showed better social adjustment and emotional capabilities and ultimately greater academic competence (Rhoades et al., 2011). Duncan et al. (as cited by Durlak et al., 2011) noted that "attention skills, but not social skills, predict achievement outcomes" (p. 419). Attention acts as a binder between individuals and learning behaviors (Blair, 2002; Rhoades et al., 2011; Schunk, 1996; Zins, 2004).

Memory. Memory acts as an additional tool to connect learning to individuals (Craik \& Lockhart, 1972). The study of memory has been characterized as storage, multifaceted, social in nature, and process-oriented (Hanna \& Meltzoff, 1993; Schunk, 1996). Memory is a tool for imitation used by children in social learning settings; memory is part of a larger cognition process (Hanna \& Meltzoff, 1993). Memory and cognition can be viewed as social context and can support social information processing (Wyer \& Srull, 2014). Social information processing is a process in which decisions and actions are made because of comprehension, memory, inference, judgment, decision making, and output generation (Wyer \& Srull, 2014). As related to the current dissertation-in-practice, memory supports the understanding of how individuals and students learn processes.

Motivation. The final cognitive component of social learning encompasses the tenets of motivation. The notion of motivation has been studied from a multitude of lenses, perhaps most notably through Maslow's (1943) work on the theory of motivation. Maslow (1943) postulated that people are motivated by needs at various levels; these needs include physiological, safety, love and belonging, esteem, and self-actualization. 
Self-actualization is the desire to find one's true self; all prior needs must be met to ultimately arrive at self-actualization (Maslow, 1943). Later, it was noted that motivation is a self-regulated process (Deci, Vallerand, Pelletier, \& Ryan, 1991; Zimmerman, 1989). Lazowski and Hulleman (2016) recognized that motivation presents itself diversely through "needs, drives, goals, aspirations, interests, and affects" (p. 2); therefore, social learning as a component of motivation can be used as a tool to ensure that learning occurs in social situations and interactions.

Motivation is a prominent area of research in higher education and supports the current dissertation-in-practice. Lazowski and Hulleman (2016) conducted a metaanalysis of motivation interventions in education that addressed the idea that student motivation is crucial to learning. Lazowski and Hulleman found that student learning outcomes were more positive in nature as student motivation increased (Lazowski \& Hulleman, 2016). The analysis recognized motivation interventions in education to be a relatively successful tool in improving student achievement outcomes (Lazowski \& Hulleman, 2016); motivation and academic success positively correlate (Zimmerman, 1989). Motivation skills act as a connector to learning (Lazowski \& Hulleman, 2016; Zimmerman, 1989). Learning occurs intrapersonally and is best completed when intrinsically motivated (Deci et al., 1991).

Intrinsic motivation repeatedly occurred as a theme in the literature and was identified as a tool to support learning (Deci et al., 1991; Lazowski \& Hulleman, 2016; Zimmerman, 1989). Intrinsic motivation connects well to the understanding of the selfdetermination theory of motivation. The theory of motivation supports the concept that learning increases when students are motivated from within; the intrinsic perspective of 
motivation emphasizes value, interest, and confidence in learning or education (Deci et al., 1991). Intrinsic motivation is related to the self-determination perspective; this perspective is less concerned with individual behavioral change outcomes and more focused on why those outcomes are desirable (Deci et al., 1991). Helping students understand desirable outcomes promotes greater self-determination (Deci et al., 1991). Motivation, along with attention and memory, add to the understanding of social learning. Cognitive components guided the further understanding of social learning theory and the considerations of this particular study.

\section{Behavioral Components of Social Learning Theory}

Bandura $(1971,2017)$ based some of the tenets of social learning theory on the work of Skinner (1948), who was among the first notable scholars to explore behavioral learning. Skinner's (1948) work concentrated on observable behaviors and operant conditioning. Skinner supported the use of reinforcements to change or modify behavior and noted that positive or negative reinforcement strengthens behavior. From that point forward, behavioral learning theory was concerned with the way in which people learn to behave in certain ways. Bandura extrapolated on Skinner's literature and postulated that individuals learn in social situations from influence, observation, imitation, and modeling. Vygotsky (1978) further built on Bandura's concept by extending the notions of learning through observations and imitation to the classroom setting with adolescents. These tenets guided the current dissertation-in-practice by further exploring behaviors related to learning.

Influence and observation. One of the key tenets of social learning is based on a developmental marker known as observation. Bandura $(1971,2017)$ proposed that 
individuals learn by noting patterns in the behavior of others and through various social interactions. Helping students navigate social, cultural, and environmental variables in the education system can boost academic persistence in traditionally underrepresented student populations (Caldwell \& Siwatu, 2003). This navigational assistance can be done using the social environment. Social environment is critical in the development of cognition; furthermore, social environment influences learning (Vygotsky, 1978). Social environment plays a critical role in observation of behavioral patterns (Schunk, 2008). Behaviors related to influence and observation encompass a fraction of the tools available to study how learning occurs.

Imitation and modeling. Imitation and modeling address another relevant piece to understanding how learning occurs. This study explored imitation and modeling through the examination of peer relationships. Higher education literature has demonstrated the effectiveness of peers; peers often act in the capacity of navigator and provide missing college knowledge in social settings (Bruffee, 1999; Harper, 2012). Specifically, peer leaders in diverse student populations often support other students within their own subpopulation to navigate campus by sharing effective methods or college-knowledge information (Harper, 2012). Individuals learn by noting patterns in the behavior of others and through various social interactions; this is an example of how imitation and modeling can be used in social learning (Bandura, 1971, 2017). Social learning theory provided a broad base of understanding for this dissertation-in-practice. This dissertation-in-practice also identified additional related ideas for contemplation. 


\section{Additional Concepts for Consideration}

Social learning theory is critical to the current dissertation-in-practice; however, several additional concepts must be considered in providing context for this study. Navigation — or the learning of college-going — is also related to retention, support measures, and re-acculturation. Figure 6 guides the remainder of this section and assists in understanding the concepts affiliated with the intersectionality of how students navigate college-going.

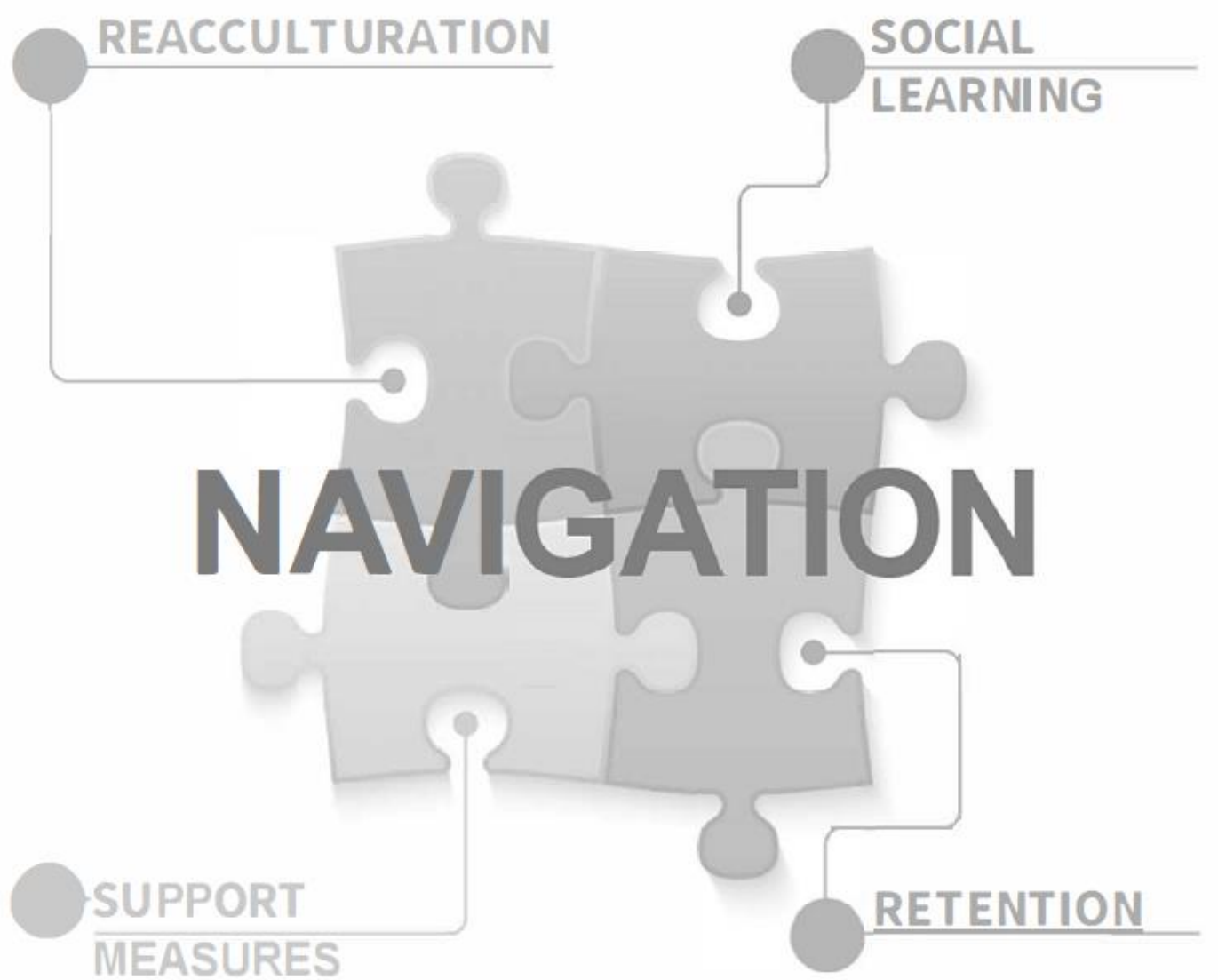

Figure 6. Pieces of navigation.

Created by Ballard (2020) to explain social learning and other relevant topics in higher education as related to navigation.

For the purposes of this study, navigation is defined as a process in which an individual learns to use existing resources for personal gain and achievement. It is 
important to note that navigation may include the identification and supersession of barriers. The definition is supported by Caldwell and Siwatu (2003) and Strayhorn (2015), who defined the term navigation as a process of orientation and experiences as they relate to the student lifecycle. The remainder of this section will address individual concepts as related to the study of student navigation of the university setting.

\section{Retention of College Students}

Retention is a critical consideration for this study, as social learning is connected to retention. Retention is multifaceted and interconnected with the characteristics students bring to college and their experiences while in college (Kuh, 2001). A relationship exists between social behaviors and student retention at the post-secondary level (Robbins, Lauver, Le, Davis, Langley, \& Carlstrom, 2004). Social learning supports many initiatives and programming designed to boost university student retention. Students' retention and degree persistence is boosted when students are able to navigate social, cultural, and environmental variables in the education system (Caldwell \& Siwatu, 2003). Additionally, study skills courses for first-time, first-year students have long-term benefits in terms of academic success (Engle, Reilly, \& Levine, 2004). First-year seminar programs as part of general education programs support students in making meaningful connections (Allen, 2006). Again, these seminars designed for student success occurred in social situations. These programs helped students develop a cultural understanding of college-going (Garrison \& Kanuka, 2004; Grant-Vallone et al., 2003; Ludwig-Hardman \& Dunlap, 2003; Smith, 2007).

Universities take many varied approaches to retention. Retention is complex and multiple factors impact student retention (Tinto, 1987). Thayer (2000) noted that 
"successful strategies will be multifaceted" (p. 5). Approaches outlined in literature included student integration and engagement, learner-centered approaches, residential learning communities, and specific online learner support (Leeds, Campbell, Baker, Ali, Brawley, \& Crisp, 2013). The existence of multiple approaches is due to the intricacy of retention. Retention is complex; some students stay at the university for the same reason other students depart (Tinto, 1999). Braxton and Hirschy (2005) defined retention as an ill-structured problem: "Ill structured problems defy a single solution" (p. 69). The quality of student and faculty interactions, the social health of students, various student entry characteristics, and commitment levels of the involved parties impact student retention (Lau, 2003; Tinto, 1987). Many variables can potentially impact individual student retention in three categories: institutional, faculty, and student factors (Lau, 2003). Institution-centered factors of retention include commitment to the student, mission and vision, institutional policy, and directed resources or programs (Braxton \& Lee, 2005; Lau, 2003; Tinto, 1987). Faculty-centered factors of retention include student and faculty interactions, curriculum, and instruction (Lau, 2003; Tinto, 1987). Studentcentered factors of retention include entry characteristics, commitment to the institution, commitment to the goal of earning degree, social integration, and academic preparation (Braxton \& Lee, 2005; Lau, 2003; Tinto, 1987). All of these factors intersect in a social setting where learning can potentially occur. These various factors that impact retention encouraged me to consider other areas of relevant literature that explore support measures implemented to increase student retention. 


\section{Support Measures}

Existing literature that addresses retention in higher education encompasses the many services provided to students by student and academic affairs professionals. Student support services designed for the learning of online students support students' cognitive development (Ludwig-Hardman \& Dunlap, 2003). Student support services include a) accommodations for specialized student needs (Smith, 2007), b) services that help students learn the skills necessary to succeed in a blended learning environment, and c) technology services (Garrison \& Kanuka, 2004). Furthermore, students who use student support services are more likely to acclimate to college and report stronger commitment to finishing their degree (Grant-Vallone et al., 2003). The use of student support services improves student retention (Garrison \& Kanuka, 2004; LudwigHardman \& Dunlap, 2003). Additionally, student retention is connected to social integration of the student at the university (Braxton \& Bayer, 1999; Braxton \& Lee, 2005; Tinto, 1987). Students reported higher levels of motivation and study skills after participating in the success skills learning program (Wibrowski et al., 2017). Existing student success programs and various initiatives highlighted a small number of practices used in higher education to support student success. A deeper look at the specific practices used to support academic success and social success reinforced the need to consider how students use these supports to navigate college-going.

Academic. Kuh (2001) hypothesized that "What students do during college counts more in terms of desired outcomes than who they are or even where they go to college" (p. 1). This understanding supports the current dissertation-in-practice through adding meaning and context to student behaviors. Student learning increases when 
individual students identify as socially and academically engaged in the institution (Tinto, 1999). Bandura's (1971) studies on attention, memory, and motivation supported the concept that engagement in the university setting through academics and student programming is a form of social learning. Normalizing shared learning, frequent quality advising, and implementation of residential learning communities or seminars could increase academic engagement (Tinto, 1999). The methods used to support students academically are similar to strategies used to connect and retain students from a social standpoint.

Social. Student engagement also occurs outside of the classroom (Astin, 1985; Terenzini et al., 1994). Students who make a greater number of new friends or institutional connections report attaining academic goals at a significantly higher rate (Skahill, 2002). Peer leaders within diverse student populations often help other students within their own subpopulation navigate campus by sharing effective methods or collegeknowledge (Harper, 2012). Bruffee (1999) supported Harper's (2012) claim that student supported navigation is an effective practice. Peer relationships and connections comprise transition communities, which support individual students in understanding the new cultural norms needed to succeed in the university setting (Bruffee, 1999). Harper and Bruffee both described peer-driven re-acculturation techniques as successful strategies for students in the university setting. Furthermore, conversation with others while negotiating the re-acculturation process is significant (Freire, 2000). Peers often act in the capacity of navigator and provide missing college knowledge in social settings (Bruffee, 1999; Harper, 2012). In this case, social learning supports the re-acculturation process seamlessly; ultimately, re-acculturation increases student retention (Rendon, 1995). 


\section{Re-acculturation to College}

Re-acculturation is the phenomenon that occurs when students are introduced to the new cultural norms and language used in the university setting; students' former beliefs, behaviors, and norms are slowly replaced by those of the university (Bruffee, 1999; Murphy \& Fleming, 2000). Re-acculturation specifically involves the following.

Giving up, modifying, or negotiating that language, values, knowledge, modes and so on that are constructed, established, and maintained by the community one is coming from, and becoming fluent in the language and so on of another community. (Bruffee, 1999, p. 298)

A student must learn the culture of academia in place of past experiences and culture to be successful (Bruffee, 1999); however, re-acculturation can be difficult. Reacculturation is a process that can lead students to feel isolated and alone as they decipher the complex university system (Glaessgen, MacGregor, Cornelius-White, Hornberger, \& Baumann, 2018). Additional barriers to student success related to re-acculturation include the negotiation of new identity, evolving environments, and identifying areas for potential academic support (Rendon, 1995).

Individuals learn by noting patterns in behavior of others and through various social interactions (Bandura, 1971, 2017). Peers have the ability to act as support systems, helping new students understand college knowledge, such as jargon (Bruffee, 1999; Harper, 2012). The university setting has a language that is separate and tacit in nature (Murphy \& Fleming, 2000). Taking tacit knowledge and making it comprehensible and relevant to multiple individuals is an intricate process (Nonaka, 1994). The process of learning about the university setting and learning university- 
specific jargon is similar. Student cultural capital is increased through the act of gathering college knowledge and can be attributed to various components of social learning (Collier $\&$ Morgan, 2008).

Cultural capital in the context of higher education includes all preexisting knowledge that students have regarding college-going or college-knowledge (Collier \& Morgan, 2008). This knowledge includes information or skills on social, academic, or emotional intelligence (Collier \& Morgan, 2008). Cultural capital supports students' venture to become successful in the post-secondary setting (Bernhardt, 2013). Students are less likely to be retained when they lack the understanding to navigate barriers or fail to re-acculturate in the post-secondary setting (Rendon, 1995). Capital increases with access to resources such as education (Bourdieu, 1991); therefore, capital is critical when considering long-term college outcomes for students. Re-acculturation supports the development of cultural capital among university students (Glaessgen et al., 2018).

This understanding of re-acculturation as it intersects with college-going and cultural capital further supported the direction of the current dissertation-in-practice. Various components of social learning were highlighted through the exploration of reacculturation. The relationship was support by Collier and Morgan (2008), who found that the basis of re-acculturation occurred in the context of social environments.

\section{Social Learning in the Collegiate Setting}

The literature indicated that social learning can occur through multiple modes. One of those modes was modeling; social learning often occurred when behavior was modeled in a social environment and students mimicked what was observed (Vygotsky, 1978). Several assumptions exist regarding how social learning theory is experienced in 
the collegiate setting. These assumptions include the idea that the relationship between a person, environment, and observed behaviors will experience shared impact. The connections between behavior, environment, and the individual impact the individual's ability to learn. The Triadic Reciprocality Model of Causality exhibits the relationship in which the learning could potentially occur (see Figure 7).

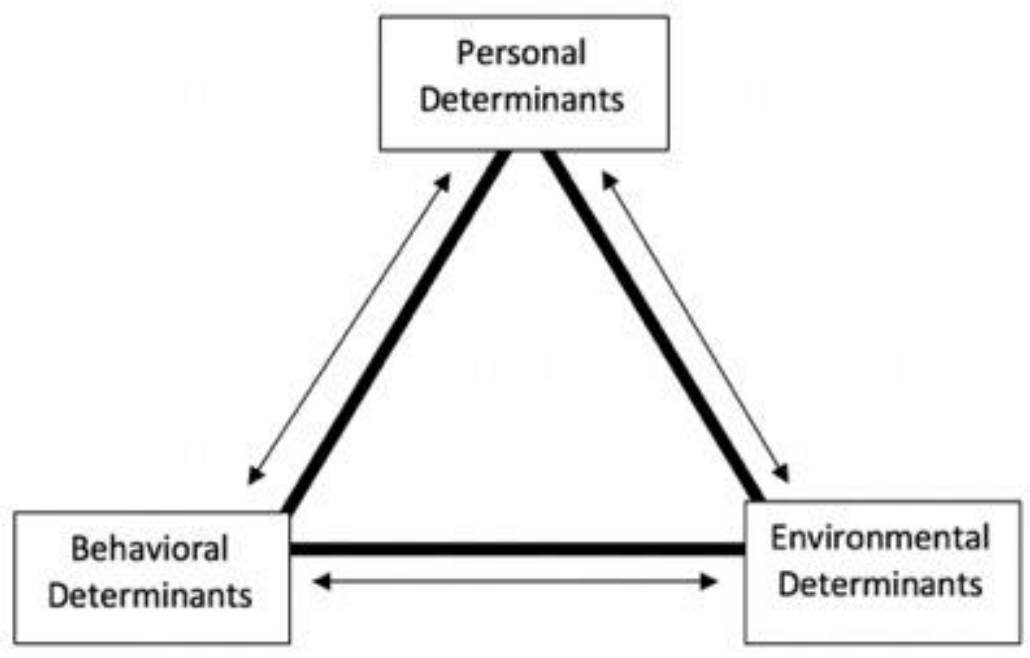

Figure 7. Triadic Reciprocality Model of Causality From Bandura (2008), p. 226.

Learning is the result of how individuals process their environment and behavior (Bandura, 1986). In the collegiate setting, that processing occurs using tools implemented and created by administrators, including retention efforts and academic support.

Furthermore, re-acculturation is processing of information to adopt new culture and identity (Bruffee, 1999).

\section{Summary}

The intricate nature of college-going led me to review the tenets of social learning theory and other relevant areas of literature pertaining to retention. While existing literature dove into the critical components of the student lifecycle as related to social 
learning, it did so in a segmented fashion. Prior literature asserted that social learning can be identified in retention, support, and re-acculturation of students. Navigation of social, cultural, and environmental variables in the education system can boost retention and degree persistence; navigation support can be learned within a social environment (Caldwell \& Siwatu, 2003). Student learning increases when individual students connect to social learning environments and experiences (Tinto, 1999); similarly, re-acculturation to college occurs in social learning environments with the support of peers (Bruffee, 1999; Harper, 2012). The tenets of social learning saturated existing literature in the areas of retention, student support, and re-acculturation; this dissertation-in-practice sought to better understand the relationship these components have with social learning theory. The scholarly review of literature guided this dissertation-in-practice and addressed the question: How do students navigate the university? College is a journey and is processoriented; therefore, the experiences of students must be continually examined (Strayhorn, 2015). Understanding a student's journey and how it relates to social learning will allow universities to better support students on an individual basis. 


\section{Section Four \\ Contribution to Practice}

\section{Plan for Dissemination of Practitioner Contribution}

The researcher plans to disseminate the findings of the dissertation-in-practice at the National Association of Student Personnel Administrators (NASPA) Conference held March 20 through 24, 2021 in Kansas City, Missouri. Applications are submitted via the NASPA online submission portal in the fall prior to the conference.

\section{Type of Document}

The information will be disseminated via an oral presentation at the NASPA National Conference. Additionally, a white paper will be drafted for the institution; the focus of the paper will be policy recommendations to meet the needs of first-year, firsttime students.

\section{Rationale for Contribution Type}

The rationale for this contribution is to address student needs and gaps in services that are noted throughout the dissertation-in-practice and recommend practices or policies to improve upon existing services. The proposed contents for these contributions include: an introduction, setting, methods, results, discussion, and recommendations.

Additionally, this contribution is to encourage the consideration of student success in regard to how students go to college. 


\section{Practitioner Document}

NAVIGATION AND SOCIAL LEARNING AMONG FIRST SEMESTER RETAINED UNIVERSITY STUDENTS: EXPLORATION OF PROGRAMS AND EXPERIENCES

AT A COMPREHENSIVE, PUBLIC, OPEN-ENROLLMENT INSTITUTION

Executive Summary for Conference Presentation

2021 NASPA Annual Conference

March 20-24, 2021

Kansas City, Missouri

By Alizabeth B. Ballard 
Slide 1

NAVIGATION AND SOCIAL LEARNING AMONG FIRST SEMESTER RETAINED UNIVERSITY STUDENTS:

EXPLORATION OF PROGRAMS AND EXPERIENCES AT A COMPREHENSIVE,

PUBLIC, OPEN-ENROLLMENT INSTITUTION

ALIZABETH BALLARD | NASPA CONFERENCE | KANSAS CITY 2021

- Welcome

- Introduce myself

- Who am I

- Where do I come from

- Background in higher education

- Why I care about FY student experiences

- Introduce Qualitative study

- An exploration of first-year student experiences

- Students participants had been retained from fall to spring term

- Using lens of social learning

- An attempt at a more in-depth look how services and programs intersect to support student success 
Slide 2

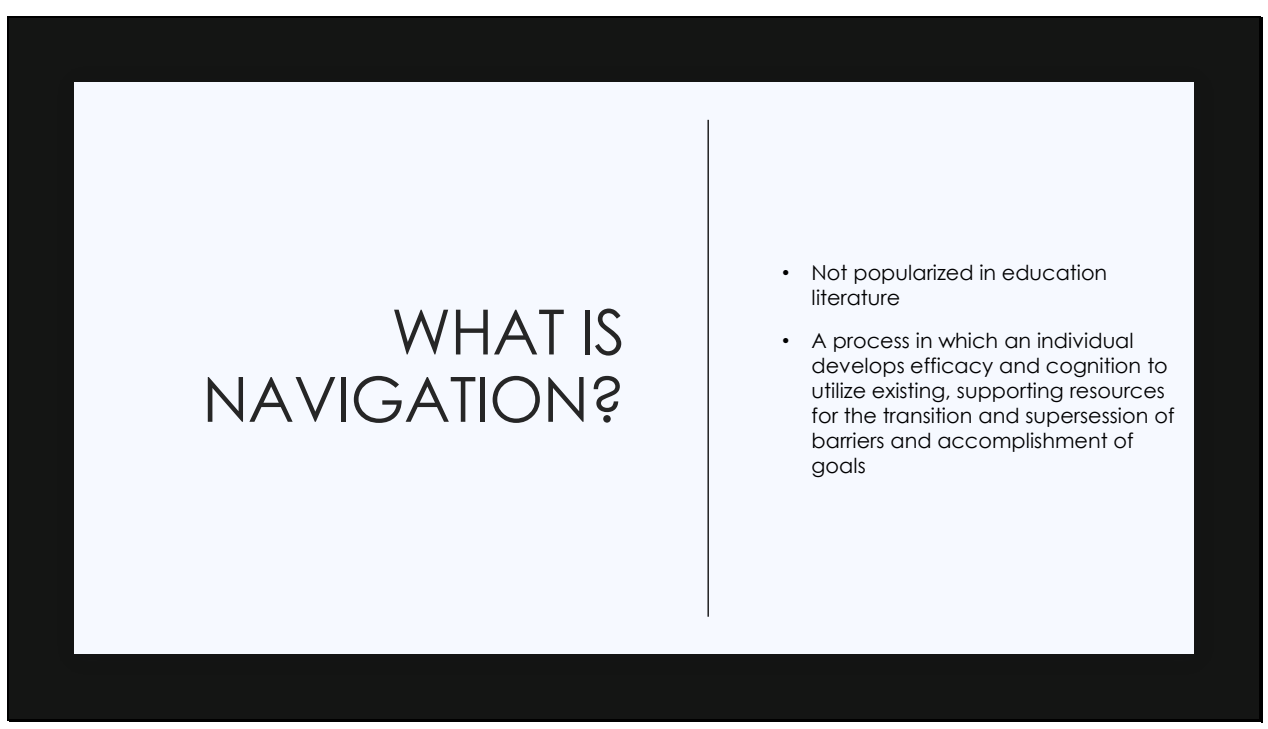

- Study focused on navigation of the university setting

- So, what is navigation?

- Navigation not popularized in research

- Exists in some student services and advising literature

- Existing literature assumes "navigation" is a term widely understood and used in higher education

- Definition for the study

- Process oriented

- Individual focused

- Development of efficacy and cognition

- Development occurs so person can utilize services and resources 
Slide 3

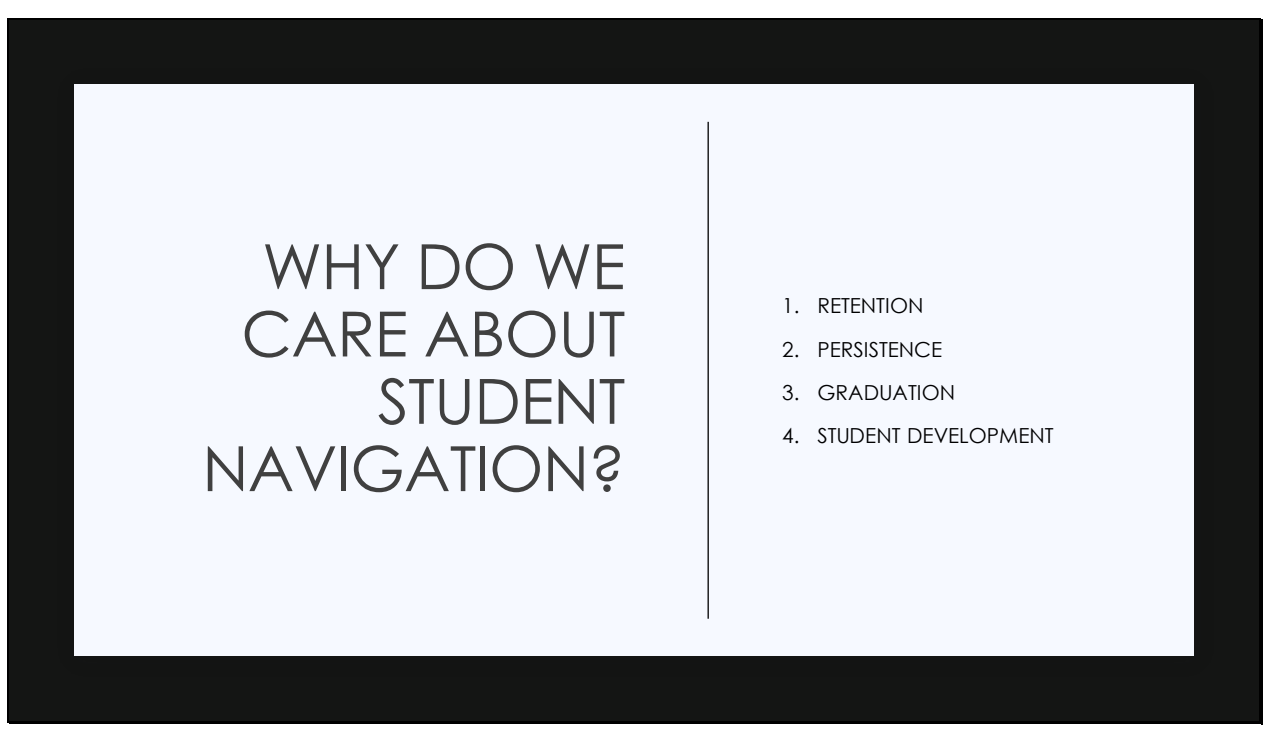

- The navigation process supports student retention and success (Aljohani, 2016).

- Navigation of social, cultural, and environmental variables in the education system boosts persistence (Caldwell \& Siwatu, 2003)

- Successful navigation improves academic achievement (Caldwell \& Siwatu, 2003)

- Navigation is a personal and intimate process of completing a journey student/professional development (Griffin \& Toldson, 2012)

- Navigation as a process of transition and gathering information in order to overcome barriers and clarify experiences (Livingston, Havice, Cawthon, \& Fleming, 2011). 
Slide 4

\section{THE PROBLEM}

\section{WHAT WE KNOW..}

-Student background and culture impact persistence (Aljohani, 2016)

- Non-cognitive factors play a role in student retention (Caldwell \& Siwatu, 2003)

-Student experiences and barriers influence student success (Murphy \& Fleming, 2000)

\section{WHAT IS MISSING?}

Research examining how university students navigate the university through the multiple lens of programs, interventions, and resources which work together to support student

success.

- What we know

- What students bring to college (e.g. background/culture) matters

- Non-cognitive factors (like SES, grit, social skills, attention, memory, motivation) impacts student success

- Experience and barriers impact retention and persistence.

- What we don't know yet

- Focused research on multiple programs/services

- How students navigate the university outside of a specific scope (e.g. FYE, Orientation, Student Support Services, Diversity \& Inclusion)

- Multiple lens with social learning theory approach

- Graphic introduction

- I designed to represent how these things (background, culture, non-cognitive factors, student experiences, and barriers) impact how our students navigate college.

- It impacts their college-going knowledge, experiences, and outcomes. 
Slide 5

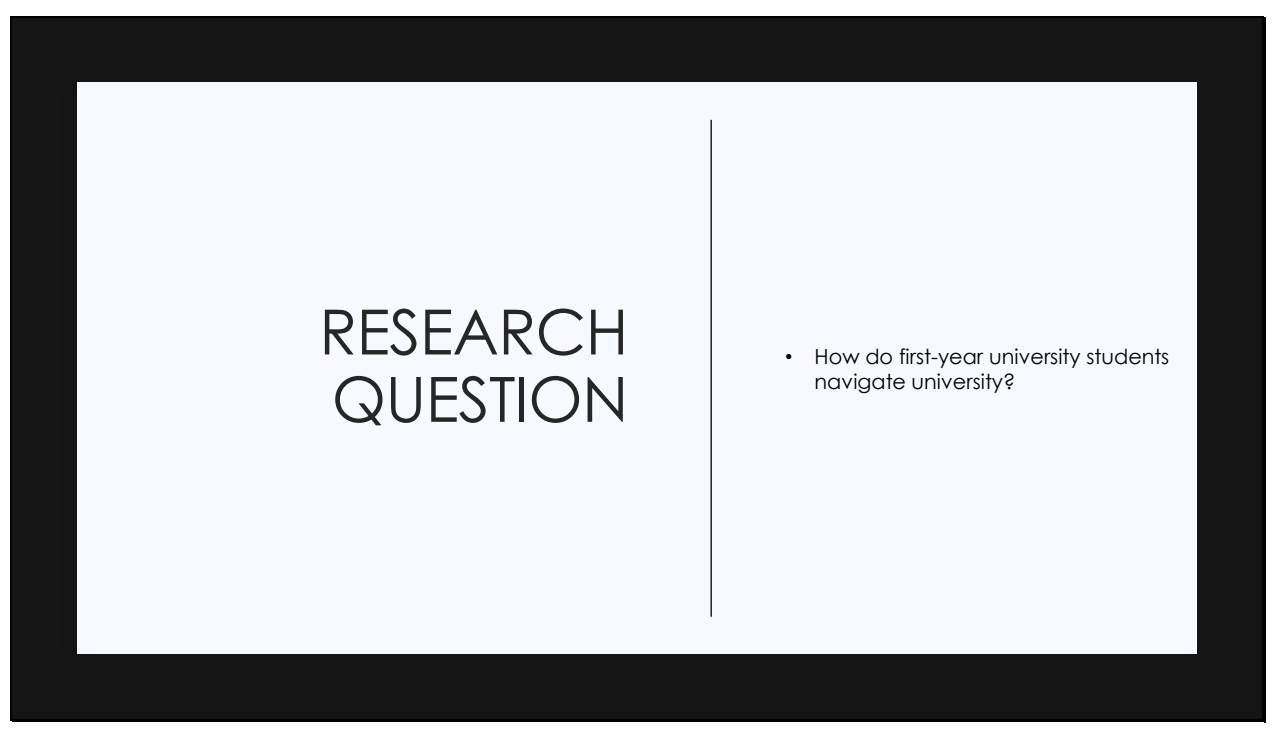

- Qualitative study sought to understand how first-year students navigate university systems.

- Overarching research question guiding this study is: "How do first-year university students navigate the university?"

- Rendon (1995) supported that future research is needed to explore the experience of navigating the university setting without the confines of a single classroom or program. 
Slide 6

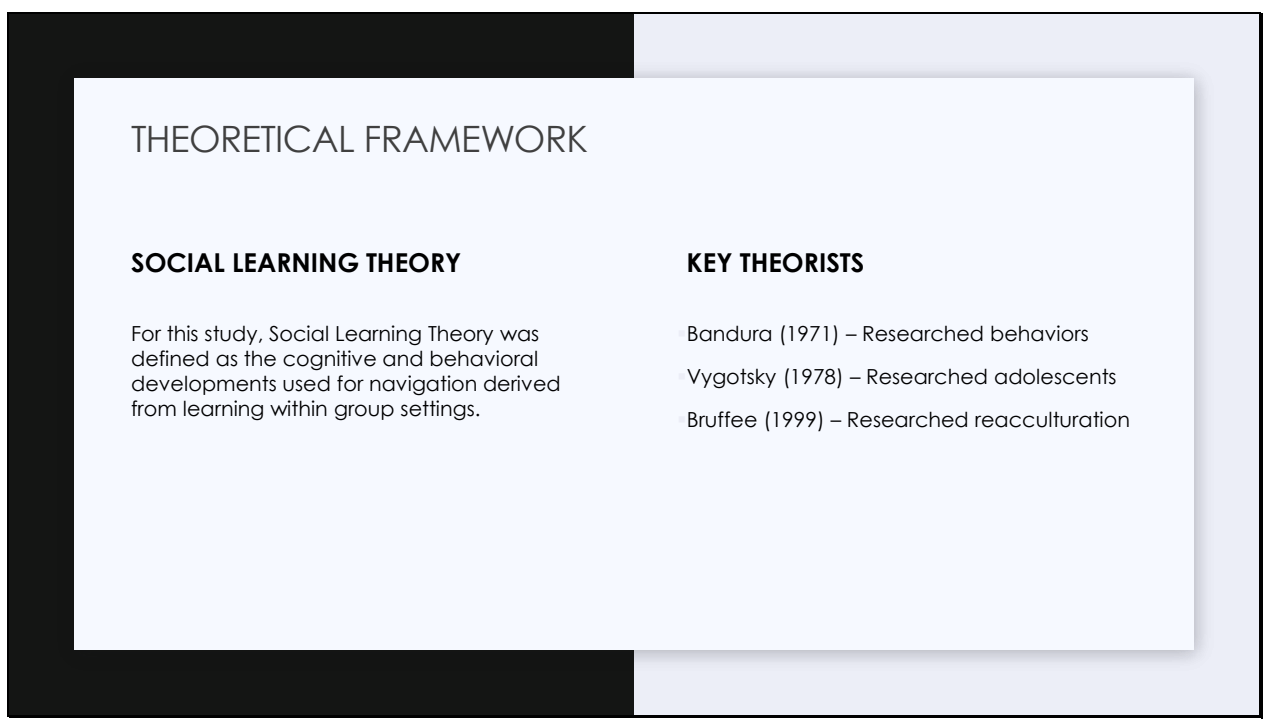

- Theoretical Framework was Social Learning Theory.

- Social Learning Theory is the cognitive and behavioral developments used for navigation derived from learning within group settings.

- Social Learning Theory was developed by Bandura (1971).

- SLT occurs in social situations from influence, observation, imitation, and modeling (Bandura, 1971, 2017).

- Individuals learn by noting patterns in behavior of others and through various social interactions (Bandura, 1971).

- Learning occurs with the use of attention, memory, and individual motivation.

- Social Learning Theory was connected to education through Vygotsky (1978) through the focus on behaviors in the classroom of adolescents.

- Social Learning Theory was also studied by Brufee (1999) through reacculturation. Reacculturation addressed how students learned (socially) to adapt/grow/change cultural and experiences to form a new identity in place of old culture, experiences, or identity. 


\section{Slide 7}

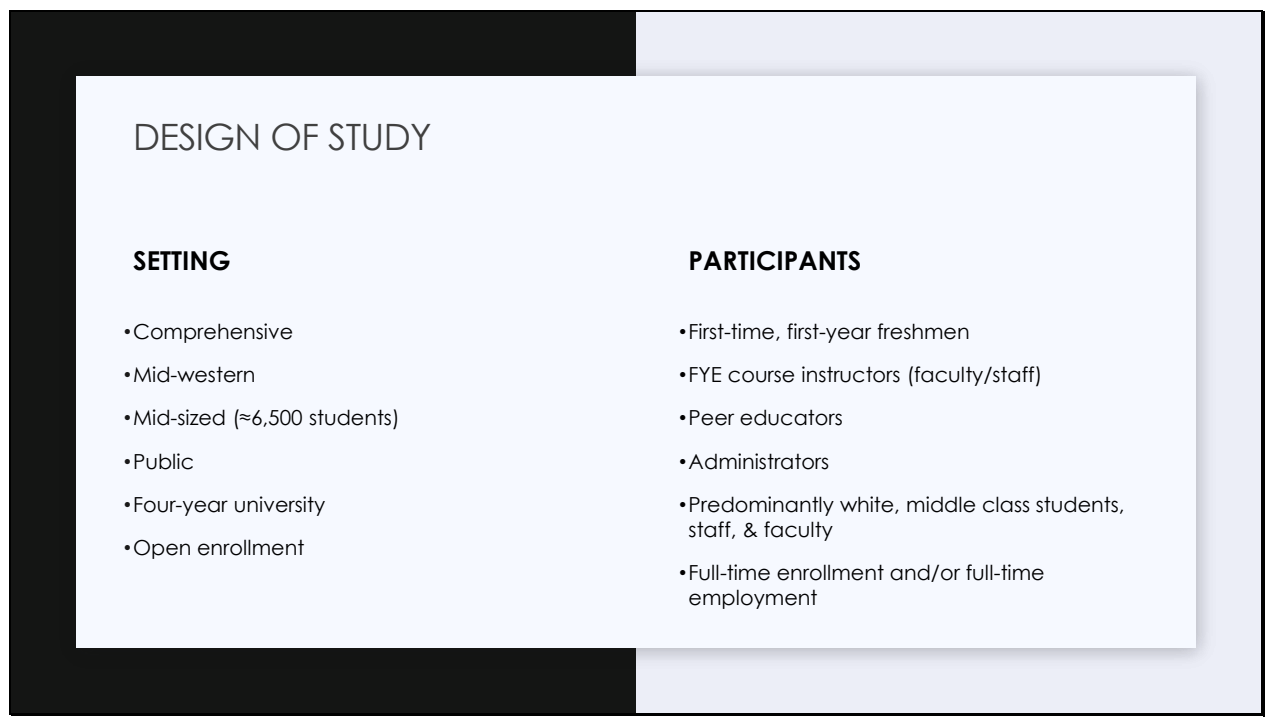

Introduce the Design of the Study

- Mid-west, Mid-sized (enrollment approximately 6,500 students)

- Public, four-year university, Comprehensive (offers associate, bachelor, master, doctoral, and certificate degree programs)

Introduce Participants

-First-time, first-year freshmen

-FYE course instructors (faculty/staff)

-Peer educators

-Administrators

-Predominantly white, middle class students, staff, \& faculty

-Full-time enrollment and/or full-time employment

-Recruitment

-Email, Second email, Scheduled focus group/interviews

-Focus groups

-Held 6 first-year student focus groups

-Held 1 peer educator focus group

-Held 2 faculty/staff focus groups (Worthington, 2019)

-Interviews

-Held 8 one-on-one interviews with people from offices identified as a resource used by students in focus groups.

-Offices represented: student life, diversity \& inclusion, First-year experiences,

Center for student success \& Retention, orientation, athletics, and enrollment management. 
Slide 8

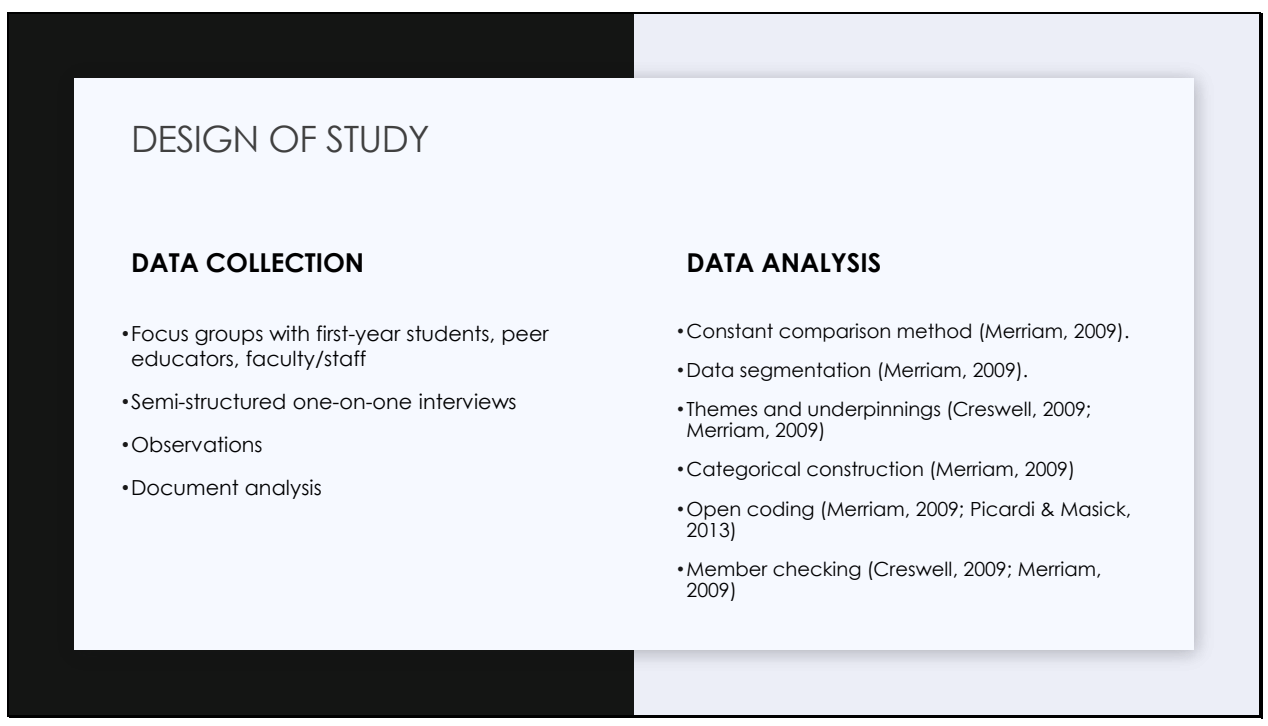

- Data Collection

- Focus groups, Transcription services used

- Structured, 9 focus groups

- Interviews

- One-on-one, Transcription services used

- Semi-structured, 8 interviews

- Observations

- Three peer educator training sessions

- Approximately 50 participants

- Training for students to act as peer educator

- Document Analysis

- 10 communication pieces reviewed

- Including handbook, orientation materials, FYE class materials

- Data Analysis

- Constant comparison was used to refine data collection with each focus group and interview

- Data segmentation allowed further clarifying information and emerging themes

- Categorical construction utilized more organic creation of themes and underpinnings

- Open coding allows the researcher to take specific words or phrases used by the participants to support the categorical construction.

- Member checking - sent emerging themes and findings to participants to verify information 
Slide 9

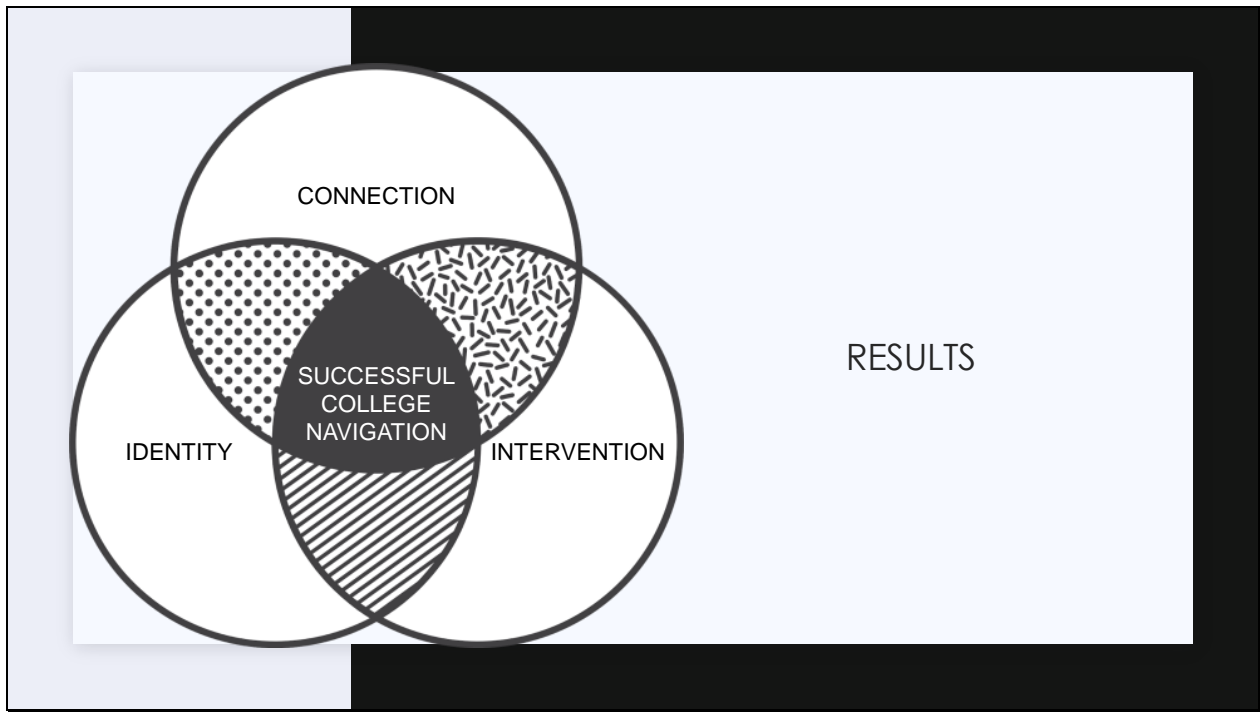


Slide 10

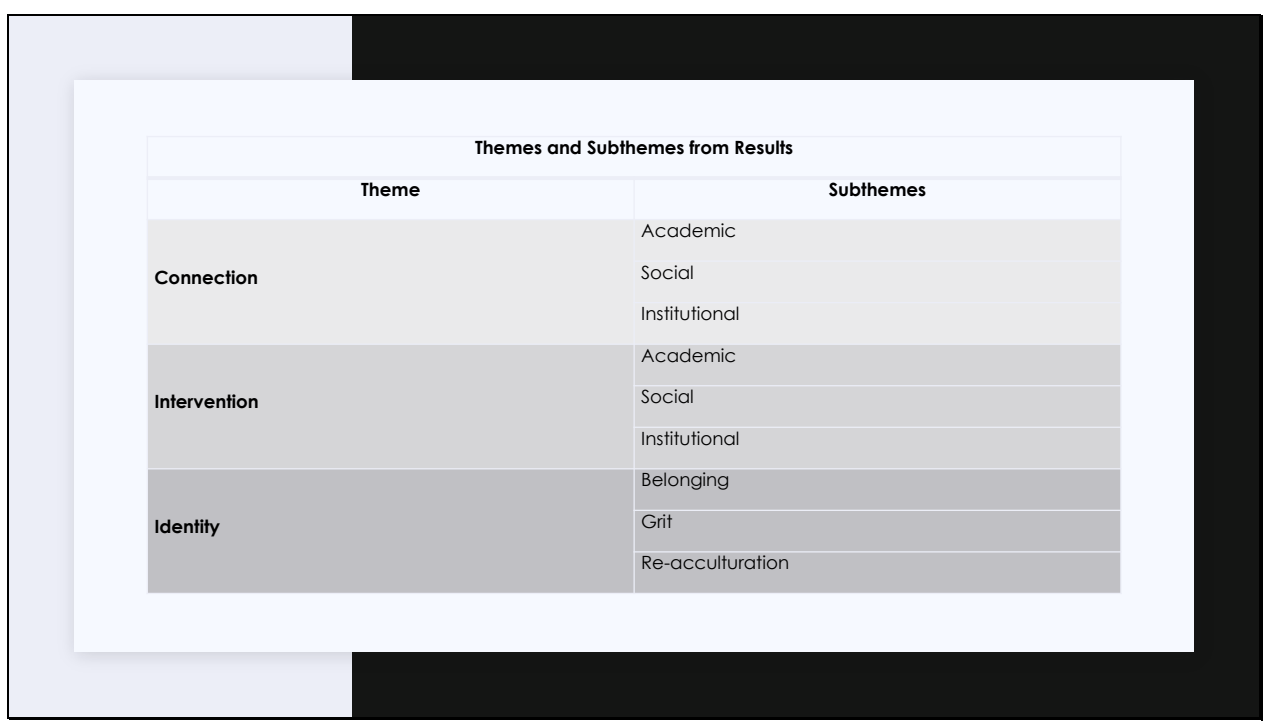




\section{Slide 11}

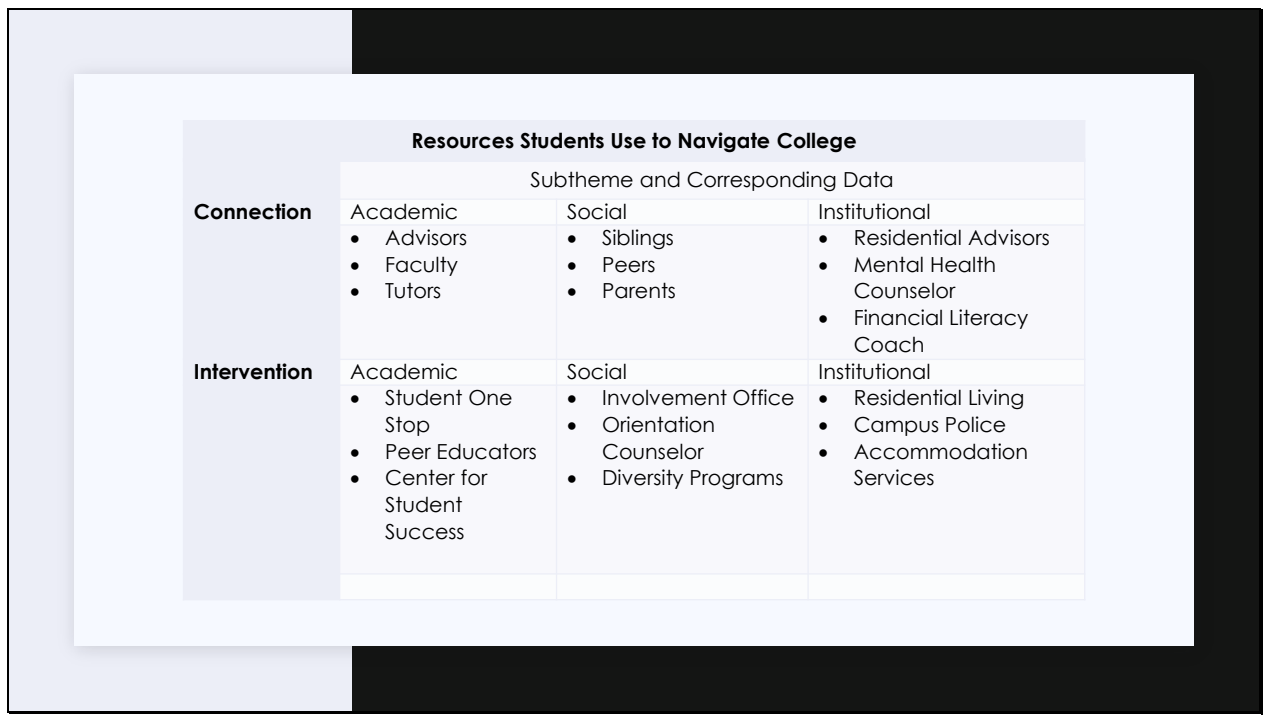

- Table 1 lists a few of the services and resources listed during student focus groups with the corresponding theme/subthemes.

- It is important to note that a few of these were listed under multiple categories.

- For example: Tutors/Tutoring Center.

- List is not totally inclusive. 
Slide 12

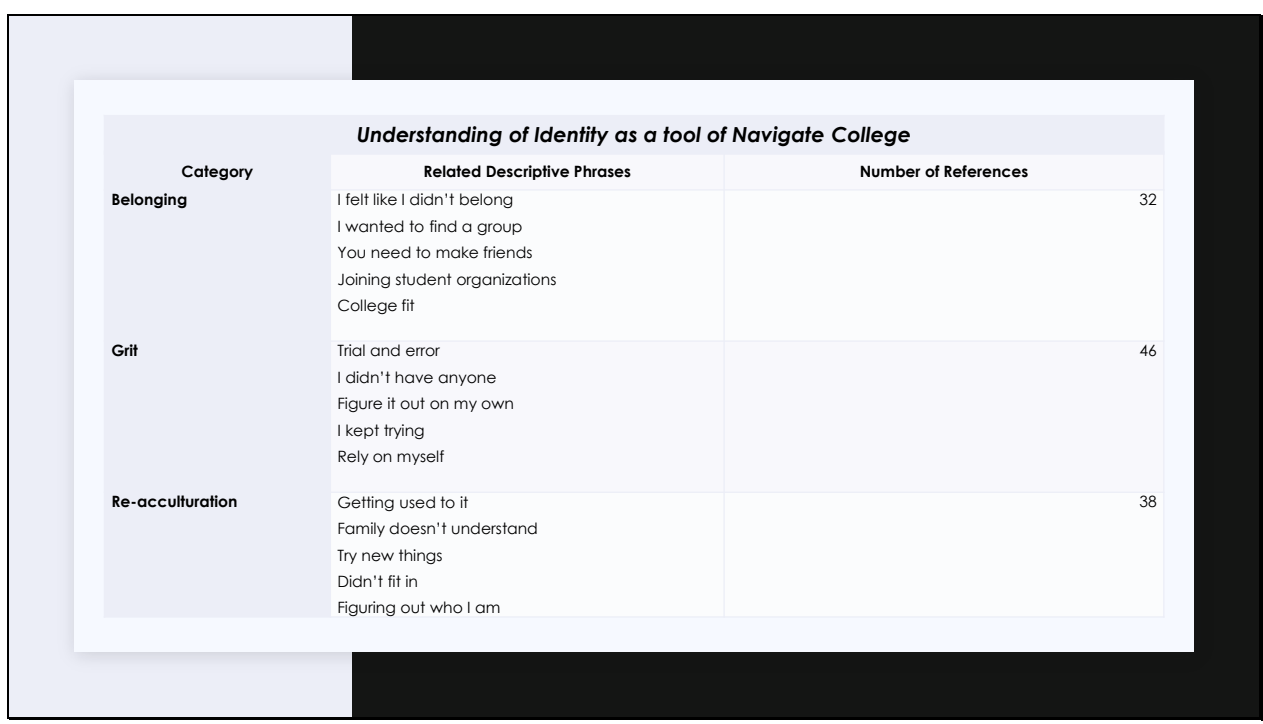




\section{Slide 13}

\section{FINDINGS: CONNECTION}

\section{Academic.}

"My advisor is really cool. Also, I have teachers who give you names and numbers and office hours of places to go when you

"I came [to the university from a technical certificate programs], so a lot of the faculty from there told me about how I can
finish my associates through here and then continue on to other degrees. Those teachers and my advisor have been a lot of
hilp."

"The professors here have been really helpful in letting us know, hey, this is what is coming up. I feel like most college

2. Social

"I'm really lucky. My brother went to college and so did both of my parents. Though I feel like I've asked my brother about a

"I've always been extremely independent. I've always done things on my own, but they weren't kidding; you need a friend

"A lot of it was my peers. I actually showed up to Worthington a week before school started because I was in band camp.

3. Institutional "Our [resident advisor] was really good about being the mediator, but we still had to find a way to talk to her and get her to
figure things out. We ended up having to be like, look, we don't think can be roommates anymore. The RA really helped with that conversation."

"We talk to our [resident advisor]. We just talked to a lot of people and just tried to get everybody's viewpoint on how was

"I've met a lot of people. The president, the custodial staff, and professors really care about my well-being. I feel like they

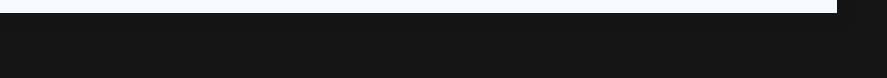


Slide 14

\section{FINDINGS: INTERVENTION}

1. Academic.

"I definitely use the tutor center a lot, even if I'm not getting tutoring help. It's just a really good place to study and work and (he class or are in the class. That's really nice."

"I was in one of the [program specific] sections. Most of the students were first generation students like me and the teacher thing weeded for our classes." "[The phone app] is really good as a first-year student. It's kind of hard to know what you just don't know. There's a lot of stuff

2. Social

- "It was my peers showing me where I need to be or who I could reach out to when I needed something."

- " "The Veteran's Center has been great. I know the director. He has done so much for me."

"Getting involved has been an important part for me. I think it is really important. Getting out and participating instead of staying in your room. I've met so many people

3. Institutional

"I had to learn there is actually a resource on campus, the diversity and inclusion or something office, where you can go and you can get help like extended time of your tests if you need it."

"Sometimes I go to skill shops at the library. They're not really advertised as much, but they present on careers or financia aid. They are just a beneficial thing.

- "The police escort on campus is nice. I haven't used it, but one of my friends did last semester. They made sure she got back to our room safe." 


\section{Slide 15}

\section{FINDINGS: IDENTITY}

1. Grit ". Not everything is going to go the way you think it will. Something's will be bad. Some will be good. That is college, but my first few
weeks, I lid not prepare well enough for an exam. I wasn't focused enough and so failure definitely was the best teacher in that
sense."

"You got to just kind of throw yourself in there, like, figure it out on your own. How to deal with classes, roommates, professors, and stuff

"I think I am actually learning by trial and error. Like, some things aren't going to work and I think you have to learn to accept that

2. Belonging "I learned that no one's going to have everything figured out, especially not when you're first starting college, but it feels like they do and you don't."

"There's not that magic moment where the lights are going to shine down and everything's just right. We all struggle." "Because English is my second language, my grammar is not the best like a lot of students who often speak different language. The

3. Reacculturation "I took a Sociology class and it covered topics that were like religion, politics, and race. You can really step on people's toes there.
had to be kind of careful. Different people have different mindsets and backgrounds. I feel different, especially since I came from a

"There isn't a quick way or like something that you just learn overnight. It's definitely something that you got to go through and learn
over time. It takes time. More than likely, you have to relearn somethings and figure out other things" "It is hard being a first-gen student because I don't really have anyone to ask. I have to adopt without really asking anyone. My family
has no idea either. That was really hard to get through. I hated being so unsure about who I was and what was happening. That was hard for me. 
Slide 16

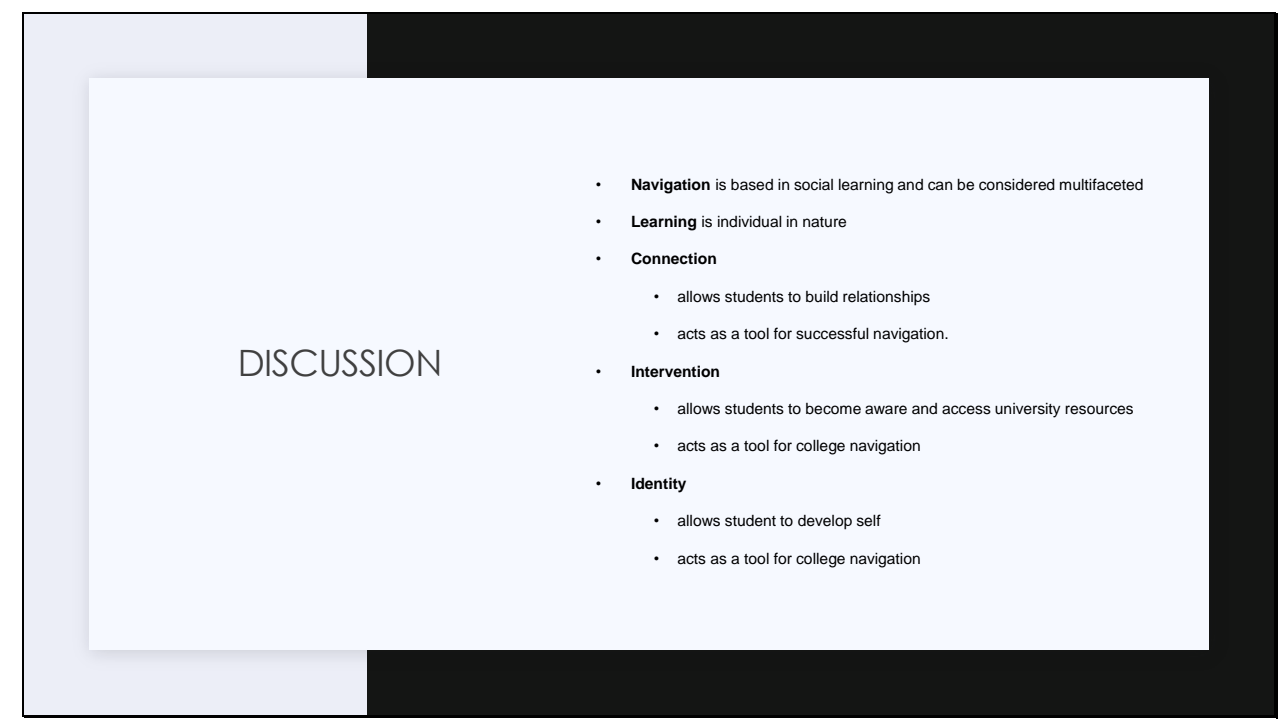

Learning is social and individual in nature (Rorty, 1999); the study results confirmed this finding. Some students reported using peers or other university personnel to navigate the university, while other student participants reported relying on themselves to figure out how to go to college. The study results support the idea that students' college navigation is based in social learning and can be considered multifaceted.

Connection allows students to build relationships with peers, faculty, staff, or other campus community members to navigate the university. This finding is affirmed by relevant literature, which has repeatedly asserted that connection is a tool of college navigation (Bruffee, 1999; Caldwell \& Siwatu, 2003; Harper, 2012; Umbach \& Wawrzynski, 2005).

Intervention. Smith (2007) and Garrison and Kanuka (2004) affirmed interventions as a tool for college navigation for students within specific student populations. Moreover, the literature acknowledged that students who use intervention support services to increase social learning report higher levels of academic achievement (Caldwell \& Siwatu, 2003; Grant-Vallone et al., 2003; Wibrowski et al., 2017).

Identity. The final theme that emerged from the study data pointed to the development of student identity as a tool for successful college navigation. While the researcher expected to find that the development of non-cognitive factors was a crucial piece of student success, the specific factors found were unanticipated. Stayhorn (2018) agreed that student belonging was a crucial component of student success. Similarly, Duckworth, Peterson, Matthews, \& Kelly (2007) found that achievement required talent, but also perseverance. Additionally, Bruffee (1999) noted that re-acculturation supported student transition. These non-cognitive characteristics supported student transition and success at the university. 
Slide 17

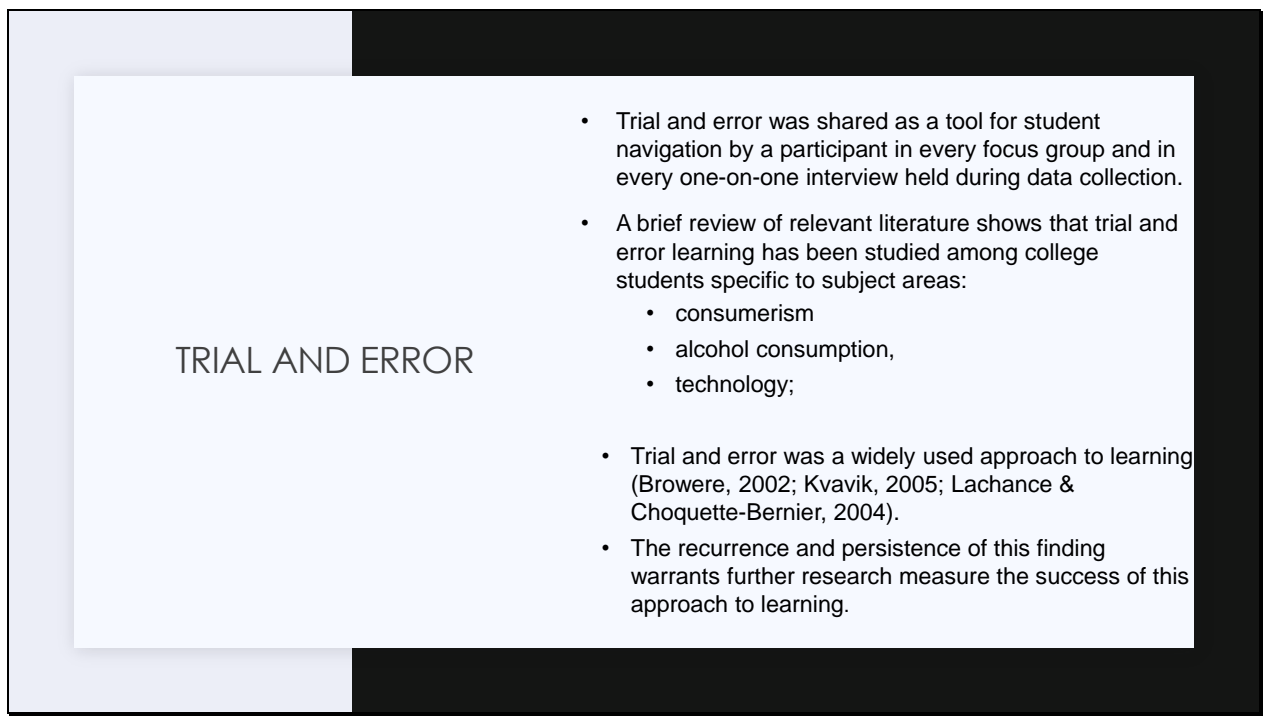




\section{Slide 18}

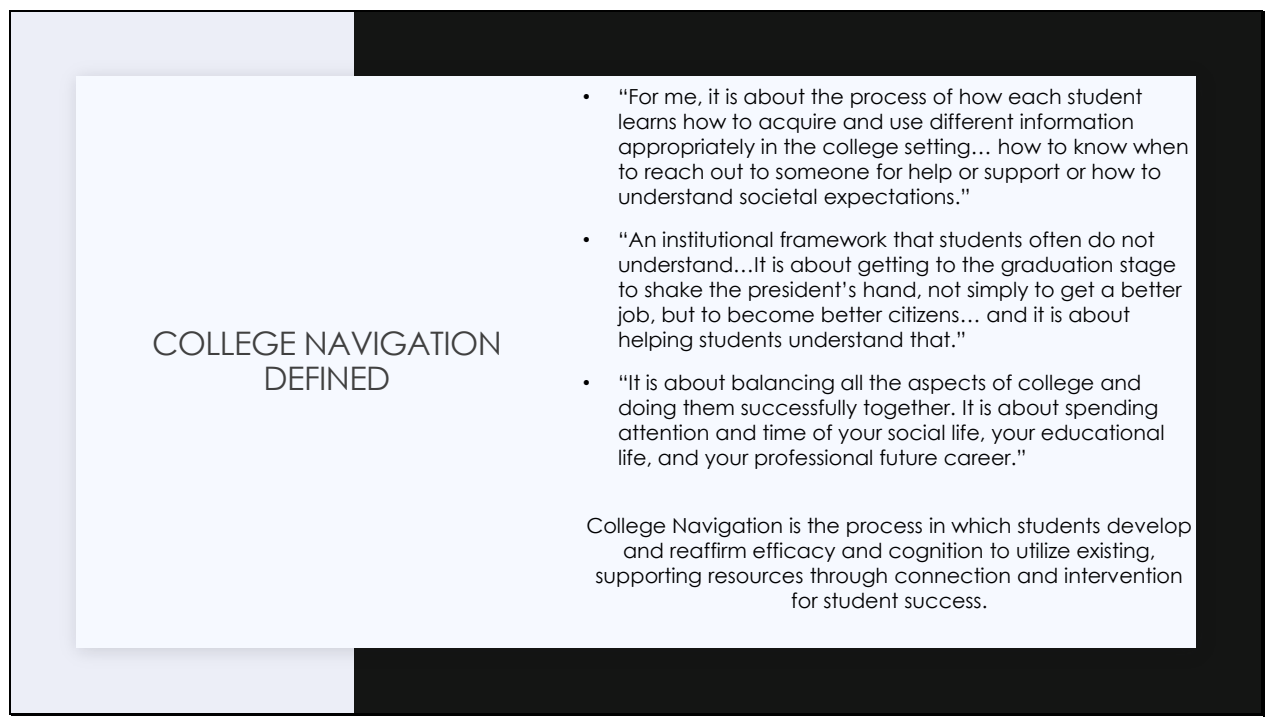

- In the introduction of this paper, a makeshift definition of navigation was introduced as a process in which an individual develops efficacy and cognition to utilize existing, supporting resources for the transition and supersession of barriers and accomplishment of goals.

- College Navigation is the process in which students develop and reaffirm efficacy and cognition to utilize existing, supporting resources through connection and intervention for student success. 


\section{Slide 19}

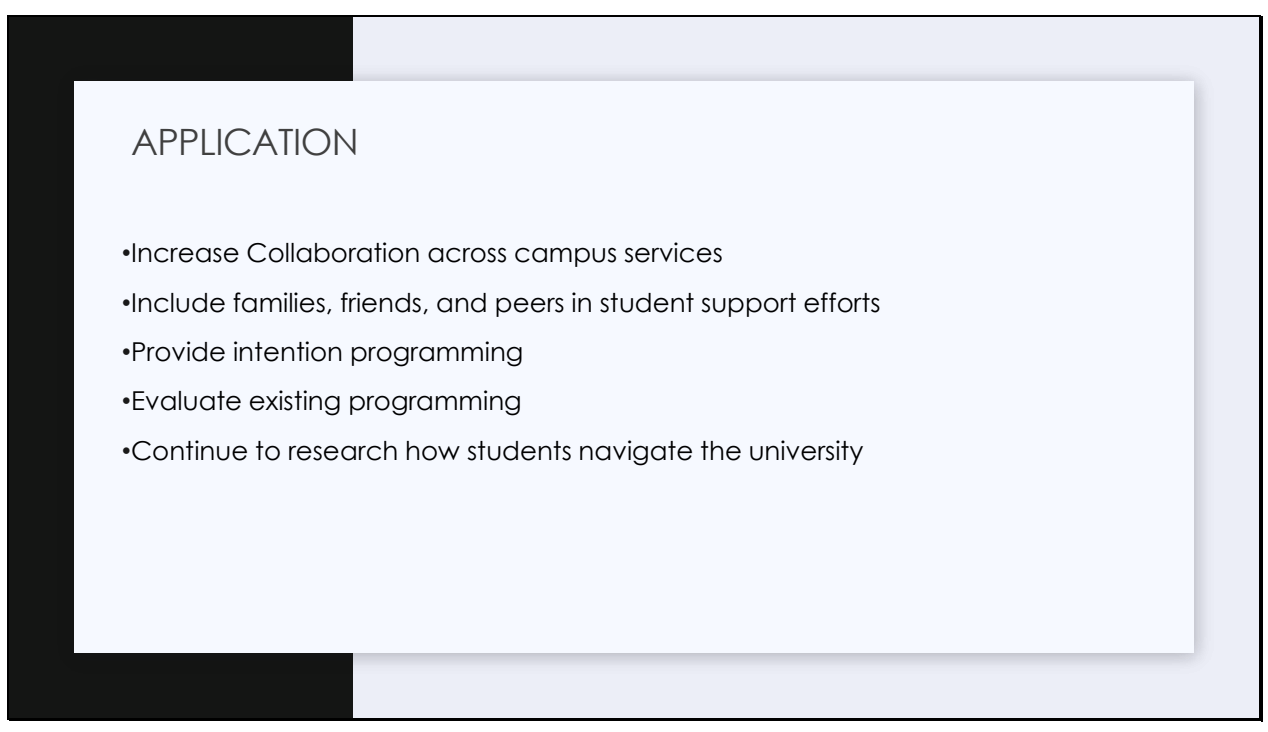

- Create an ad hoc committee tasked to increase collaboration and coordination of firstyear student transition services.

-Assess existing programming and events for student connection, intervention, and development to identify gaps in services.

-Address gaps in services through future programming or events planned from a threepronged approach clearly identifying the connectors, the intervention, and the development prior to implementing programming or events.

-Further explore student experiences longitudinally through the use of scholarly research to track student success during college as well as post-graduation. Further research on trial and learning approach to learning "college-going". 
Slide 20

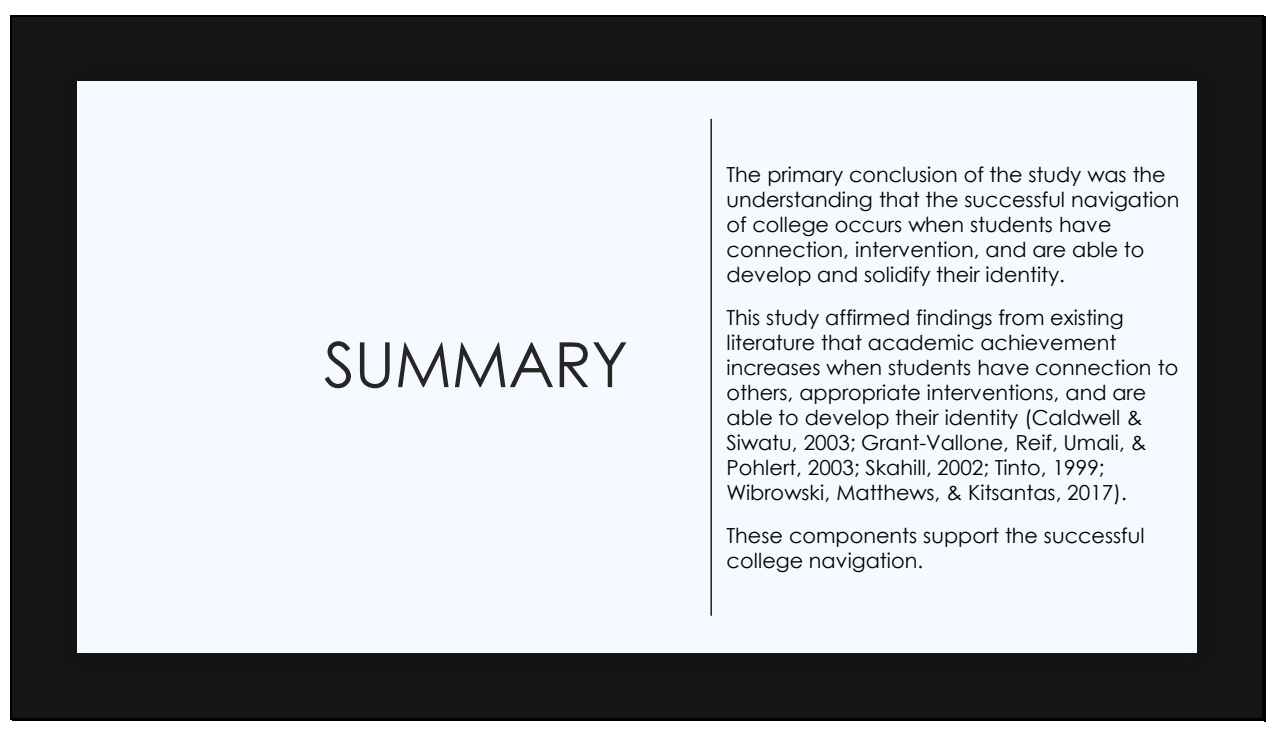

- Higher education professionals, faculty, programs, interventions, and student development do not occur in a silo.

- These individuals, offices, and components all work together to increase student potential for successful college navigation and eventual success post-graduation. 
Slide 21

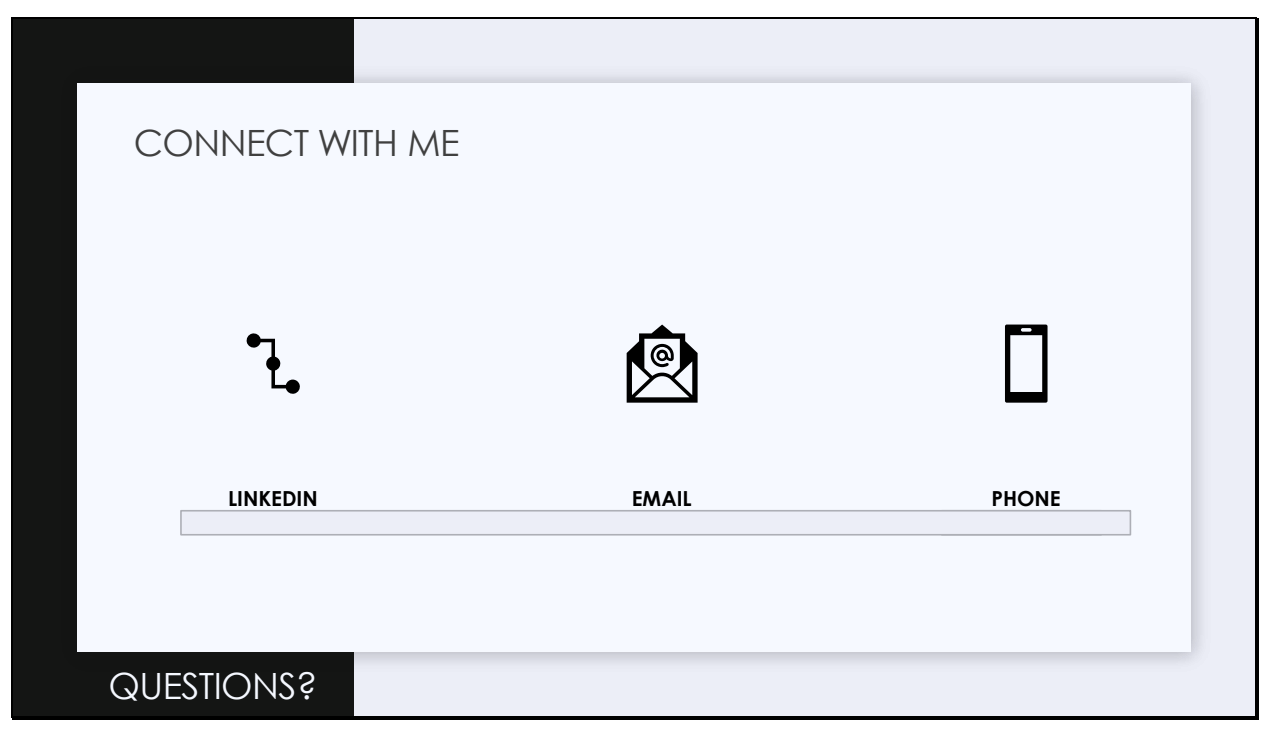


Slide 22

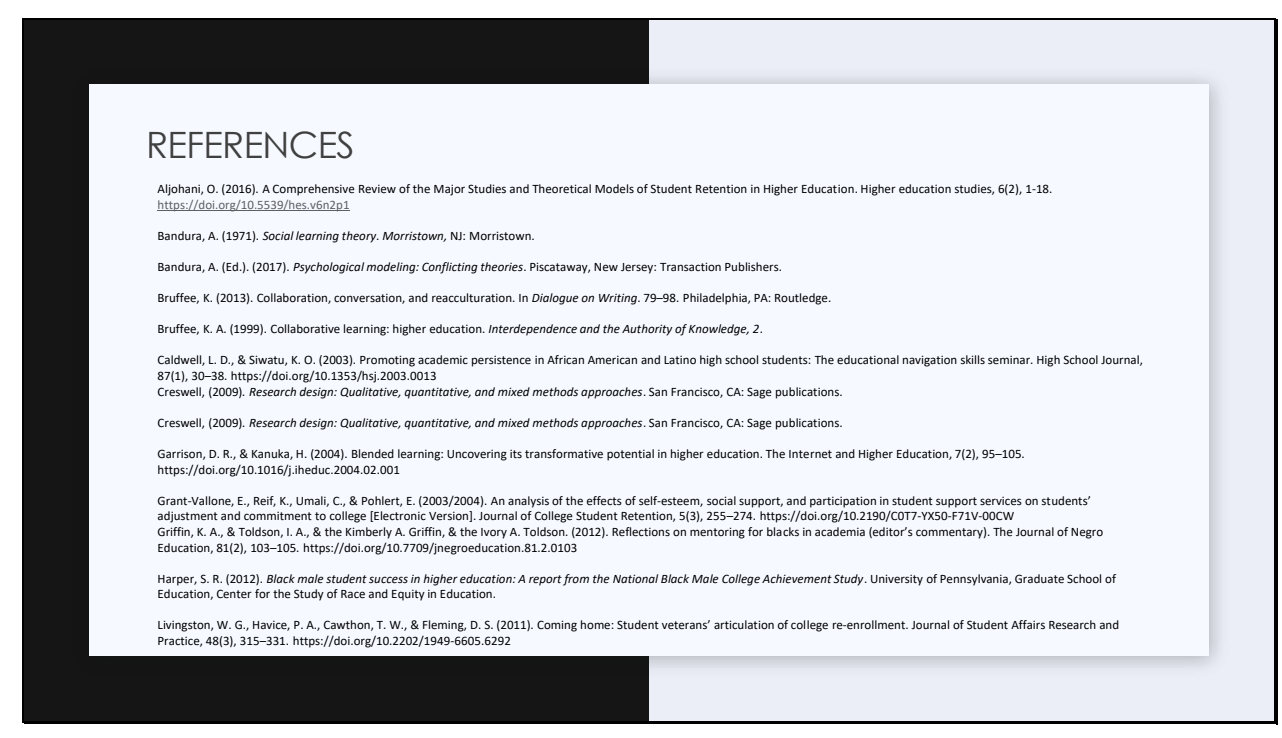


Slide 23

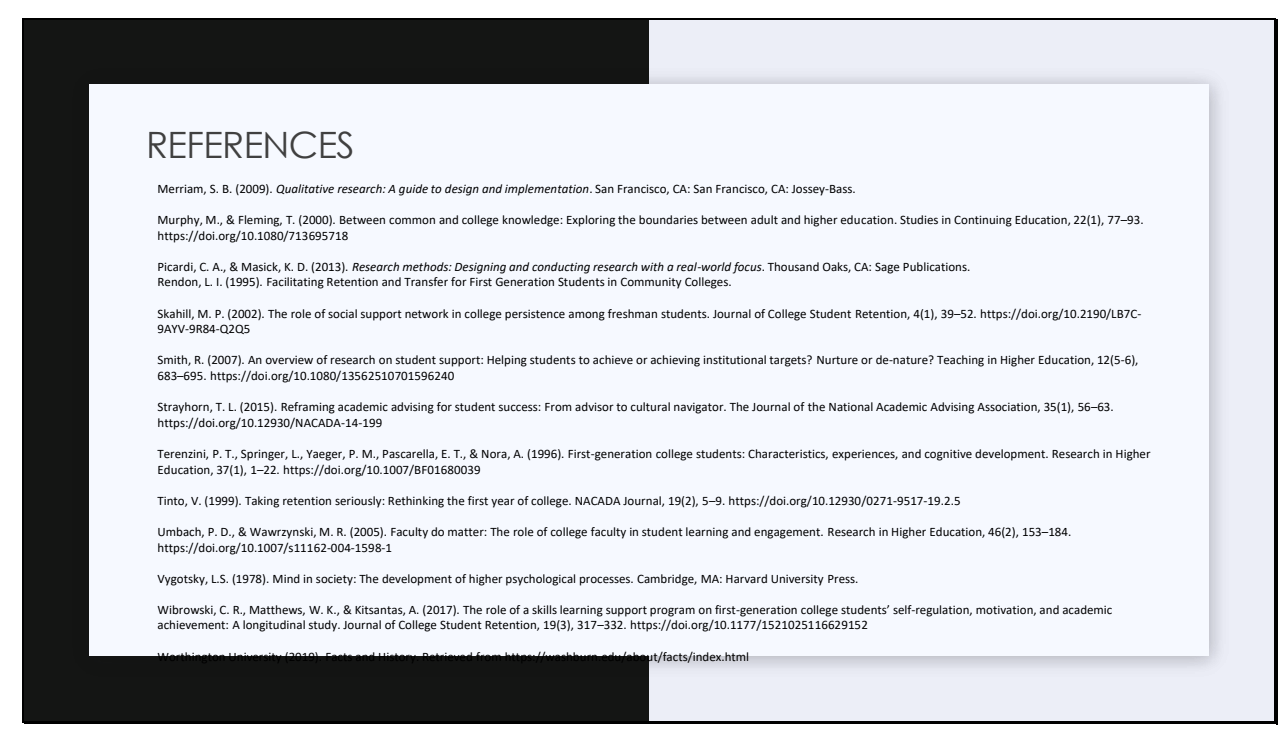




\section{Chapter Five}

\section{Contribution to Scholarship}

\section{Plan for Scholarship}

Target journal. The current plan is to contribute to the scholarship to the field of higher education by submitting an article to the Journal of Higher Education. This journal was chosen because of the large readership and the respected reputation of publishing peer-reviewed articles in the field of higher education.

Rationale for target journal. The rationale for submitting a journal article to the Journal of Higher Education includes the fact that this journal is the largest research publication in field, reports on a wide variety of topics and is inclusive of the student life cycle.

\section{Plan for Submission}

- Who: Journal of Higher Education

- When: Fall 2020

- How: Electronic submission through the Editorial Manager portal for the Journal of Higher Education. The Editorial Manager can be found at: https://www.editorialmanager.com/jhe/default.aspx.

\section{Format of Proposed Article}

The research article will be submitted for printed publication. The submission requirements include a completed manuscript that is less than 10,000 words and compiled in the following order: title page, abstract, keywords, main text introduction, materials and methods, results, discussion, acknowledgments, declaration of interest statement; references, appendices, tables, and figures. The proposed article follows this section. 


\title{
SUBMISSION COVER PAGE
}

\section{Journal of Higher Education}

Navigation and Social Learning Among First Semester Retained University Students

\author{
Alizabeth Ballard \\ School of Nursing, Washburn University, Topeka, USA \\ Email Correspondence should be sent to alizabeth.ballard@gmail.com
}

No potential conflict of interest was reported by the authors. 


\begin{abstract}
Retention is an important measure of success (Tinto, 1999); therefore, student success is an area of interest among professionals in the field of higher education (Hunter, 2006; Rendon, 1995). This qualitative study sought to understand how first-year students navigate the university and aimed to increase student success and support students to commencement exercises and beyond. Specifically, the study examined student experiences through social learning and considered the various programs, interventions, and resources that work together to support student success. Focus groups, one-on-one interviews, document analysis, and observations were conducted to collect support data saturation. Three themes emerged from the collected data: connection, intervention, and identity. Each of these themes revealed insights about the associations between college navigation and student success. Prior literature supported the idea that connection, intervention, and identity are tools of college navigation (Bruffee, 1999; Caldwell \& Siwatu, 2003; Garrison \& Kanuka, 2004; Harper, 2012; Smith, 2007; Umbach \& Wawrzynski, 2005). Moreover, the literature acknowledged that students who use intervention support services to increase social learning reported higher levels of academic achievement (Caldwell \& Siwatu, 2003; Grant-Vallone, Reif, Umali, \& Pohlert, 2003; Wibrowski, Matthews, \& Kitsantas, 2017). The findings of this study reaffirmed that higher education professionals, faculty, programs, and interventions occur simultaneously to increase student potential for successful college navigation; these resources are deeply connected and cannot support student success alone.
\end{abstract}

Keywords: Navigation; student success; first-year; first-year experience; retention 


\section{Navigation and Social Learning Among First Semester Retained University}

\section{Students}

\section{Introduction}

Retention is an important measure of success within all student populations (Tinto, 1999); therefore, student success is an area of interest among professionals in the field of higher education (Hunter, 2006; Rendon, 1995). Relevant literature in the field highlighted underlying issues or barriers that decrease the likelihood for students to be retained and succeed at the post-secondary level (Rendon, 1995; Tinto, 1975); targeted retention efforts should be implemented to avoid these barriers and support all students until graduation day (Tinto, 1999). Institutions have established collaborative efforts to support student success and persistence to graduation; these measures have been designed to support students in learning about the institution and its processes (Bruffee, 2012).

Institutions must continually identify the best practices of connecting students to resources to increase student success (Aljohani, 2016). Academic persistence increases when students understand how to navigate social, cultural, and environmental variables in the education system (Caldwell \& Siwatu, 2003). It is important to note that navigation is referenced in points of academic literature but is not commonly defined. Literature has provided various definitions of navigation. Caldwell and Siwatu (2003) described navigation as a process of orientation related to student success and academic efficacy. Navigation also described the career path where stressors and barriers exist (Griffin \& Toldson, 2012). Furthermore, Livingston et al. (2011) studied veteran students and defined navigation as a process of transition where information is gathered to overcome barriers and clarify experiences. For the purpose of this study, navigation is defined as a 
process in which an individual develops efficacy and cognition to use existing, supporting resources for the transition and supersession of barriers and accomplishment of goals. This qualitative study sought to understand how first-year students navigate the university; a further understanding of navigation may increase student success and help administrators support students to commencement exercises and beyond

\section{Literature Review}

First-year seminars assist students in making connections and understanding the resources that are available at the university level (Goodman \& Pascarella, 2006). These seminars provided specific interventions designed to support first-year students. Hunter (2006) highlighted the importance of first-year student success in the higher education community due to funding changes. Furthermore, Hunter (2006) noted the role of proactive intervention in areas of student success like the FYE program. FYE programs are a transitional tool designed to support student acclimation to the university setting (Hunter, 2006). Prior literature addressed the experiences of students in first-year programming; however, a gap exists regarding the navigation of these students throughout the university setting at large. The experience of navigating the university setting is larger than the confines of a single classroom or program (Rendon, 1995). Furthermore, Rendon (1995) highlighted that "academic integration...[and] social integration [are] equally important to student retention" (p. 6). Rendon further noted that higher education institutions should "create conditions for optimal learning" (p. 1). Additional literature regarding student success was reviewed to understand the existing relationship of academic and social integration and the role they respectively have in student success. 


\section{Student Success}

Rendon (1995) theorized that students at community college experience difficulty remaining at the institution due to negotiation of new identity, evolving environments, and identifying areas for potential academic support; these are some of the key tenets of student success. Rendon was not the first scholar to identify barriers that existed for students to be retained and ultimately graduate from college. Tinto $(1975,2003)$ examined barriers that exist for all students, such as prior education preparation, institutional connection, and external factors. Furthermore, existing literature illuminated various types of student experiences in the university setting. Terenzini et al. (1996) studied first-generation student experience as it relates to cognitive development. Hu and Kuh (2003) studied student experiences in relation to diversity and inclusion. Umbach and Wawrzynski (2005) studied student experiences in relation to faculty members in the university setting. While the literature examined the specific experiences of university students, none of these studies have examined the navigation of the university with a wider lens encompassing multiple programs, experiences, and interventions.

Rendon (1995) provided a basis for further questions about student experiences as they relate to a lack of understanding the world of higher education; however, Rendon did not specifically address navigation of the university setting. Rendon laid the foundation for future studies to investigate student experiences related to navigation. Rendon reported that "students lack the cultural and social capital needed to make full use of the academic and social learning community" (p. 7). This finding illuminated the idea that the university setting is often difficult for students to navigate, though little data exists on how successful students learn to navigate the university. A gap exists in the 
literature regarding how students make use of academic and social resources at university.

\section{Statement of the Problem}

Persistence and non-cognitive factors impact the student lifecycle, and the reacculturation process has been examined through the lens of student retention and success (Aljohani, 2016). Scholars have studied persistence to learn more about patterns and contributing factors of student departure from the university from a quantitative perspective (Tinto, 1975, 2003). The role of non-cognitive factors in student persistence has also been investigated (Caldwell \& Siwatu, 2003). Additionally, the process of students learning new cultures and customs that exist at the collegiate level has been explored (Murphy \& Fleming, 2000). This literature impacted how higher education professionals understand students' navigation of their college experience to arrive to graduation at the university. Prior literature explored the relationship of college navigation through a singular focus; however, data is lacking on how university students navigate the university through the lens of various programs, interventions, and resources which work together to support student success. The Student Characteristic Funnel demonstrates how these characteristics work together to support student navigation. 


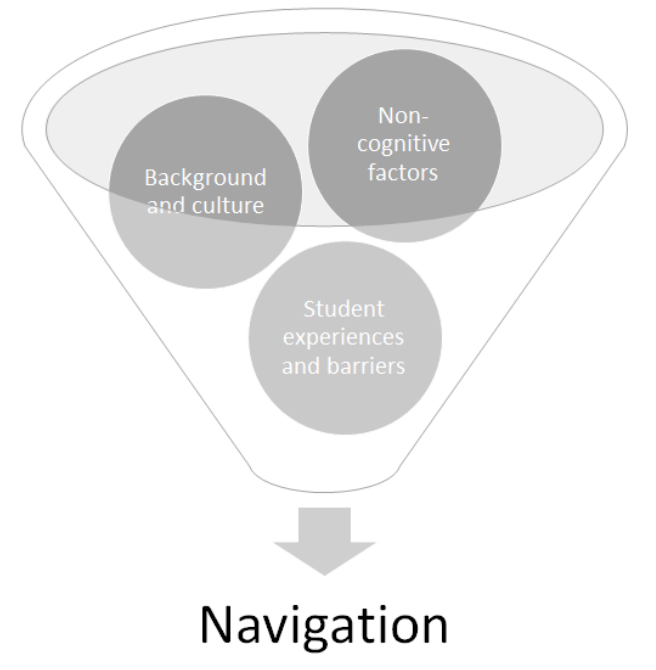

Figure 8. Student Characteristic Funnel.

Student Characteristic Funnel. The student characteristic funnel was developed by Alizabeth Ballard (2020) to explain how existing characteristics come together to yield student navigation of the university.

\section{Purpose of the Study}

This study sought to explore the experiences of first-year, first-time students navigating the university setting. The study filled a gap in the literature that was highlighted by the work completed by Rendon (1995) on the experiences of community college students learning to re-acculturate at the post-secondary level. This study will support higher education professionals' understanding on best student services practices. The study will also inform practitioners in higher education working with first-year students on how those students navigate the university setting.

\section{Research Question}

Further studies are needed to explore the experience of first-year students navigating the university setting without the confines of a classroom, program, or intervention (Rendon, 1995). This study used qualitative methods of exploration to understand how first-year students navigate the university ecosystem. The overarching 
research question that guided the study was: "How do first-year university students navigate university?"

\section{Theoretical Framework: Social Learning Theory}

This study explored social learning theory to better understand how students learn in the university setting. Social learning occurs when individuals learn from peers through various techniques (Bandura, 1971). Encompassing attention, memory, and motivation, social learning have been linked to both behavioral and cognitive learning theories (Bandura, 1971, 2017). Individuals learn in social situations through influence, observation, imitation, and modeling (Bandura, 1971, 2017). Similarly, Vygotsky (1978) noted the relationship of social environments and development of cognition and studied behavior patterns in adolescents, noting what are known now as social learning behaviors. Social learning is a tool for intellection and adaptation (Vygotsky, 1978). Social learning theory has been identified as a vehicle for human learning in which a social setting creates endless opportunities for development (Schunk, 2008). Schunk (2008) noted that "Knowledge, rules, skills, strategies, beliefs, and attitudes" (p. 78) are solidified through social interactions and observations with other individuals and peers; this is social learning theory at its core.

For this study, social learning theory was defined as the cognitive and behavioral developments used for navigation that are derived from learning within group settings; this definition is well supported by Bandura's (1971) initial findings. Furthermore, social learning is connected to educational practices through Vygotsky's (1978) work with adolescents and social learning. Like adolescents, university students learn in social settings; students learn college-going knowledge, rules, and strategies from peers and 
teachers (Bruffee, 1999; Harper, 2012). Social learning is critical to understanding how students learn to navigate college and gain understanding of college-going.

\section{Methods}

This qualitative study used multiple methods of data collection to explore student experiences in a cross-sectional, qualitative manner. The study focused on collecting rich, thick descriptions of student experiences at Worthington University related to navigating college. The next section will detail the design of the study.

Setting. The qualitative research was conducted at a comprehensive, mid-western, mid-sized, public, 4-year university. The university reported enrollment of approximately 7,000 students across all programs and levels. The institution is an open-enrollment institution, meaning that the university does not have minimal admission requirements (Worthington University, 2019).

Participants. Study participants included a) first-time, first-year freshmen who were retained from the fall to spring semester, b) FYE course instructors, c) peer educators, d) faculty, and e) administrators. All participants were recruited and selected through a purposeful sampling technique. Recruitment e-mails were sent to first-year students, peer educator students, staff, and faculty who taught the first-year seminar course at the institution. The recruitment e-mails were followed up by a second e-mail requesting participation. Respondents were screened to ensure they met the basic requirements of the study and then assigned to a focus group time. One-on-one interviews were extended to specific administrators on campus who were listed during student focus groups as a resource used to navigate the university. 
Students at the university reported being predominantly White, middle-class students enrolling in various majors. Additionally, more female-identifying students were enrolled at the university compared to male-identifying students at the time of the study. All staff and faculty participants were employed full-time at the university. Staff and faculty at the university also reported as being predominantly White, upper-middle class individuals. The faculty members who acted as the lead faculty member for the seminar courses taught across various majors and programs on campus. Staff members involved in the study worked directly with first-year students at the university in various roles.

\section{Data Collection Tools}

Data collection methods included focus groups, one-on-one interviews, observations, and document analysis of campus-wide resources. The multiple data collection strategies allowed the data to be triangulated. Triangulation is a practice in qualitative studies that strengthens the validity of the research (Creswell, 2009; Merriam, 2009; Picardi \& Masick, 2013). Focus groups were conducted with student participants, university staff, peer educators, and faculty. One-on-one interviews were conducted in a semi-structured manner with institution administrators. A semi-structured interview format gives the interviewer the ability to respond situationally and provides the opportunity to explore the emerging response to the phenomenon (Merriam, 2009). Additionally, institutional materials regarding campus-based resources were reviewed. These materials included documents such as the orientation manual, the student handbook, and admission materials. The use of mining data from documents such as surveys or public records is a practical data collection method that allows one to gather further insight into a phenomenon (Merriam, 2009). 
Focus groups, interviews, and document analysis were conducted until data saturation was reached. This study conducted six first-year student focus groups, one peer educators focus group, and two faculty and staff focus groups. Eight one-on-one interviews were conducted with administrators and three peer educator training sessions were observed. In addition, document analysis was used to support the goal of saturation. Reaching saturation in data collection improves the trustworthiness of the data collected (Creswell, 2009).

\section{Data Analysis}

A constant comparison method was implemented while collecting data. The use of constant comparison in qualitative research allows the data to be segmented (Merriam, 2009). Data segmentation allows scholars to examine similarities and further focus on the collected data.

Themes and underpinnings were identified using categorical construction, which allowed emerging themes in the data to occur in a more organic way (Merriam, 2009). Open coding used specific words or phrases stated by the participants to support category construction (Merriam, 2009; Picardi \& Masick, 2013). The study used member-checking to validate the data collected. Member-checking, or respondent validation, is a practice that gathers feedback from participants on data collected and emerging themes to ensure the data was not misinterpreted (Creswell, 2009; Merriam, 2009).

\section{Limitations, Assumptions, and Design Controls}

Limitations for this qualitative study included the small sample size, which may lead to a lack of generalizability to other institutions. Additionally, it is important to note that use of purposeful sampling meant that not all students at Worthington were 
represented. Another limitation included the fact that the researcher worked at the institution where the data was being collected and therefore had a pre-existing professional relationship with many of the participants of the study. Finally, the data collected was primarily self-reported data. The self-reported data is the experience of the individual participants and may not appropriately reflect the experience of every student.

\section{Results}

Three themes clearly emerged from the data analysis. These three themes are connection, intervention, and identity (see Figure 9).

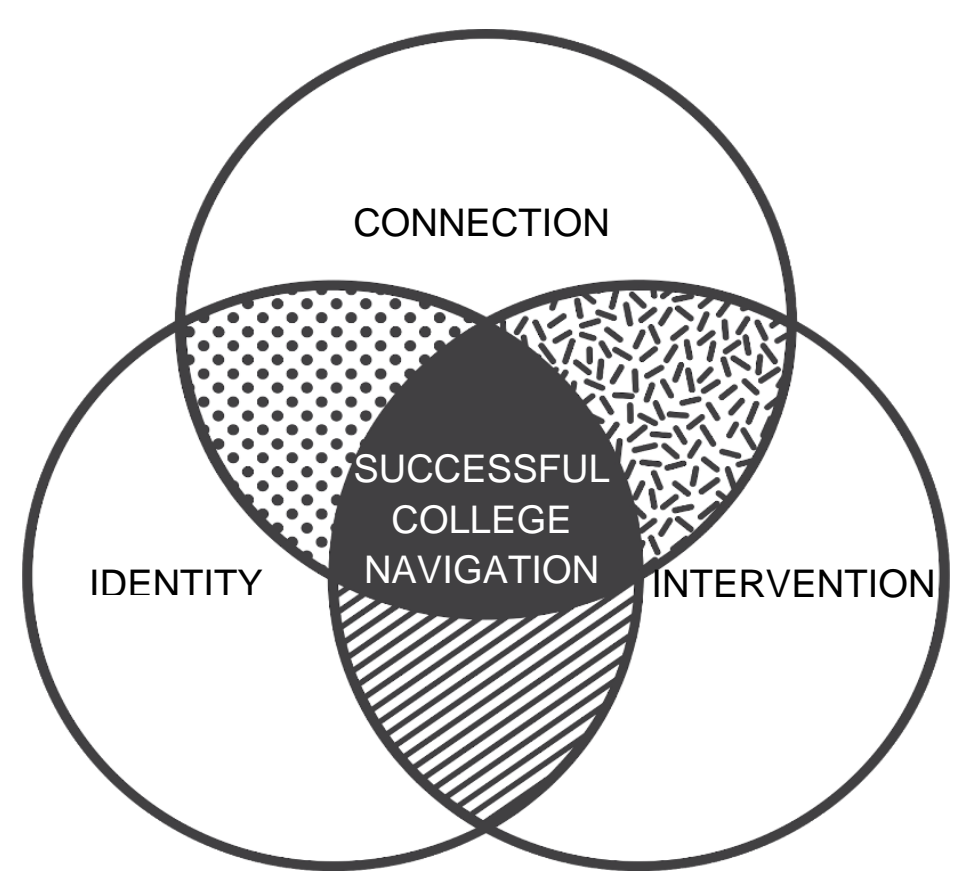

Figure 9. Visualization of results

Venn diagram of thematic results from study. The diagram demonstrates how successful college navigation is supported by connection, intervention, and identity.

Additionally, three subthemes emerged (see Table 1). Each of these themes revealed insight about the associations between college navigation and student success. The three predominate themes were initially identified through the student focus group 
and affirmed by the staff and faculty focus groups, student observations, interviews, and document analysis. These three themes will be further detailed and discussed in the remainder of this section.

\section{Table 1.}

Themes and Subthemes from Data Analysis

\begin{tabular}{|c|c|}
\hline Theme & Subthemes \\
\hline \multirow{4}{*}{ Connection } & Academic \\
\hline & Social \\
\hline & Institutional \\
\hline & Academic \\
\hline \multirow[t]{3}{*}{ Intervention } & Social \\
\hline & Institutional \\
\hline & Belonging \\
\hline \multirow[t]{2}{*}{ Identity } & Grit \\
\hline & Re-acculturation \\
\hline
\end{tabular}

Connection. Connection emerged as the most prominent theme of the study. The data regarding connection was further categorized into three subthemes. The subthemes regarding student connection included academic connection, social connection, and institutional connection.

Academic. The subtheme of academic connection was apparent in the data collected. Participants reported awareness and utilization of specific resources that directly related to their success in academic courses. Resources such as faculty, advisors, and tutors were prominent and repeatedly identified in multiple student participant focus groups. When asked specifically about how students learn to go to college, one student said, "My advisor is really cool. Also, I have teachers who give you names and numbers and office hours of places to go when you need help." This notion was affirmed multiple times with similar sentiments. Another student reported the following. 
I came [to the university from a technical certificate programs], so a lot of the faculty from there told me about how I can finish my associates through here and then continue on to other degrees. Those teachers and my advisor have been a lot of help.

Academic connection was tied to the perception that those who work in academic affairs want students to be successful. This notion is best affirmed by the student who said, "The professors here have been really helpful in letting us know, hey, this is what is coming up. I feel like most colleges probably wouldn't have as much of the caring environment."

Social. Another subtheme within connection was social connection. Student participants overwhelmingly reported navigating college with the help of multiple social connections. Some students reported using familial connections such as parents, older siblings, or extended family. Other students reported making connections with peers or friends as a tool for college navigation. For example, one student shared, "I'm really lucky. My brother went to college and so did both of my parents. Though I feel like I've asked my brother about a lot more stuff than my parents." Familial connections were frequently highlighted as well as peer connections; one student participant had this to say about success in classes: "I've always been extremely independent. I've always done things on my own, but they weren't kidding; you need a friend to pass." This notion was affirmed again as another student participant shared about their experience learning about college. When asked about how students learned to navigate college, the student said:

A lot of it was my peers. I actually showed up to Worthington a week before school started because I was in band camp. And so, some of my section leaders helped show me where my classes were ahead of time. 
Institutional. The final subtheme that emerged in relation to student connection was a connection made to the institution. These connections were identified by student participants as connections to offices that provide support and were not directly related to courses. While these support services were not tied directly to academic courses, support services made a positive impact on students' ability to succeed at navigating college. For example, residential living and the residential advisors were repeatedly reported as a great resource. A student participant had this to say about learning to live with a difficult roommate:

Our [resident advisor] was really good about being the mediator, but we still had to find a way to talk to her and get her to figure things out. We ended up having to be like, look, we don't think can be roommates anymore. The RA really helped with that conversation.

Another student shared a similar experience and stated, "We talk to our [resident advisor]. We just talked to a lot of people and just tried to get everybody's viewpoint on how was the best way to handle it." Another office identified as providing student support services included the registrar office and the Office for Diversity and Inclusion. Participants noted that student support is the culture of the institution. A student participant shared this about institutional culture: "I've met a lot of people. The president, the custodial staff, and professors really care about my well-being. I feel like they want me to succeed."

Intervention. Intervention also emerged as a prominent theme of the collected data. Subthemes were used to further categorized and interpret the data. Similar to 
connection, the intervention subthemes included academic interventions, social interventions, and institutions interventions.

Academic. Student participants noted the awareness and use of academic interventions created by the university. These interventions included support programs, mentoring opportunities, and technology designed to support student success. One student highlighted the use of an academic intervention.

I definitely use the tutor center a lot, even if I'm not getting tutoring help. It's just a really good place to study and work and be surrounded by people that have either taken the class or are in the class. That's really nice.

The academic interventions reported by students as useful included programs specifically designed to increase the success of students at the Worthington campus. One student shared this about their first-year seminar course: "I was in one of the [program specific] sections. Most of the students were first-generation students like me and the teacher made sure we had everything we needed for our classes." Academic interventions were varied; another student shared, "[The phone app] is really good as a first-year student. It's kind of hard to know what you just don't know. There's a lot of stuff you got to keep track of."

Social. Student participants reported peer interventions as a tool for navigating the university. For example, one student stated, "It was my peers showing me where I need to be or who I could reach out to when I needed something." Another student reported using population-specific resources to find students with shared experience: “The Veteran's Center has been great. I know the director. He has done so much for me.” Another student shared that engagement was a meaningful social intervention for student success. 
The student reported, "Getting involved has been an important part for me. I think it is really important, getting out and participating instead of staying in your room. I've met so many people."

Institutional. The final type of intervention was identified as institutional interventions. These interventions included services and programs available to students on campus but were not directly related to academic success. These interventions included services such as student health, counseling services, diversity and inclusion programs, skill shops, and campus police. Multiple students reported using these critical services. One student shared, "I had to learn there is actually a resource on campus, the diversity and inclusion or something office, where you can go and you can get help like extended time on your tests if you need it." Another student reported using skill shops, stating that, "Sometimes I go to skill shops at the library. They're not really advertised as much, but they present on careers or financial aid. They are just a beneficial thing." Another student reported, “The police escort on campus is nice. I haven't used it, but one of my friends did last semester. They made sure she got back to our room safe."

The students reported multiple resources, connections, and interventions as valuable tools for navigating the university. Student responses were recorded in Table 1. 
Table 2.

Resources Students Use to Navigate College

\begin{tabular}{|c|c|c|c|}
\hline Theme & \multicolumn{3}{|c|}{ Subtheme and Corresponding Data } \\
\hline Connection & $\begin{array}{l}\quad \text { Academic } \\
\text { - Advisors } \\
\text { - Faculty } \\
\text { - Tutors } \\
\text { - Librarians } \\
\text { - Department Staff }\end{array}$ & $\begin{array}{l}\text { Social } \\
\text { - Siblings } \\
\text { - Peers } \\
\text { - Parents } \\
\text { - Roommates } \\
\text { - Student } \\
\text { Organizations }\end{array}$ & $\begin{array}{l}\quad \text { Institutional } \\
\text { - Residential Advisors } \\
\text { - Residential Hall } \\
\text { Director } \\
\text { - Mental Health } \\
\text { Counselor } \\
\text { - Financial Literacy } \\
\text { Coach }\end{array}$ \\
\hline Intervention & $\begin{array}{l}\quad \text { Academic } \\
\text { - Student One Stop } \\
\text { - Peer Educators } \\
\text { - Center for Student } \\
\text { Success } \\
\text { - Phone app for } \\
\text { academic record } \\
\text { - Success Coaches } \\
\text { - Specific Program } \\
\text { Coordinators } \\
\text { - Writing Center }\end{array}$ & $\begin{array}{l}\quad \text { Social } \\
\text { - Involvement Office } \\
\text { - Orientation } \\
\text { Counselor } \\
\text { - Diversity Programs } \\
\text { - Phone app for } \\
\text { campus events } \\
\text { - Campus Bulletin } \\
\text { Boards }\end{array}$ & $\begin{array}{l}\quad \text { Institutional } \\
\text { - Residential Living } \\
\text { - Campus Police } \\
\text { - Accommodation } \\
\text { Services } \\
\text { - Admission Officer } \\
\text { - Orientation Program } \\
\text { - Career Services } \\
\text { - Counseling Services } \\
\text { - Health Center }\end{array}$ \\
\hline
\end{tabular}

Identity. Identity emerged as the final prominent theme of the study. This final theme cemented a well-rounded approach to the student experience of navigating college. The data on the theme of identity was categorized into three subthemes: grit, belonging, and re-acculturation. Responses regarding student identity and the frequency noted in data collection were recorded in Table 2. 
Table 3.

Understanding of Identity as a tool of Navigate College

\begin{tabular}{|c|c|c|}
\hline Category & Related Descriptive Phrases & Number of References \\
\hline Belonging & $\begin{array}{l}\text { I felt like I didn't belong } \\
\text { I wanted to find a group } \\
\text { You need to make friends } \\
\text { Joining student organizations } \\
\text { College fit }\end{array}$ & 32 \\
\hline Grit & $\begin{array}{l}\text { Trial and error } \\
\text { I didn't have anyone } \\
\text { Figure it out on my own } \\
\text { I kept trying } \\
\text { Rely on myself }\end{array}$ & 46 \\
\hline Re-acculturation & $\begin{array}{l}\text { Getting used to it } \\
\text { Family doesn't understand } \\
\text { Try new things } \\
\text { Didn't fit in } \\
\text { Figuring out who I am }\end{array}$ & 38 \\
\hline
\end{tabular}

Grit. The first subtheme that emerged was individual grit. An overwhelming sense of necessity for grit was garnered from student participant focus groups. This subtheme was the strongest subtheme recorded in data collection. One student shared, “My first few weeks, I did not prepare well enough for an exam. I wasn't focused enough and so failure definitely was the best teacher in that sense." Another student affirmed this experience and stated, "You got to just kind of throw yourself in there, like, figure it out on your own. How to deal with classes, roommates, professors, and stuff like that because it's a whole new ball game." Remarkably, every focus group had at least one student who 
remarked about trial and error. One student in particular stated the following about trial and error.

I think I am actually learning by trial and error. Like, some things aren't going to work and I think you have to learn to accept that that's okay. Not everything is going to go the way you think it will. Some things will be bad. Some will be good. That is college, but mostly, that is life.

Interestingly, the idea of trial and error was shared by a participant in every focus group and in every one-on-one interview held during data collection. This finding is further discussion in the discussion section.

Belonging. The next subtheme that emerged was student belonging. Belonging resonated throughout multiple focus groups of student participants. Students shared about their personal experiences regarding belonging at Worthington University as they navigated the university. One student shared, "I learned that no one's going to have everything figured out, especially not when you're first starting college, but it feels like they do and you don't." Another student stated, “There's not that magic moment where the lights are going to shine down and everything's just right. We all struggle." Another student participant shared, "Because English is my second language, my grammar is not the best like a lot of students who often speak different language. The experiences with offices like the writing center or my peers in classes aren't always positive."

Re-acculturation. The final subtheme that emerged from the data analysis was reacculturation. Re-acculturation includes activities that supported students in learning or relearning culture and experiences. One student addressed the idea of re-acculturation as follows. 
I took a sociology class and it covered topics that were like religion, politics, and race. You can really step on people's toes there. I had to be kind of careful. Different people have different mindsets and backgrounds. I feel different, especially since I came from a [rural town]. I'm learning a lot about how to fit in.

Another student shared,

There isn't a quick way or like something that you just learn overnight. It's definitely something that you got to go through and learn over time. It takes time. More than likely, you have to relearn some things and figure out other things.

Student participants who identified as first-generation shared about how re-acculturation is tied to their identity as a first-generation student. The student shared:

It is hard being a first-gen student because I don't really have anyone to ask. I have to adapt without really asking anyone. My family has no idea either. That was really hard to get through. I hated being so unsure about who I was and what was happening. That was hard for me.

\section{Discussion}

The student focus groups were the most critical component of data collection and analysis in this study. Data points were collected to support the understanding of student experiences. The findings were reviewed through the lens of social learning theory and student success to best understand and interpret the experiences of students. 


\section{College Navigation and Student Success}

Learning is social and individual in nature (Rorty, 1999); the study results confirmed this finding. Some students reported using peers or other university personnel to navigate the university, while other student participants reported relying on themselves to figure out how to go to college. College and university experiences are by-in-large social experiences; however, social learning must contain some level of individual attention, memory, and motivation to be successful. This concept is well supported by Bandura's $(1971,2017)$ understanding that social learning encompasses three individual components: attention, memory, and motivation. Additionally, confirmed learning is positively impacted through social situations (Strayhorn, 2008). Furthermore, college navigation is largely supported by the ideals of social learning theory. The study results support the idea that students' college navigation is based in social learning and can be considered multifaceted.

Observations, staff and faculty focus groups, interviews, and document analysis solidified the findings from student participant focus groups. Connection, intervention, and development of student identity are all important aspects of successful college navigation for first-year students. Social learning theory supports and is deeply connected to each thematic finding.

Connection. As noted in the results section, connection emerged as one of the most prominent themes of the study. Connection-identified through focus groups, interviews, observation, and document analysis — allows students to build relationships with peers, faculty, staff, or other campus community members to navigate the university. This finding is affirmed by relevant literature, which has repeatedly asserted that 
connection is a tool of college navigation (Bruffee, 1999; Caldwell \& Siwatu, 2003; Harper, 2012; Umbach \& Wawrzynski, 2005). Specifically, Tinto (1999) promoted student success through frequent quality advising, residential learning communities, and academic seminars; these were identified as tools of connection. Additionally, connection increases student success, and students who make a greater number of new friends or institutional connections report increase academic achievement (Skahill, 2002). Peer leaders within diverse student populations often help other students within their own subpopulation to navigate campus by sharing effective methods or college-knowledge (Harper, 2012). Connection stood out among the themes and highly relied on social learning behaviors as a tool for successful navigation. The classification of these connectors as tools is largely supported by Bandura's (1971) understanding of social learning.

Intervention. Another major theme of the study was intervention. This study classified interventions as the programs, events, offices, or various services designed to support student navigation of the university setting. The results identified multiple intervention resources at Worthington University, which included tutoring services, diversity and inclusion programs, and campus police, to name a few. Again, social learning behaviors guide student use and interaction with these intervention services. Furthermore, these interventions are also well supported by prior literature. Smith (2007) and Garrison and Kanuka (2004) affirmed interventions as a tool for college navigation for students within specific student populations. Moreover, the literature acknowledged that students who use intervention support services to increase social learning report 
higher levels of academic achievement (Caldwell \& Siwatu, 2003; Grant-Vallone et al., 2003; Wibrowski et al., 2017).

Identity. The final theme that emerged from the study data pointed to the development of student identity as a tool for successful college navigation. While the researcher expected to find that the development of non-cognitive factors was a crucial piece of student success, the specific factors found were unanticipated. Instead of finding themes of motivation, memory, and attention, the researcher found subthemes of belonging, grit, and re-acculturation within the data. While unexpected, this theme and subthemes were well supported by relevant literature. Stayhorn (2018) agreed that student belonging was a crucial component of student success. Similarly, Duckworth, Peterson, Matthews, \& Kelly (2007) found that achievement required talent, but also perseverance. Additionally, Bruffee (1999) noted that re-acculturation supported student transition. These non-cognitive characteristics supported student transition and success at the university.

An in-depth look at the research demonstrates a clear definition for belonging, grit, and re-acculturation that support the understanding of these tools of navigation for university students. Belonging defined by Strayhorn (2018) as a student's broad sense of connection and importance within the university setting; the definition included student perception regarding topics like social support, academic support, and being cared about by peers, faculty, and staff. Stayhorn's (2018) affirmed that the development of belonging among college students mattered when considering student experiencing. Duckworth and Gross (2014) defined belonging as persistence toward goals despite obstacles, barriers, or hindrances. Reed and Jerimiah (2017) noted that while grit is not 
the only contributor to student success, it certainly is a component when considering student experiences. Bruffee (1999) also acknowledged development of identity occurs through re-acculturation. Furthermore, Freire (2000) identified the benefit of spoken conversations between peers while negotiating the re-acculturation process; reacculturation mattered when considering student experience. The literature and the findings of this qualitative study supported the understanding that development of identity through belonging, grit, and re-acculturation were crucial to understanding student experience and promoting student success. These tools of student developmentbelonging, grit, and re-acculturation-directly relate to a student's ability to successfully navigate the university setting.

Trial and Error. As identified in the results section, the idea of trial and error was shared as a tool for student navigation by a participant in every focus group and in every one-on-one interview held during data collection. This was the most surprising finding during the research study. A brief review of relevant literature shows that trial and error learning has been studied among college students specific to subject areas like consumerism, alcohol consumption, and technology; the results demonstrated a consensus among college aged-students that trial and error was a widely used approach to learning (Browere, 2002; Kvavik, 2005; Lachance \& Choquette-Bernier, 2004). The recurrence and persistence of this finding warrants further research measure the success of this approach to learning.

\section{Navigation Defined}

The final finding that emerged through this study is a better supported definition of navigation. In the introduction of this paper, a makeshift definition of navigation was 
introduced as a process in which an individual develops efficacy and cognition to use existing, supporting resources for the transition and supersession of barriers and accomplishment of goals. This definition guided the study; however, the data collected reaffirmed and narrowed the definition for college navigation through focus groups and interviews of students, staff, administers, and faculty. Study participants shared similar sentiments about what college navigation meant to each of them. One study participant said:

For me, it is about the process of how each student learns how to acquire and use different information appropriately in the college setting...how to know when to reach out to someone for help or support or how to understand societal expectations.

An administrator also shared their definition of college navigation.

An institutional framework that students often do not understand...It is about getting to the graduation stage to shake the president's hand, not simply to get a better job, but to become better citizens....and it is about helping students understand that.

Multiple participants noted that college navigation was the amalgamation of experiences viewed holistically. All of the participants agreed that "It is about balancing all the aspects of college and doing them successfully together. It is about spending attention and time of your social life, your educational life, and your professional future career.” These sentiments were initially reported in student participant focus groups and reaffirmed through staff and faculty focus groups and interviews with administrators. 
After reviewing the data and considering the gap within existing literature, it felt necessary to clearly define college navigation for higher education literature. College navigation is the process in which students develop and reaffirm efficacy and cognition to use existing, supporting resources through connection and intervention for student success.

\section{Conclusion}

The primary conclusion of the study was the understanding that the successful navigation of college occurs when students have connection, intervention, and are able to develop and solidify their identity. Furthermore, this study affirmed existing literature, which asserted that academic achievement increases when students have connection to others, appropriate interventions, and are able to develop their identity (Bruffee, 1999; Caldwell \& Siwatu, 2003; Grant-Vallone et al., 2003; Reed \& Jerimiah, 2017; Skahill, 2002; Strayhorn, 2018; Tinto, 1999; Wibrowski et al., 2017). These components support students in the successful navigation of the university.

It is critical to remember that higher education professionals, faculty, programs, and interventions work simultaneously; student development does not occur in a silo. Students experience these components of college concurrently which calls for great collaboration across the university campus. These individuals, offices, and components all work together to increase student potential for successful college navigation and eventual success post-graduation. Furthermore, implications for practice include an obligation to students to work together as a collective to best support their development as a person and as a scholar. In light of this, the following is recommended to Worthington University: 
- Create an ad hoc committee tasked with increasing collaboration and coordination of first-year student transition services

- Assess existing programming and events for student connection, intervention, and development to identify gaps in services

- Address gaps in services through future programming or events planned from a three-pronged approach that clearly identifies the connectors, the intervention, and the opportunity for student development prior to implementing programming or events

- Further explore student experiences longitudinally through the use of scholarly research to track student success during college as well as post-graduation Worthington University and the field of higher education would benefit from further exploration of student experiences and successes from a more inclusive and longitudinal approach. Future research should include a longitudinal study of student academic achievement compared to connection, intervention, and identity. Future research could also include a review of the collaboration of transition services at the institutional level and an in-depth exploration of trial and error approach to learning college-going behaviors or college navigation. The results of these studies could solidify best practices in the field and support student persistence and success. In conclusion, more information is needed to better understand student experiences from a more inclusive approach. This study was a first step toward that understanding. 


\section{References}

Aljohani, O. (2016). A comprehensive review of the major studies and theoretical models of student retention in higher education. Higher Education Studies, 6(2), 1-18. doi:10.5539/hes.v6n2p1

Bandura, A. (1971). Social learning theory. Morristown, NJ, US: General Learning Press.

Bandura, A. (Ed.). (2017). Psychological modeling: Conflicting theories. Piscataway, NJ, US: Transaction.

Brower, A. M. (2002). Are college students alcoholics?. Journal of American College Health, 50(5), 253-255.

Bruffee, K. A. (1999). Collaborative learning: Higher education, interdependence and the authority of knowledge. Baltimore, MD, US: Johns Hopkins University Press.

Bruffee, K. (2012). Collaboration, conversation, and reacculturation. In G. DeLuca (Ed.), Dialogue on writing: Rethinking ESL, basic writing, and first-year composition (pp. 79-98). New York, NY, US: Routledge

Caldwell, L. D., \& Siwatu, K. O. (2003). Promoting academic persistence in African American and Latino high school students: The educational navigation skills seminar. High School Journal, 87(1), 30-38. doi:10.1353/hsj.2003.0013

Creswell, (2009). Research design: Qualitative, quantitative, and mixed methods approaches. San Francisco, CA, US: Sage.

Duckworth, A., \& Gross, J. J. (2014). Self-control and grit: Related but separable determinants of success. Current directions in psychological science, 23(5), 319325. 
Duckworth, A. L., Peterson, C., Matthews, M. D., \& Kelly, D. R. (2007). Grit:

perseverance and passion for long-term goals. Journal of personality and social psychology, 92(6), 1087.

Freire, P. (2000). Pedagogy of the oppressed (M. B. Ramos, Trans.). New York, NY, US: Continuum.

Garrison, D. R., \& Kanuka, H. (2004). Blended learning: Uncovering its transformative potential in higher education. Internet and Higher Education, 7, 95-105. doi:10.1016/j.iheduc.

2004.02.001

Goodman, K., \& Pascarella, E. (2006). First-year seminars increase persistence and retention: A summary of the evidence. In S. J. Carrey (Ed.), Peer review: Successful transitions to college through first-year programs (3 ed., Vol. 8, pp. 26-28). Washington, DC, US: Association of American Colleges \& Universities.

Grant-Vallone, E., Reif, K., Umali, C., \& Pohlert, E. (2003/2004). An analysis of the effects of self-esteem, social support, and participation in student support services on students' adjustment and commitment to college. Journal of College Student Retention, 5, 255-274. doi:10.2190/C0T7-YX50-F71V-00CW

Griffin, K. A., \& Toldson, I. A. (2012). Reflections on mentoring for Blacks in academia (Editor's commentary). Journal of Negro Education, 81, 103-105. doi:10.7709/ jnegroeducation.81.2.0103 
Harper, S. R. (2012). Black male student success in higher education: A report from the National Black Male College Achievement study. Philadelphia, PA, US: University of Pennsylvania, Graduate School of Education, Center for the Study of Race and Equity in Education. Retrieved from https://webapp.usc.edu/web/rossier/publications/231/Harper $\% 20(2012) \% 20 \mathrm{Black} \% 20 \mathrm{Male} \% 20$ Success.pdf

Hu, S., \& Kuh, G. D. (2003). Diversity experiences and college student learning and personal development. Journal of College Student Development, 44, 320-334. doi:/10 $.1353 / \mathrm{csd} .2003 .0026$

Hunter, M. S. (2006). Fostering student learning and success through first-year programs. Peer Review, 8(3), 4-7. Retrieved from https://www.aacu.org/

Kvavik, R. B. (2005). Convenience, communications, and control: How students use technology. Educating the net generation, 1(2005), 7-1.

Lachance, M. J., \& Choquette-Bernier, N. (2004). College students' consumer competence: a qualitative exploration. International Journal of Consumer Studies, $28(5), 433-442$.

Livingston, W. G., Havice, P. A., Cawthon, T. W., \& Fleming, D. S. (2011). Coming home: Student veterans' articulation of college re-enrollment. Journal of Student Affairs Research and Practice, 48(3), 315-331. doi:10.2202/1949-6605.6292

Merriam, S. B. (2009). Qualitative research: A guide to design and implementation. San Francisco, CA, US: Jossey-Bass. 
Murphy, M., \& Fleming, T. (2000). Between common and college knowledge: Exploring the boundaries between adult and higher education. Studies in Continuing Education, 22, 77-93. doi:10.1080/713695718

Picardi, C. A., \& Masick, K. D. (2013). Research methods: Designing and conducting research with a real-world focus. Thousand Oaks, CA, US: Sage.

Reed, L., \& Jeremiah, J. (2017). Student grit as an important ingredient for academic and personal success. In Developments in Business Simulation and Experiential Learning: Proceedings of the Annual ABSEL conference (Vol. 44, No. 1).

Rendon, L. I. (1995). Facilitating retention and transfer for first generation students in community colleges. Washington, DC, US: U.S. Department of Education, Office of Educational Research and Improvement, Educational Resources Information Center.

Rorty, R. (1999). Philosophy and social hope. London, England: Penguin.

Schunk, D. H. (2008). Metacognition, self-regulation, and self-regulated learning: Research recommendations. Educational Psychology Review, 20, 463-467. doi:10.1007 /s10648-008-9086-3

Skahill, M. P. (2002). The role of social support network in college persistence among freshman students. Journal of College Student Retention, 4, 39-52. doi:10.2190/LB7C -9AYV-9R84-Q2Q5 
Smith, R. (2007). An overview of research on student support: Helping students to achieve or achieving institutional targets? Nurture or de-nature? Teaching in Higher Education, 12, 683-695. doi:10.1080/13562510701596240

Strayhorn, T. L. (2008). How college students' engagement affects personal and social learning outcomes. Journal of College and Character, 10(2). doi:10.2202/19401639.1071

Strayhorn, T. L. (2018). College students' sense of belonging: A key to educational success for all students. New York, NY: Routledge.

Terenzini, P. T., Springer, L., Yaeger, P. M., Pascarella, E. T., \& Nora, A. (1996). Firstgeneration college students: Characteristics, experiences, and cognitive development. Research in Higher Education, 37, 1-22. doi:10.1007/BF01680039

Tinto, V. (1975). Dropout from higher education: A theoretical synthesis of recent research. Review of Educational Research, 45, 89-125. doi:10.3102/00346543045001089

Tinto, V. (1999). Taking retention seriously: Rethinking the first year of college. NACADA Journal, 19(2), 5-9. doi:10.12930/0271-9517-19.2.5

Tinto, V. (2003). Learning better together: The impact of learning communities on student success. Higher Education Monograph Series, 1(8), 1-8. Retrieved from http://www .nhcuc.org/ 
Umbach, P. D., \& Wawrzynski, M. R. (2005). Faculty do matter: The role of college faculty in student learning and engagement. Research in Higher Education, 46, 153-184. doi:10.

1007/s11162-004-1598-1

Vygotsky, L.S. (1978). Mind in society: The development of higher psychological processes. Cambridge, MA, US: Harvard University Press.

Wibrowski, C. R., Matthews, W. K., \& Kitsantas, A. (2017). The role of a skills learning support program on first-generation college students' self-regulation, motivation, and academic achievement: A longitudinal study. Journal of College Student Retention, 19, 317-332. doi:10.1177/1521025116629152

Worthington University. (2019a). Facts and history. Retrieved from https://washburn.edu/ about/facts/index.html 


\section{Chapter Six}

\section{Scholarly Practitioner Reflection}

\section{Leadership Development Reflection}

When used intentionally, scholarship and practice can work jointly to support positive change in practice (Perry \& Zambo, 2016). The Carnegie Project on the Educational Doctorate addresses the need for practitioners of education to be agents of change by using research and theory in applicable manners (Perry \& Zambo, 2016). This tenet and calling have been a guiding principle of the education I have received through the state-wide cooperative education program. The remainder of this dissertation-inpractice will reflect on my personal and professional growth in the program, as well as my perspective on scholarship. The past three years have deeply changed and inspired me to continue becoming the best scholarly practitioner that I can be in higher education. First, I want to address the growth and development I experienced as an educational leader.

\section{Educational Leader}

I am a learner. This truth impacts my professional life. To dive deeper into the definition of learning and learners, I studied how Clifton, Anderson, and Schreiner (2006) defined a learner. Clifton et al. asserted that the characteristics of a learner include an enjoyment of finding new facts, understanding new processes, and continual improvement. These tenets resonate with me. Learning is a central theme to my life and has been for as long as I can remember. Clifton et al. also noted that learners are often drawn to the process of learning. I identify strongly with the notion that learning is process oriented. My personal journey of learning has been a key formative experience 
for me in the past several years. I acquired the tools and skillset needed to best support students through gaining a better understanding of my personal strengths and learning more about learning paradigms, how adults learn, and barriers to learning. I am a learner, but over the past several years, I have also discovered that I am a leader.

\section{Constructivist Learning Paradigm}

As a learner and a leader, I subscribe to a constructivist paradigm. The constructivism learning theory operates with the understanding that learning is about making meaning of our experiences (Merriam \& Bierema, 2014). As a doctoral student, making meaning has been a critical part of my personal and academic growth. I reflected on Merriam and Bierema's (2014) definition of learning to best understand who I am as a learner and a leader. Merriam and Bierema described learning as a "change in human disposition or capacity" (p. 25) and, in a more personal manner, as a "moral and ethical endeavor with the goal of becoming fully human" (p. 25). Merriam and Bierema continued to identify the role of learning theories in a broader understanding of the word learning. Learning theories are vital because they inform how people learn or how learning occurs. This principle will support me as I continue to work with students and find ways to help each student succeed. I have grown as a leader through understanding the basis and the historical context of the experiences shared by the collective academia.

My past has been defined by learning, and more specifically, a constructivism approach to learning; these concepts will also define my future. The various types of learning include adult learning, experiential learning, and transformational learning (Caffarella \& Daffron, 2013). Learning and my identity as a learner will continue to impact my personal and academic life. In the past, I have attempted to make meaning of 
the world around me. In the future, I will be in a position to help others navigate the notions of learning and help individuals make meaning of their own learning based on their own experiences. For me, this process will be most fulfilling experience and defining moment as a learner and as a leader. As a learner, I will help others grow to love learning through the various theories and types of learning. As a leader, I will help others share their passion and experiences in a way that is authentic to who they are as a human.

\section{Authentic Leadership}

Authentic leadership is complex and difficult to describe in nature; authentic leadership has many lenses and can be defined in multiple ways (Northouse, 2009). The components of authentic leadership include self-awareness, internalized moral perspective, balancing process, and rational transparency (Northouse, 2010). Looking back on my time in the program, authentic leadership is one of the theories that most defined my transformation as a leader. I have become a more authentic leader through readings, assignments, and interactions with my peers; I can finally see myself as an educational leader. This was an important transition for me, as I historically struggled with my identity as a leader. This program gave me knowledge to support my anecdotal experiences from practice, which gave me a better sense of self-awareness. The Perry (2016) reading gave me a new perspective of my role as a scholarly practitioner in the field of education. Leadership can occur in subgroups, committees, or teams of a larger organization; this notion supported my new understanding of myself as a leader with unassigned power (Levi, 2015).

I found a lot of value in the summer assignments within our small teams. These experiences gave me an opportunity to practice leadership in a safe environment. To that 
idea, my peers have inspired me to focus on being transparent in how I lead and be honest with those who I have the opportunity to lead. My group from the first summer encouraged me to believe in my own ability as a leader regardless of my age and formal role. These experiences with my peers helped me reflect on the idea that leadership does not happen in a silo and can be a fluid concept. Group dynamics can evolve, and leaders can help grow others within groups and organizations (Levi, 2015). This assertion has been true to my experience, as I emerge from this program as a stronger leader.

Authentic leadership has impacted my professional life in unexpected ways. I find myself more aware of my role and my beliefs in approaching student success. This allows me to be more vocal about issues that arise in my professional life. Additionally, my practice of leadership has changed after exploring authentic leadership. I strive to be transparent in my decision making and approach to working with students. I am intentional in the way I lead in less formal capacities. I strive to be the best version of myself; a person who is compassionate, student-centered, and data-driven. Authentic leadership will impact my professional career in the future. I appreciate the transparency and intentional action-taking that is derived from authentic leadership. Johnson (2018) stated that change occurs when leaders choose "paths of greater resistance" (p. 109). I am able to make a difference in the field of education by choosing to be an authentic and courageous leader. When I choose a different path as a leader, I "make it possible for others to question their own" (Johnson, 2018, p. 113).

\section{Scholarship}

Perry (2016) addressed the topic of what it means to be a scholarly practitioner. Perry's conclusions gave me a new perspective of my role as a student affairs 
professional in the field of education. Scholarly practitioners are good stewards of data and use relevant literature to address problems in practice. Scholarship allows practitioners to apply theoretical frameworks in a meaningful way and address problems of practice that limit student supports. Perry was not alone in the considerations of what it means to be a scholarly practitioner. The curriculum of the Educational Leadership and Policy Analysis program has been filled with scholars who are data-driven but studentcentered. Datnow and Park (2014) supported the idea that leaders should use data to make informed decisions for their organization. Nonaka (1994) addressed the ways in which organizations create, share, and re-envision knowledge. Bolman and Deal (2013) illuminated that the scholarship framework is people-centered in nature. Scholarship is all of these things to me: data driven, sharing and re-envisioning knowledge, and peoplecentered.

\section{Data Driven}

Datnow and Park (2014) — two scholars and leaders in the education community—addressed concerns of equity versus equality. I believe equity and equality are terms often used interchangeably in educational settings; however, these terms are truly different. When used to guide student-focused decision-making, equity and equality yield two very different outcomes. For me, equality in education is ensuring every student is provided the same of everything; this could be seen in every day education as every student receiving the same text book regardless of school district, teachers who are educated at the same level in every classroom, and students receiving the same educational supports and resources regardless of need. Alternatively, equity in education is ensuring every student is provided what they need to succeed individually; this could 
be seen in every day education practices as additional time for testing when student have learning disabilities, additional services for students who may need help taking notes during classes, or ensuring need-based funding is available for students from low socioeconomic backgrounds. The American education system needs more equity. We should be showing up for students where they are and doing our best to help. Scholarly practitioners should make decisions with equity in mind and use data in a meaningful way (Datnow \& Park, 2014). Datnow and Park are excellent examples of change agents. I hope to use my future research and publications to share my passion for improving the educational community. More than anything, I am and will continue to be an advocate for students. I will continue to champion education, access, and data-driven, student-focused decision making.

\section{Knowledge-Creating Culture}

An article was assigned as an external reading in the final semester of coursework. This reading addressed the ways in which organizations create, share, and re-envision knowledge (Nonaka, 1994). This article was intended to support the understand of how organizations learn; however, it also gave me a new perspective on organizational analysis. The article provided insight on how organizational members foster learning culture and provided me with a greater understanding of organizational lenses. Learner organizations can be described as an organizational framework (Nonaka, 1994). The process of creating, sharing, and understanding knowledge is a leveled process starting with an individual and eventually spiraling to others within an organization (Nonaka, 1991). Nonaka's (1994) concept of organizational learning had a large impact upon the way I approach leadership and learning in an organizational 
setting. Educational leaders discuss the difficulties in addressing issues created by tribal knowledge. Nonaka described tribal knowledge as "tacit knowledge" (p. 98). Tacit knowledge is described as "highly personal" and "difficult to formalize" (p. 98). I am leading the effort to specify and clarify tacit knowledge by using Nonaka's principles on tacit knowledge. The article made me reassess how I create and share information in my role as a leader and a follower and has greatly impacted my daily operations as an education leader and scholarly practitioner in higher education. The article will support how I choose to lead in the future; by understanding the nature of tacit knowledge, I will be able to better support the professional development of others by creating better organizational structures.

\section{Student Centered}

The human resource framework is based upon core assumptions that support the style and approach to organizational culture and structure (Bolman \& Deal, 2013). The literature acknowledged that organizations need people as much as people need organizations and asserted that organizations exist to address the needs of constituents or key stakeholders (Bolman \& Deal, 2013). The tenets of the human resource framework relate strongly to my personal practice as a scholarly practitioner in higher education. I approach my role in my professional life with a student-centered mindset. Simply put, nothing happens without students. This student-centered lens ensures that my decisions are consistently made with the success of the student in mind. When approaching advising and student progression concerns, examining situations through a human resource lens reminds me that nothing happens without students and we must address student needs to the fullest of our abilities upon each opportunity given. The human 
resource lens supports the institutional commitment to support students as an institution and as a professional workforce. The human resource lens asserts that scholarship should be for the sake of bettering student success outcomes and furthering the education community. Scholarship should not only be for the sake of progress, but for the sake of students.

\section{Summary}

I have grown as a person and as a professional from my experiences in the Educational Leadership and Policy Analysis program. The program has helped me reaffirm my identity as a learner, establish an identity as a leader, and reaffirm my commitment to the profession of education. The articles that have most shaped my experience will continue to support my personal and professional development. The other students and faculty who I have had the opportunity to work with have changed my life for the better. 


\section{References}

Aljohani, O. (2016). A comprehensive review of the major studies and theoretical models of student retention in higher education. Higher Education Studies, 6(2), 1-18. doi:10.5539/hes.v6n2p1

Allen, M. J. (2006). Assessing general education programs. San Francisco, CA, US: Jossey-Bass.

American Educational Research Association. (2011). Code of ethics. Educational Researcher, 40(3), 145-156. doi:10.3102/0013189X11410403

Astin, A. W. (1985). Achieving educational excellence. San Francisco, CA, US: JosseyBass.

Astin, A. W., \& Oseguera, L. (2002). Degree attainment rates at American colleges and universities. Retrieved from https://www.heri.ucla.edu/PDFs/pubs/TFS/Special /Monographs/DegreeAttainmentRatesAtAmericanCollegesAndUniversities.pdf

Badura, B. A., Millard, M., \& Shah, K. (2008). Are peer educators really peers? Journal of American College Health, 56, 566-568. doi:10.3200/JACH.56.5.566-568

Bandura, A. (1971). Social learning theory. Morristown, NJ, US: General Learning Press.

Bandura, A. (1979). Self-referent mechanisms in social learning theory. American Psychologist, 34, 439-441. doi:10.1037/0003-066X.34.5.439.b

Bandura, A. (Ed.). (2017). Psychological modeling: Conflicting theories. Piscataway, NJ, US: Transaction.

Bell, A. D., Rowan-Kenyon, H. T., \& Perna, L. W. (2009). College knowledge of 9th and 11th grade students: Variation by school and state context. Journal of Higher Education, 80, 663-685. doi:10.1080/00221546.2009.11779039 
Berlyne, D. E. (1951). Attention, perception and behavior theory. Psychological Review, 58, 137-146. doi:10.1037/h0058364

Bernhardt, P. E. (2013). The advancement via individual determination (AVID) program: Providing cultural capital and college access to low-income students. School Community Journal, 23, 203-222. Retrieved from https://www.schoolcommunitynetwork.org/SCJ .aspx

Blair, C. (2002). School readiness. Integrating cognition and emotion in a neurobiological conceptualization of children's functioning at school entry. American Psychologist, 57, 111-127. doi:10.1037/0003-066X.57.2.111

Bolman, L. G., \& Deal, T. E. (2013). Reframing organizations. San Francisco, CA, US: Jossey-Bass.

Bourdieu, P. (1991). Language and symbolic power. Cambridge, MA, US: Harvard University Press.

Braxton, J. M., \& Bayer, A. E. (1999). Faculty misconduct in collegiate teaching. Baltimore, MD, US: Johns Hopkins University Press.

Braxton, J. M., \& Hirschy, A. S. (2005). Theoretical developments in the study of college student departure. In A. Seidman (Ed.), College student retention: Formula for student success (pp. 61-87). Westport, CT, US: Praeger.

Braxton, J. M., \& Lee, S. D. (2005). Toward reliable knowledge about college student departure. In A. Seidman (Ed.), College student retention: Formula for student success (pp. 107-128). Westport, CT, US: Praeger. 
Brower, A. M. (2002). Are college students alcoholics? Journal of American College Health, 50(5), 253-255.

Bruffee, K. A. (1999). Collaborative learning: Higher education, interdependence and the authority of knowledge. Baltimore, MD, US: Johns Hopkins University Press.

Bruffee, K. (2012). Collaboration, conversation, and reacculturation. In G. DeLuca (Ed.), Dialogue on writing: Rethinking ESL, basic writing, and first-year composition (pp. 79-98). New York, NY, US: Routledge

Caffarella, R. S. 1., \& Daffron, S. R. (2013). Planning programs for adult learners: a practical guide. Third edition. San Francisco: Jossey-Bass.

Caldwell, L. D., \& Siwatu, K. O. (2003). Promoting academic persistence in African American and Latino high school students: The educational navigation skills seminar. High School Journal, 87(1), 30-38. doi:10.1353/hsj.2003.0013

Carnegie Foundation for the Advancement of Teaching. (2011). The Carnegie classification of institutions of higher education. Menlo Park, CA, US: Author.

Clifton, D. O., Anderson, E., \& Schreiner, L. A. (2006). StrengthsQuest: Discover and develop your strengths in academics, career, and beyond ( $2^{\text {nd }}$ ed.). New York, NY: Gallup Press.

Collier, P. J., \& Morgan, D. L. (2008). "Is that paper really due today?": Differences in first-generation and traditional college students' understandings of faculty expectations. Higher Education, 55, 425-446. doi:10.1007/s10734-007-9065-5

Complete College America. (2014). Four-year myth. Retrieved from https://completecollege.org /wp-content/uploads/2017/05/4-Year-Myth.pdf 
Craik, F. I., \& Lockhart, R. S. (1972). Levels of processing: A framework for memory research. Journal of Verbal Learning and Verbal Behavior, 11(67), 1-684. doi:10.1016/S0022-5371(72)80001-X

Creswell, (2009). Research design: Qualitative, quantitative, and mixed methods approaches. San Francisco, CA, US: Sage.

Datnow, A., \& Park, V. (2014). Data-driven leadership (Vol. 12). New York, NY, US: John Wiley \& Sons.

Deci, E. L., Vallerand, R. J., Pelletier, L. G., \& Ryan, R. M. (1991). Motivation and education: The self-determination perspective. Educational Psychologist, 26, 325-346. doi: 10.1080

/00461520.1991.9653137

Dodd, J. D. (2015). Worthington University: 150 Years. Kansas City, MO, US: Kansas City Star Books.

Duckworth, A., \& Gross, J. J. (2014). Self-control and grit: Related but separable determinants of success. Current directions in psychological science, 23(5), 319325.

Duckworth, A. L., Peterson, C., Matthews, M. D., \& Kelly, D. R. (2007). Grit: perseverance and passion for long-term goals. Journal of personality and social psychology, 92(6), 1087.

Durlak, J. A., Weissberg, R. P., Dymnicki, A. B., Taylor, R. D., \& Schellinger, K. B. (2011). The impact of enhancing students' social and emotional learning: A metaanalysis of school-based universal interventions. Child Development, 82, 405432. doi:10.1111/j.1467-8624.2010.01564.x 
Engle, C. C., Reilly, N. P., \& Levine, H. B. (2004). A case study of an academic retention program. Journal of College Student Retention, 5, 365-383. doi:10.2190/JP0W5358-Y7DJ-14B2

Evans, M. G. (1970). The effects of supervisory behavior on the path-goal relationship. Organizational Behavior and Human Performance, 5, 277-298. doi:10.1016/0030-5073(70)90021-8

Freire, P. (2000). Pedagogy of the oppressed (M. B. Ramos, Trans.). New York, NY, US: Continuum.

Garrison, D. R., \& Kanuka, H. (2004). Blended learning: Uncovering its transformative potential in higher education. Internet and Higher Education, 7, 95-105. doi:10.1016/j.iheduc. 2004.02.001

Gill, S. J. (2010). Developing a learning culture in nonprofit organizations. Atlanta, GA, US: Sage. doi:10.4135/9781452272030

Glaessgen, T. A., MacGregor, C. J., Cornelius-White, J. H., Hornberger, R. S., \& Baumann, D. M. (2018). First-generation students with undecided majors: A qualitative study of university reacculturation. Journal of the National Academic Advising Association, 38(1), 22-35. doi:10.12930/NACADA-16-030

Goodman, K., \& Pascarella, E. (2006). First-year seminars increase persistence and retention: A summary of the evidence. In S. J. Carrey (Ed.), Peer review: Successful transitions to college through first-year programs (3 ed., Vol. 8, pp. 26-28). Washington, DC, US: Association of American Colleges \& Universities. 
Grant-Vallone, E., Reif, K., Umali, C., \& Pohlert, E. (2003/2004). An analysis of the effects of self-esteem, social support, and participation in student support services on students' adjustment and commitment to college. Journal of College Student Retention, 5, 255-274. doi:10.2190/C0T7-YX50-F71V-00CW

Griffin, K. A., \& Toldson, I. A. (2012). Reflections on mentoring for Blacks in academia (Editor's commentary). Journal of Negro Education, 81, 103-105. doi:10.7709/ jnegroeducation.81.2.0103

Hanna, E., \& Meltzoff, A. N. (1993). Peer imitation by toddlers in laboratory, home, and day-care contexts: Implications for social learning and memory. Developmental Psychology, 29, 701-710. doi:10.1037/0012-1649.29.4.701

Harper, S. R. (2012). Black male student success in higher education: A report from the National Black Male College Achievement study. Philadelphia, PA, US: University of Pennsylvania, Graduate School of Education, Center for the Study of Race and Equity in Education. Retrieved from https://webapp.usc.edu/web/rossier/publications/231/Harper \%20(2012)\%20Black\%20Male\%20Success.pdf

House, R. J. (1971). A path goal theory of leader effectiveness. Administrative Science Quarterly, 16, 321-339. doi:10.2307/2391905

Hu, S., \& Kuh, G. D. (2003). Diversity experiences and college student learning and personal development. Journal of College Student Development, 44, 320-334. doi:/10 $.1353 /$ csd.2003.0026 
Hunter, M. S. (2006). Fostering student learning and success through first-year programs. Peer Review, 8(3), 4-7. Retrieved from https://www.aacu.org/

Imparato, M. (2006). Worthington University history. Retrieved from https://worthington.edu /about/files/Worthington-history-chapter.pdf

Inkelas, K. K., Daver, Z. E., Vogt, K. E., \& Leonard, J. B. (2007). Living-learning programs and first-generation college students' academic and social transition to college. Research in Higher Education, 48, 403-434. doi:10.1007/s11162-0069031-6

Johnson, A. G. (2018). Privilege, power, and difference ( $2^{\text {nd }}$ ed.). New York, NY: McGraw-Hill.

Kuh, G. D. (2001). The National Survey of Student Engagement: Conceptual framework and overview of psychometric properties. Retrieved from http://nsse.indiana.edu/pdf /psychometric_framework_2002.pdf

Kvavik, R. B. (2005). Convenience, communications, and control: How students use technology. Educating the net generation, 1(2005), 7-1.

Labaree, D. F. (2017). A perfect mess: The unlikely ascendancy of American higher education. doi:10.7208/chicago/9780226250588.001.0001

Lachance, M. J., \& Choquette-Bernier, N. (2004). College students' consumer competence: a qualitative exploration. International Journal of Consumer Studies, $28(5), 433-442$. 
Lau, L. K. (2003). Institutional factors affecting student retention. Education, 124(1), 126-136. https://www.projectinnovation.com/education.html

Lazowski, R. A., \& Hulleman, C. S. (2016). Motivation interventions in education: A meta-analytic review. Review of Educational Research, 86, 602-640. doi:10.3102/

0034654315617832

Leeds, E. M., Campbell, S. M., Baker, H., Ali, R., Brawley, D., \& Crisp, J. (2013). The impact of student retention strategies: An empirical study. International Journal of Management in Education, 7, 22-43. Retrieved from https://digitalcommons.kennesaw.edu/facpubs

Levi, D. (2015). Group dynamics for teams. San Francisco, CA, US: Sage.

Livingston, W. G., Havice, P. A., Cawthon, T. W., \& Fleming, D. S. (2011). Coming home: Student veterans' articulation of college re-enrollment. Journal of Student Affairs Research and Practice, 48(3), 315-331. doi:10.2202/1949-6605.6292

Loss, C. P., \& McGuinn, P. J. (2016). The convergence of K-12 and higher education: Policies and programs in a changing era. Cambridge, MA, US: Harvard Education Press.

Lucas, G. A. (2001). Coping style, need for cognition, and college students' attitudes toward psychological counseling (Doctoral Dissertation). University of Nebraska, Lincoln, NE, US.

Ludwig-Hardman, S., \& Dunlap, J. C. (2003). Learner support services for online students: Scaffolding for success. International Review of Research in Open and Distributed Learning, 4(1). doi:10.19173/irrodl.v4i1.131 
Maslow, A. H. (1943). A theory of human motivation. Psychological Review, 50, 370396. doi:10.1037/h0054346

Merriam, S. B. (2009). Qualitative research: A guide to design and implementation. San Francisco, CA, US: Jossey-Bass.

Merriam, S. B., \& Bierema, L. L. (2014). Adult learning: Linking theory and practice. San Francisco, CA, US: Jossey-Bass.

Mintzberg, H. (1979). The structuring of organizations. Englewood Cliffs, NJ, US: Prentice-Hall.

Murphy, M., \& Fleming, T. (2000). Between common and college knowledge: Exploring the boundaries between adult and higher education. Studies in Continuing Education, 22, 77-93. doi:10.1080/713695718

Nonaka, I. (1994). A dynamic theory of organizational knowledge creation. Organization Science, 5, 14-37. doi:10.1287/orsc.5.1.14

Northouse, P. (2009). Leadership: Theory and practice. Thousand Oaks, CA, US: Sage Publications.

Piaget, J. (1936). Origins of intelligence in the child. London, England: Routledge \& Kegan Paul.

Perry, J. A., \& Zambo, D. (2016). The Carnegie Project on the Education Doctorate: A Partnership of Universities and Schools Working to Improve the Education Doctorate and K-20 Schools. In Blessinger, P. \& Cozza, B. (Eds.) (2016). University Partnerships for Academic and Program Development. West Yorkshire, England: Emerald Publishing. 
Picardi, C. A., \& Masick, K. D. (2013). Research methods: Designing and conducting research with a real-world focus. Thousand Oaks, CA, US: Sage.

Reed, L., \& Jeremiah, J. (2017). Student grit as an important ingredient for academic and personal success. In Developments in Business Simulation and Experiential Learning: Proceedings of the Annual ABSEL conference (Vol. 44, No. 1).

Rendon, L. I. (1995). Facilitating retention and transfer for first generation students in community colleges. Washington, DC, US: U.S. Department of Education, Office of Educational Research and Improvement, Educational Resources Information Center.

Rhoades, B. L., Warren, H. K., Domitrovich, C. E., \& Greenberg, M. T. (2011). Examining the link between preschool social-emotional competence and first grade academic achievement: The role of attention skills. Early Childhood Research Quarterly, 26, 182-191. doi:10.1016/j.ecresq.2010.07.003

Robbins, S. B., Lauver, K., Le, H., Davis, D., Langley, R., \& Carlstrom, A. (2004). Do psychosocial and study skill factors predict college outcomes? A meta-analysis. Psychological Bulletin, 130, 261-288. doi:10.1037/0033-2909.130.2.261

Rorty, R. (1999). Philosophy and social hope. London, England: Penguin.

Schmidt, L. C., \& Graziano, J. (2016). Building synergy for high-impact educational initiatives: First-year seminars and learning communities. National Resource Center for the First-Year Experience and Students in Transition. Columbia, SC: University of South Carolina. 
Schunk, D. H. (1996, October). Self-evaluation and self-regulated Learning. Paper presented at the Graduate School and University Center, University of New York, New York, NY, US.

Schunk, D. H. (2008). Metacognition, self-regulation, and self-regulated learning: Research recommendations. Educational Psychology Review, 20, 463-467. doi:10.1007

/s10648-008-9086-3

Seidman, I. (2013). Interviewing as qualitative research: A guide researchers in education and the social sciences (4th ed.). New York, NY, US: Teachers College Press.

Skahill, M. P. (2002). The role of social support network in college persistence among freshman students. Journal of College Student Retention, 4, 39-52. doi:10.2190/LB7C -9AYV-9R84-Q2Q5

Skinner, B. F. (1948). Superstition in the pigeon. Journal of Experimental Psychology, 38, 168-172. doi:10.1037/h0055873

Smith, R. (2007). An overview of research on student support: Helping students to achieve or achieving institutional targets? Nurture or de-nature? Teaching in Higher Education, 12, 683-695. doi:10.1080/13562510701596240

Strayhorn, T. L. (2008). How college students' engagement affects personal and social learning outcomes. Journal of College and Character, 10(2). doi:10.2202/19401639 .1071 
Strayhorn, T. L. (2015). Reframing academic advising for student success: From advisor to cultural navigator. Journal of the National Academic Advising Association, 35(1), 56-63. doi:10.12930/NACADA-14-199

Strayhorn, T. L. (2018). College students' sense of belonging: A key to educational success for all students. New York, NY: Routledge.

Terenzini, P. T., Rendon, L. I., Upcraft, M. L., Millar, S. B., Allison, K. W., Gregg, P. L., \& Jalomo, R. (1994). The transition to college: Diverse students, diverse stories. Research in Higher Education, 35, 57-73. doi:10.1007/BF02496662

Terenzini, P. T., Springer, L., Yaeger, P. M., Pascarella, E. T., \& Nora, A. (1996). Firstgeneration college students: Characteristics, experiences, and cognitive development. Research in Higher Education, 37, 1-22. doi:10.1007/BF01680039

Thayer, P. B. (2000). Retention of students from first generation and low income backgrounds. Journal of the Council for Opportunity in Education. Retrieved from https://www .trioprograms.org/clearinghouse

Thelin, J. R. (2011). A history of American higher education. Baltimore, MD, US: Johns Hopkins University Press.

Tinto, V. (1975). Dropout from higher education: A theoretical synthesis of recent research. Review of Educational Research, 45, 89-125. doi:10.3102/00346543045001089

Tinto, V. (1987). Leaving college: Rethinking the causes and cures of student attrition. Chicago, IL, US: University of Chicago Press. 
Tinto, V. (1999). Taking retention seriously: Rethinking the first year of college. NACADA Journal, 19(2), 5-9. doi:10.12930/0271-9517-19.2.5

Tinto, V. (2003). Learning better together: The impact of learning communities on student success. Higher Education Monograph Series, 1(8), 1-8. Retrieved from http://www .nhcuc.org/

Umbach, P. D., \& Wawrzynski, M. R. (2005). Faculty do matter: The role of college faculty in student learning and engagement. Research in Higher Education, 46, 153-184. doi:10. 1007/s11162-004-1598-1

Vroom, V. H. (1964). Work and motivation (Vol. 54). New York, NY: Wiley. Vygotsky, L.S. (1978). Mind in society: The development of higher psychological processes. Cambridge, MA, US: Harvard University Press.

Vygotsky, L. (1997). Interaction between learning and development. In M. Gauvin, \& M. Cole (Eds.), Readings on the Development of Children (pp. 29-36). New York, NY, US: W. H. Freeman.

Wibrowski, C. R., Matthews, W. K., \& Kitsantas, A. (2017). The role of a skills learning support program on first-generation college students' self-regulation, motivation, and academic achievement: A longitudinal study. Journal of College Student Retention, 19, 317-332. doi:10.1177/1521025116629152 
Williamson, L. V., Goosen, R. A., \& Gonzalez, G. F., Jr. (2014). Faculty advising to support student learning. Journal of Developmental Education, 38(1), 20. Retrieved from http:// ncde.appstate.edu/publications

Worthington University. (2018). Learning outcomes, objectives, and assessments. Retrieved from https://worthington.edu/academics/undergraduate-programs/firstyear/wu-101 /LearningOutcomes.pdf

Worthington University. (2019a). Facts and history. Retrieved from https://washburn.edu/ about/facts/index.html

Worthington University. (2019b). The Worthington University libraries and the center for student success and retention: Mission, vision and strategic plan. Retrieved from https:// libguides.worthington.edu/Municipal/about Wyer, Jr, R. S., \& Srull, T. azK. (2014). Advances in social cognition, Volume I: A dual process model of impression formation. Milton Park, Abingdon, England: Psychology Press.

Zimmerman, B. J. (1990). Self-regulated learning and academic achievement: An overview. Educational Psychologist, 25, 3-17. doi:10.1207/s15326985ep2501_2

Zins, J. E. (Ed.). (2004). Building academic success on social and emotional learning: What does the research say? New York, NY, US: Teachers College Press. 


\section{Appendix A:}

\section{Probing Research Questions for Student Focus Groups}

\begin{tabular}{|c|c|}
\hline \multirow[t]{2}{*}{ Opening } & Tell us your name and your major. \\
\hline & In one sentence, can you define what "college navigation" means to you? \\
\hline Introduction & $\begin{array}{l}\text { 3. Resources often help us "navigate" college. State as many resources that have } \\
\text { helped you "navigate" college; share as many as you can remember. }\end{array}$ \\
\hline \multirow{3}{*}{ Key } & $\begin{array}{l}\text { Follow up: Consider the resources you listed and consider the use of those resources. } \\
\text { Now, tell me about a time when you used one of these resources. What happened? } \\
\text { What went well? What would you have changed about the experience if you could? }\end{array}$ \\
\hline & $\begin{array}{l}\text { 4. What has been the most complex concept about going to college that you } \\
\text { learned this last year? How did you learn about it? }\end{array}$ \\
\hline & $\begin{array}{l}\text { Think of your experiences at college. Was there a time when you had to } \\
\text { "figure it out"? What comes to mind when you think of that experience? How did you } \\
\text { figure your "it" out? }\end{array}$ \\
\hline Ending & $\begin{array}{l}\text { 6. Is there anything else about navigating college that you would like to share } \\
\text { with me? }\end{array}$ \\
\hline
\end{tabular}




\section{Appendix B:}

\section{Probing Research Questions for Faculty/Staff Focus Groups}

\begin{tabular}{ll}
\hline Opening & $1 . \quad$ Tell us your name and your role at the institution. \\
& $2 . \quad$ Define what "college navigation" means to you? \\
Introduction & 3. Do students ask you "college-going" questions? What type of questions do \\
& they ask? \\
Key & $4 . \quad$ Tell me a story about a time when you interacted with a student who didn't \\
& know what to do at college. What was the situation? What did you do? How did you \\
& help the student? \\
& $5 . \quad$ What is the best advice you give students about college navigation? Why do \\
& you give this advice? \\
Ending & $6 . \quad$ Is there anything else about navigating college that you would like to share \\
& with me?
\end{tabular}




\section{Appendix C:}

\section{Interview Questions for Faculty/Staff}

\begin{tabular}{|c|c|c|}
\hline \multirow[t]{2}{*}{ Opening } & 1. & Tell us your name and your role at the institution. \\
\hline & 2. & Define what "college navigation" means to you? \\
\hline \multirow[t]{2}{*}{ Transition } & 3. & How do you think that students learn to navigate the university setting? \\
\hline & 4. & What trends do you see in higher education regarding college-going/navigation? \\
\hline \multirow[t]{2}{*}{ Introduction } & $\begin{array}{l}5 . \\
\text { resource } \\
\text { barriers }\end{array}$ & $\begin{array}{l}\text { What barriers do you think exist for students attempting to navigate college? What } \\
\text { s exist to address these barriers at Worthington? How do we further address those }\end{array}$ \\
\hline & $\begin{array}{l}6 . \\
\text { Explain }\end{array}$ & $\begin{array}{l}\text { How do student past experiences impact college-going knowledge in your opinion? } \\
\text { your answer with an anecdote. }\end{array}$ \\
\hline \multirow[t]{2}{*}{ Key } & 7. & How do college-going resources intersect? \\
\hline & 8. & What college-going resources intersect specifically here at Worthington? \\
\hline \multirow[t]{2}{*}{ Ending } & 9. & Define college navigation. \\
\hline & 10. & Is there anything else about navigating college that you would like to share with me? \\
\hline
\end{tabular}




\section{Appendix D:}

\section{Informed Consent Letter}

January 2019

Dear Participant:

Thank you for participating in the study regarding navigation and social learning. This study, "Navigation and Social Learning among First Semester Retained University Students: exploration of programs and experiences at a comprehensive, public, openenrollment institution" is being conducted as a dissertation research project and as research to be reported in peer edited journals. The study will be used to provide explicit knowledge to others about student experiences related to how students navigate the university.

As a study participant, you will be asked a series of questions about the college experience in a focus group. The time allowed for the completion of the study is not expected to take longer than one hour in time. Please read below to understand how your input will be used in the study and how your rights as a participant will be protected.

1. Participation in this study is completely voluntary. You may withdraw from participation at any time, including the middle of the study, or after it is completed. If you decide at a later time you do not wish your input to be included in the study, you may withdraw. Please do not hesitate to contact me at 785.670.1533, or by email, alizabeth.ballard@ gmail.com.

2. Should you decide to participate, your identity, as well as your input, will remain anonymous. You will be assigned a random pseudonym, and when referred to in the study, you will be identified as either a participant in the research study or by the pseudonym. If you are still interested in in participating in this research project you will be required to sign a consent letter before the project begins.

3. This study has been approved by the University of Missouri-Columbia and Worthington University IRB committees. Questions regarding your rights as a participant/participant's parent or any other matter pertaining to this study can be submitted to the committee at irb@missouri.edu.

Regards,

Alizabeth Ballard 


\section{VITA}

Alizabeth Ballard began her educational career from Truman State University completing a Bachelor of Science in 2013. She completed a Master of Science from Northwest Missouri State University in 2017. Ballard began her career in higher education working with TriO programming. Since her first job in higher education, she has held various roles within enrollment management. Ballard plans to continue working in higher education supporting national efforts to increase access and equitable outcomes in education. 